\title{
DOSES E FREQÜÊNCIAS DE APLICAÇÃO DE NITROGÊNIO E POTÁSSIO VIA FERTIRRIGAÇÃO PARA TOMATEIRO
}

\author{
GLÁUCIA REGINA ANTI
}

Engenheira Agrônoma

Orientador: Prof. Dr. QUIRINO AUGUSTO DE CAMARGO CARMELLO

Dissertação apresentada à Escola Superior de Agricultura "Luiz de Queiroz", da Universidade de São Paulo, para a obtenção do título de Mestre em Agronomia, Área de Concentração: Solos e Nutrição de Plantas

PIRACICABA

Estado de São Paulo - Brasil

Setembro - 2000 
Aos meus pais

\section{DEDICO}

Ao Heitor, Ana Beatriz, Luciene, Nelson, Catarina e Larissa 


\section{AGRADECIMENTOS}

A Deus pela vida e oportunidades.

Ao Prof. Dr. Quirino Augusto de Camargo Carmello, pela orientação e amizade.

À Fundação de Amparo à Pesquisa do Estado de São Paulo (FAPESP) pela concessão da bolsa.

À Coordenação do Curso de Pós-Graduação em Solos e Nutrição de Plantas pela oportunidade.

Aos professores do Departamento de Solos e Nutrição de Plantas Antônio Roque Dechen e Francisco Antônio Monteiro pela amizade e sugestões.

Aos professores do Departamento de Horticultura da ESALQ, Keigo Minami e João Tessarioli Neto pelas sugestões.

Aos professores do Departamento de Engenharia Rural, José Antonio Frizzone e Marcos Vinícius Folegatti pela contribuição.

Ao Prof. Dr. Décio Barbin do Departamento de Ciências Exatas, pela atenção, amizade e sugestões.

À Agroflora, em especial ao Dr. Paulo Della Vechia, pelo fornecimento das sementes.

Aos funcionários Sueli M. A. C. Bovi, Nivanda M. de Moura, Lúcia H. S. P. Forti, Edinéia C. S. Mondoni, Mirtes V. Sesso, Nancy Campos Amaral, e Lino Stênico pela valiosa contribuição na realização do trabalho e pela amizade.

Aos amigos Ênio F. F. Silva, Anderson Soares Pereira, Mônica S. Camargo e Jonas Ruschel pela amizade, ajuda e sugestões.

Ao Dr. Eder Joao Pozzebon pelas opiniões e ajuda na elaboração dos gráficos, pelo apoio e inextimada atenção.

Ao Engenheiro Agrônomo Marcelo Corrêa Alves pela análise estatística dos dados. 


\section{ÍNDICE}

Pág.

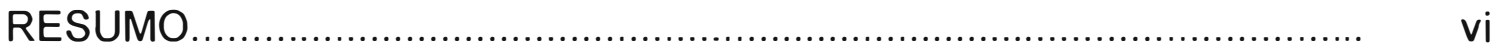

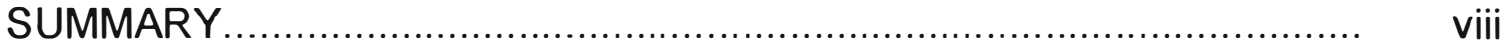

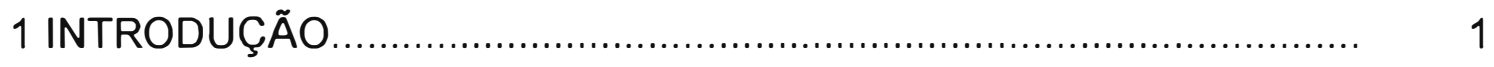

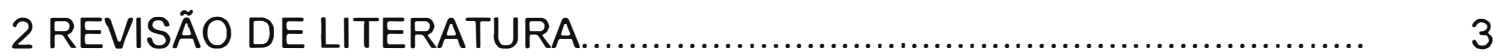

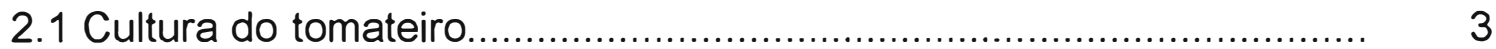

2.2 Nutrição mineral e adubação do tomateiro........................................ 5

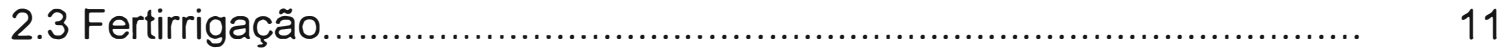

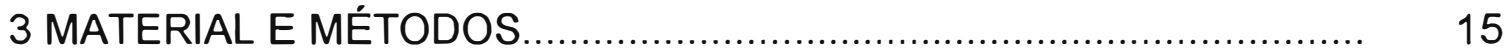

3.1 Descrição da área experimental................................................... 15

3.2 Características do solo............................................................ 15

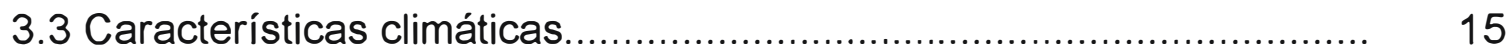

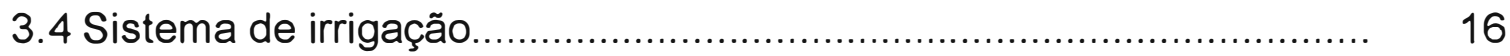

3.5 Extratores da solução do solo........................................................ 16

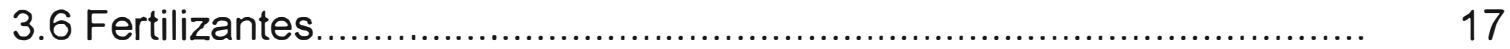

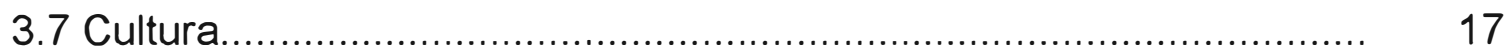

3.8 Delineamento experimental e tratamentos...................................... 17

3.9 Preparo da área experimental...................................................... 18

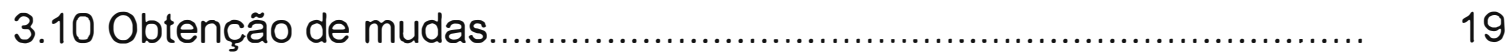

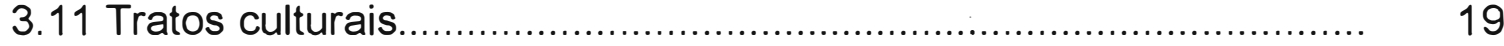

3.12 Manejo da irrigação................................................................ 20

3.12 Monitoramento da solução do solo................................................. 21

3.14 Coleta e análise do material vegetal............................................ 22

3.15 Análise estatística.................................................................... 22

4 RESULTADOS E DISCUSSÃO..................................................... 24

4.1 Monitoramento da solução do solo................................................. 24

4.2 Efeitos na produção....................................................................... 30

4.2.1 Número de frutos.................................................................... 30

4.2.2 Massa de material fresco dos frutos........................................... 31 
4.3 Efeito nas concentrações de nutrientes............................................. 34

4.3.1 Concentrações de nutrientes nas folhas diagnósticas...................... 34

4.3.1.1 Concentrações de nitrogênio........................................................ 34

4.3.1.2 Concentrações de fósforo........................................................... 35

4.3.1.3 Concentrações de potássio......................................................... 37

4.3.1.4 Concentrações de cálcio............................................................ 41

4.3.1.5 Concentrações de magnésio......................................................... 45

4.3.1.6 Concentrações de enxofre ..................................................... 48

4.3.1.7 Concentrações de boro............................................................... 51

4.3.1.8 Concentrações de cobre.............................................................. 53

4.3.1.9 Concentrações de ferro......................................................... 55

4.3.1.10 Concentrações de manganês................................................... 59

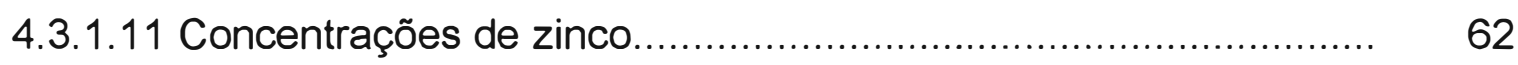

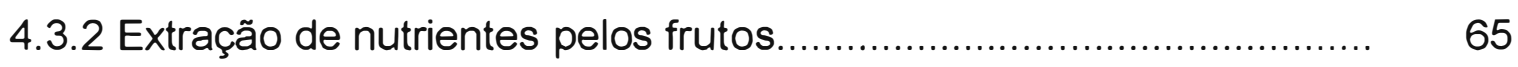

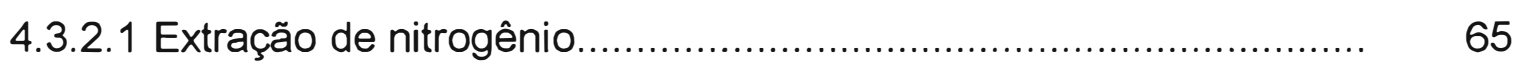

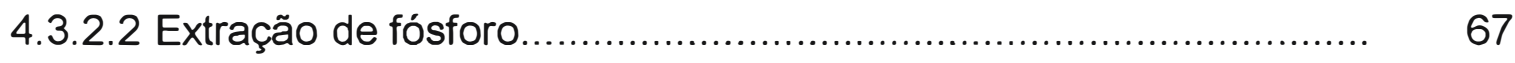

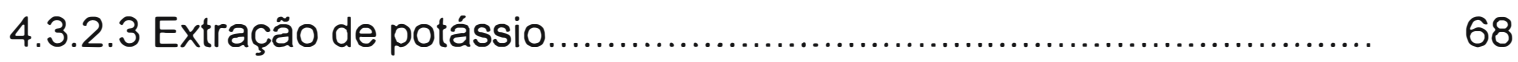

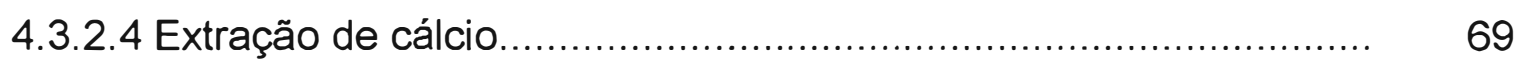

4.3.2.5 Extração de magnésio................................................................ 70

4.3.2.6 Extração de enxofre............................................................... 71

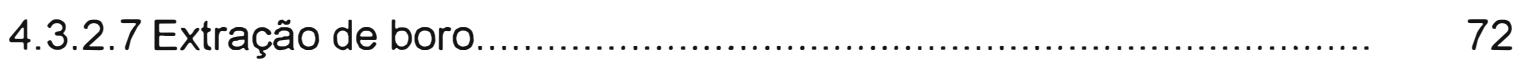

4.3.2.8 Extração de cobre ............................................................. 73

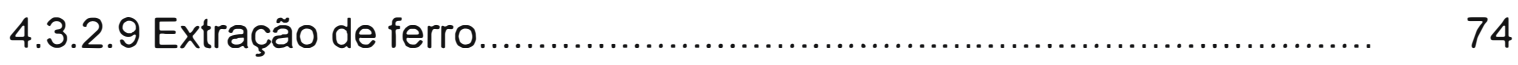

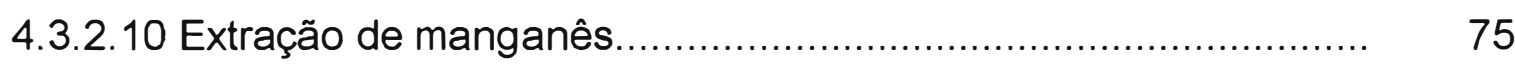

4.3.2.11 Extração de zinco............................................................... 76

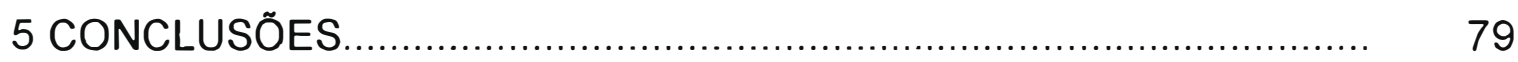

REFERÊNCIAS BIBLIOGRÁFICAS................................................. 80 


\title{
DOSES E FREQÜÊNCIAS DE APLICAÇÃO DE NITROGÊNIO E POTÁSSIO VIA FERTIRRIGAÇÃO PARA TOMATEIRO
}

\author{
Autora: Gláucia Regina Anti \\ Orientador: Prof. Dr. Quirino A. de C. Carmello
}

\section{Resumo}

Das hortaliças produzidas no Brasil, o tomate ocupa o primeiro lugar em valor e volume de produção e o segundo lugar em área colhida. Sendo esta cultura tão importante, é fundamental o conhecimento dos muitos fatores que contribuem para sua alta produtividade, dos quais, o manejo adequado da fertilização e da água de irrigação.

Para avaliar os efeitos de doses de nitrogênio e potássio aplicadas via fertirrigação e a freqüência de aplicação na cultura do tomateiro, foi conduzido um experimento em campo, na área experimental do Departamento de Engenharia Rural, localizada na Fazenda Areão, pertencente à Escola Superior de Agricultura "Luiz de Queiroz" (ESALQ), da Universidade de São Paulo (USP). $O$ delineamento experimental foi inteiramente casualizado foi composto de três doses de nitrogênio $\left(155,310\right.$ e $\left.465 \mathrm{~kg} \mathrm{ha}^{-1}\right)$, três doses de potássio (190, 380 e $570 \mathrm{~kg} \mathrm{ha}^{-1}$ ), e duas freqüências de aplicação (3 e 7 dias). 0 cultivar utilizado foi o Carmem.

Das freqüências de aplicação, a que demonstrou-se mais eficiente foi a cada sete dias, que possibilitou o melhor manejo da fertirrigação. Porém a produção de tomate foi muito baixa nestas condições, sendo a maior $8750 \mathrm{~kg}$ $h^{-1}$. A concentração dos nutrientes na folha diagnósticas apresentou-se 
deficiente ou próxima desta condição. Da mesma forma, a extração de nutrientes pelos frutos também foi baixa, sendo entre os macronutrientes: nitrogênio > potássio > fósforo > magnésio > enxofre > cálcio, e entre os micronutrientes: zinco > ferro > cobre > manganês > boro. 


\title{
DOSES AND FREQUENCIES OF NITROGEN AND POTASSIUM APPLICATION THROUGH FERTIRRIGATION IN TOMATO PLANTS
}

\author{
Author: Gláucia Regina Anti \\ Adviser: Prof. Dr. Quirino A. de C. Carmello
}

\section{Summary}

In Brazil, the tomato is the vegetable with the largest value and volum of production, and it has the second harvested area. As it is a so important crop, it is necessary to know the factors which contributes for its high yield, as the adequate water and fertilization management.

To evaluate the effect of nitrogen and potassium dose appplied by fertirrigation and the frequency of application, an experiment in field was carried out in the experimental area of the Rural Engineering Department, in the Areão Farm, which belongs to the "Luiz de Queiroz "College of Agronomy (ESALQ), University of São Paulo (USP). The randomized design was made up of three nitrogen doses $\left(155,310\right.$ and $\left.465 \mathrm{~kg} \mathrm{ha}^{-1}\right)$, three potassium doses $(190,380$ and $570 \mathrm{~kg} \mathrm{ha}^{-1}$ ) and two frequencies of application ( 3 and 7 days). It was used the cultivar Carmem.

The more efficient application frequency was at each 7 days, which gave the better fertirrigation management. However, the tomato production was very small, $8750 \mathrm{~kg} \mathrm{ha}^{-1}$, under this condition, and the nutrient concentration in the diagnostic leaves showed deficient or near of this condition. The nutrient extration by fruits was low too, the macronutrients extratiopn order was: nitrogen 
$>$ potassium > phosphorus > magnesium >sulphur > calcium, and for micronutrients extraction was found zinc > iron > copper > manganese > boron. 


\section{INTRODUÇÃO}

A cultura do tomateiro apresentou no Brasil expressivo crescimento nos últimos anos, chegando a atingir em 1999 mais de 3,1 milhões de toneladas, cultivadas em cerca de 65 mil hectares. Esta marca deixa o país entre os dez maiores produtores mundiais (Agrianual, 2000).

Os estados brasileiros que se destacam na produção de tomate são: São Paulo, Minas Gerais, Santa Catarina, Rio Grande do Sul, Rio de Janeiro e Goiás. Em São Paulo, a principal região abastecedora da CEAGESP é a sudoeste, sendo Apiaí, Ribeirão Branco e Itapeva os maiores produtores, seguidos de Mogi Guaçu, Elias Fausto e Sumaré (Camargo Filho, 1999).

O tomateiro é uma planta altamente susceptivel ao ataque de pragas e doenças, apresenta ciclo relativamente curto e possui elevado valor comercial e alta capacidade de produção, que acabam exigindo a aplicação de grande quantidade de insumos e serviços, fazendo com que os recursos financeiros aplicados sejam elevados. Todavia, mesmo com as variações de seu preço no mercado, a cultura do tomateiro assegura um bom retorno econômico ao produtor que conseguem alta produtividade.

São muitos os fatores que afetam a produtividade do tomateiro, mas pode-se destacar o manejo da fertilização como um dos mais importantes. Duas condições de fertilidade do solo são comumente encontradas na cultura do tomateiro: a) solos com teores elevados dos nutrientes minerais, essenciais para o desenvolvimento das plantas, porém completamente 
desbalanceados entre si; ou b) solos com nutrientes minerais em concentraçōes menores do que aquelas requeridas para o cultivo econômico da cultura.

A fertirrigação é uma opção para se atingir o manejo adequado de fertilizantes, pois consiste na aplicação de nutrientes via água de irrigação. Tal técnica aumenta a disponibilidade dos nutrientes para as plantas e reduz os gastos com a mão de obra, já que o adubo é fornecido às plantas através do sistema de irrigação. Através da fertirrigação também é possivel parcelar-se o adubo em um maior número de vezes, evitando-se as perdas por lixiviação.

Considerando-se esses aspectos, o trabalho teve como objetivo avaliar 0 efeito de doses de nitrogênio e potássio aplicados via fertirrigação e a freqüência de aplicação na cultura do tomateiro. 


\section{REVISÃO DE LITERATURA}

\subsection{A cultura do tomateiro}

O tomateiro é uma planta originária da região montanhosa dos Andes, onde podem ser encontradas suas formas selvagens. A domesticação da planta foi feita pelos Astecas no México. Foi levado pelos espanhóis para a Europa como planta ornamental e em 1554 já estava catalogada em um herbário italiano. Havia uma crença de que tratava-se de uma planta venenosa, sendo portanto, sua aceitação muito lenta. Em 1810 o tomateiro retoma à América, mas somente em 1830 torna-se importante como fonte de alimento nos Estados Unidos da América (Trani et al., 1994). No Brasil, o tomateiro foi introduzido a mais de um século, por meio da imigração italiana e portuguesa (Nagai, 1989).

A pesquisa com o tomateiro no Brasil teve início no Instituto Agronômico de Campinas em 1938, onde foram introduzidos e avaliados cultivares, estudadas as épocas de plantio, espaçamento, doses e tipos de fertilizantes, controle de pragas e doenças. Esses estudos foram realizados pelo pesquisador Olympio de Toledo Prado, fundador da Seção de Olericultura da instituição. Em 1960, o cultivar Angela proporcionou um grande impulso na expansão do cultivo, pois apresenta resistência ao vírus $\mathrm{Y}$, podridão apical $\mathrm{e}$ rachaduras dos frutos. No ano de 1986 foi lançado o cultivar Santa Clara, mais apropriada para o verão, com resistência ao PVY, Altemária, Septoria e Fitoftora (Trani et al., 1994). 
Estudos genéticos, fisiológicos e patológicos freqüentemente adotam a planta do tomateiro como adequada. Até agora, muitas das informações sobre tomates tem sido fragmentadas: desenvolvimento de tomates no campo e em ambientes protegidos são considerados separadamente e as descobertas mais fundamentais da pesquisa tem sido freqüentemente insuficientes para se conseguir seu envolvimento direto ou indireto na produção comercial da cultura. Da mesma forma, a pesquisa científica é muitas vezes descuidada com o problema da produção comercial da cultura e as possíveis relações de seu trabalho com a cultura comercial (Atherton \& Rudich, 1986).

Das hortaliças produzidas no Brasil, o tomateiro (Lycopersicon esculentum Mill.) ocupa destaque, com uma produção de $839.820 \mathrm{Mg}$ apenas no Estado de São Paulo (Trani et al., 1997). Uma comparação feita por Camargo Filho \& Mazzei (1996), entre as décadas de 70 e 80, demonstrou que houve um aumento de $49 \%$ na produtividade enquanto a área cultivada aumentou somente 11\%. Em 1999, a área cultivada no Brasil foi de 66.000 ha, com uma produtividade de $47.745 \mathrm{~kg} \mathrm{ha}^{-1}$ e produção de $3.151 .170 \mathrm{Mg}$ (FAO, 1999).

O tomateiro é uma planta anual da classe das dicotiledôneas, pertence à família das Solanáceas e é a espécie Lycopersicon esculentum Mill.. Pode apresentar hábito de crescimento determinado ou indeterminado. Quando o crescimento é determinado, o caule é ramificado e não apresenta dominância apical. Para o crescimento indeterminado, o caule principal cresce mais que as ramificações laterais, caracterizando a dominância apical. Há também plantas caracterizadas como anãs, cuja características se assemelham ao crescimento indeterminado, porém apresenta internódios muito curtos.

O sistema radicular é pivotante, mais profundo em plantas semeada diretamente e mais superficial e ramificado nas plantas transplantadas. $O$ volume de raízes maior encontra-se entre 5 e $35 \mathrm{~cm}$ de profundidade.

As folhas são alternadas, compostas de número ímpar de folíolos, peciolados, com limbo oval apontado e com bordas serrilhadas. Nas axilas das 
folhas crescem ramos laterais que se desenvolvem e frutificam, podendo também ramificar.

As flores são amarelas, variando de 1 a $2 \mathrm{~cm}$ de diâmetro. São hermafroditas, por isso sua reprodução é autógama. Os frutos são do tipo baga e apresentam formato variável. A cor pode variar entre vermelho, rosado ou amarelo. As sementes são pequenas, medindo de 3 a $4 \mathrm{~mm}$ de comprimento por cerca de $3 \mathrm{~mm}$ de largura e 0,5 a $1 \mathrm{~mm}$ de espessura. Um grama de semente pode conter entre 250 e 430 unidades.

O plantio é a forma de propagação mais comum, através de mudas, quando apresentam de 6 a 8 folhas, obtidas a partir de sementes, podendo-se também fazer a semeadura direta (Trani et al., 1994).

Segundo Filgueira (1982), o tomateiro é uma palnta anual que se adapta aos diversos tipos de solo, desde que não sejam excessivamente argilosos e compactados ou mal drenados.

\subsection{Nutrição mineral e adubação do tomateiro}

Dentre os fatores de produção, a nutrição mineral é o mais relacionado com os aumentos na produtividade e a melhoria da qualidade dos frutos. Dos nutrientes fornecidos por meio da adubação química, destacam-se nitrogênio, fósforo e potássio, que devem ser aplicados de acordo com as exigências da cultura e o método de adubação utilizado (Haag et al., 1993).

Para Whitney et al. (1985), a concentração de nutrientes na planta, em uma determinada época, é correspondente ao valor integral de todos os fatores que influenciam na concentração do elemento, na hora da coleta do material. A idade dos tecidos, diferentes genótipos, e a interação entre nutrientes e o meio ambiente são fatores que interferem na concentração dos nutrientes (Smith, 1986).

Em grande parte do período de desenvolvimento do tomateiro ocorrem simultaneamente o crescimento vegetativo e o desenvolvimento reprodutivo, com futificação, em média, com doze níveis de cachos. A fase que antecede a 
maturação dos frutos do primeiro e do segundo cacho requer uma elevada quantidade de nutrientes minerais e carboidratos para o crescimento dos frutos. Assim, a parte vegetativa é momentaneamente paralisada e a fase é considerada como o período de maior exigência de água, de nutrientes e de condições ambientais adequadas, tal como temperatura (Takahashi, 1993).

As necessidades de elementos minerais para o tomateiro são supridas pela aplicação de fertilizantes ao solo, na época adequada e na posição ideal de aplicá-los (Fontes \& Horino, 1991). Barbosa (1993) afirma que a extração de nutrientes pelo tomateiro até 30 dias é irrisória, desaconselhando-se adubações pesadas em pré-plantio.

Buscando determinar a marcha de absorção do tomateiro, Gargantini \& Blanco (1963) utilizaram a variedade Santa Cruz 1639, cultivada em vaso, em casa de vegetação. Durante o ciclo da planta, foram colhidas e analisadas amostras para determinar os teores dos macronutrientes nas raízes, no caule, nas folhas e nos frutos. Os autores concluíram que 1) os nutrientes absorvidos em maior quantidade foram $\mathrm{Ke} \mathrm{N}$, seguidos pelo $\mathrm{Ca}, \mathrm{S}, \mathrm{P}$ e $\mathrm{Mg}$; 2) a absorção de nutriente alcançou o máximo entre os 100 e 120 dias após a germinação, para o $\mathrm{N}, \mathrm{KMg}$ e $\mathrm{S}$, enquanto que o $\mathrm{Ca}$ e $\mathrm{P}$ foram absorvidos continuamente do início ao final do experimento; 3) foi grande a translocação de $\mathrm{N}, \mathrm{P}, \mathrm{K} \mathrm{e} \mathrm{Mg} \mathrm{da}$ parte vegetativa para os frutos; 4) considerando a produção de $41 \mathrm{Mg} \mathrm{ha}^{-1}$, os frutos da cultura absorveram $72 \mathrm{~kg}$ de $\mathrm{N}, 18 \mathrm{~kg}$ de $\mathrm{P}, 130 \mathrm{~kg}$ de $\mathrm{K}, 7 \mathrm{~kg}$ de $\mathrm{Ca}, 7 \mathrm{~kg}$ de $\mathrm{Mg}$ e $9 \mathrm{~kg}$ de $\mathrm{S}$.

Fernandez et al. (1975) observou em um estudo de absorção de nutrientes pelo tomateiro que a quantidade de macronutrientes absorvidos segue a ordem: $\mathrm{K}$ e N> $\mathrm{Ca}>\mathrm{Mg}>\mathrm{S}>\mathrm{P}$. Entre os micronutrientes temos; $\mathrm{Fe}>$ $\mathrm{Mn}>\mathrm{Zn}>\mathrm{B}>\mathrm{Cu}$. Fayad (1998) trabalhando com tomate Santa Clara em condições de campo, observou que a absorção de nutrientes seguiu a ordem: $K$ $>\mathrm{N}>\mathrm{Ca}>\mathrm{S}>\mathrm{P}>\mathrm{Mg}$, e entre os micronutrientes $\mathrm{Cu}>\mathrm{Mn}>\mathrm{Fe}>\mathrm{Zn}$.

Uma forma muito utilizada de se fazer a avaliação do estado nutricional da planta é a análise foliar ou de tecido. Essa prática permite uma correlação 
adequada entre os niveis de nutrientes no solo, na planta e a produção.

A parte do tomateiro a ser coletada para a diagnóse foliar é a folha com pecíolo situada abaixo do primeiro cacho, na ocasião do primeiro fruto maduro, em 25 plantas por hectare (Trani et al., 1996).

Para o Estado de São Paulo, Trani et al. (1996) recomendaram para o tomateiro estaqueado, que a calagem eleve a saturação por bases até $80 \%$ e o teor de $\mathrm{Mg}$ ao mínimo de $9 \mathrm{mmol}_{\mathrm{c}} \mathrm{dm}^{-3}$. A adubação orgânica deve ser feita com 20 a $30 \mathrm{Mg} \mathrm{ha}^{-1}$ de esterco de curral bem curtido ou composto ou 5 a $8 \mathrm{Mg} \mathrm{ha}^{-1}$ de esterco de galinha curtido. A adubação mineral deve ser feita nos sulcos 8 a 10 dias antes do transplante e, de acordo com a análise do solo, aplica-se as seguintes quantidades de nutrientes:

Tabela 1: Recomendação de adubação de plantio para o tomate estaqueado em função do resultado da análise do solo.

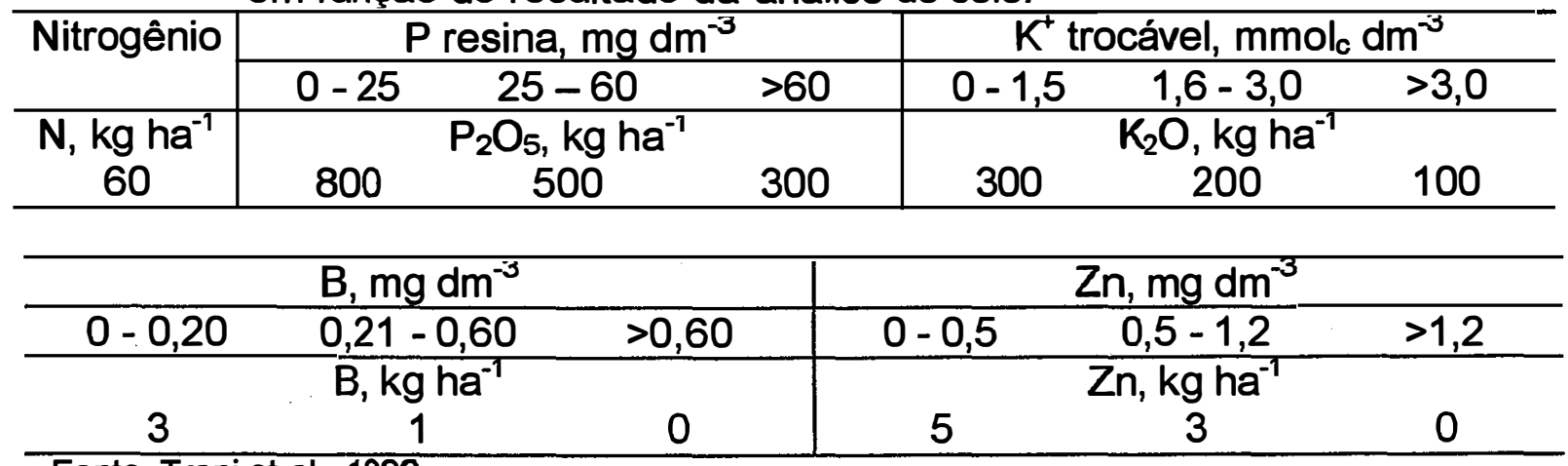

Fonte: Trani et al., 1996.

$\mathrm{Na}$ adubação de plantio, deve-se utilizar 20 a $40 \mathrm{~kg} \mathrm{ha}^{-1}$ de $\mathrm{S}$. A adubação de cobertura deve ser feita com 200 a $300 \mathrm{~kg} \mathrm{ha}^{-1}$ de $\mathrm{N}$ e 120 a 240 $\mathrm{kg} \mathrm{ha}^{-1}$ de $\mathrm{K}_{2} \mathrm{O}$, parcelados de 4 a 6 vezes, com intervalos entre as aplicações de 15 a 20 dias. As quantidades maiores ou menores dependem da análise do solo e das follhas, da cultivar utilizada e da produtividade esperada. É recomendado utilizar-se parte do $\mathbf{N}$ na forma nítrica.

É possivel produzir-se tomate com pequena margem de lucro sob niveis limitantes de nutrientes, mas um manejo adequado no fornecimento de 
nutrientes é fundamental para a obtenção de uma produção de boa qualidade e altamente lucrativa (Adams, 1986).

\subsection{Fertirrigação}

A irrigação é uma prática agrícola essencial para o manejo de muitas culturas e a aplicação de fertilizantes nessa água proporciona uma forma econômica e eficiente de aplicação de fertilizantes para as plantas. Na cultura do tomateiro a irrigação pode ser feita tanto por sulco quanto por aspersão ou gotejamento. O uso da aspersão é limitado, pois essa prática lava os defensivos aplicados nas folhas, favorecendo o desenvolvimento de doenças. A irrigação por sulco é restrita, quando a água for um fator limitante. $O$ gotejamento permite o melhor controle sobre a água aplicada e uma maior eficiência no seu uso, todavia, ele exige um investimento inicial maior (Alves et al., 1982).

Para o cultivo do tomateiro, o volume de água a ser aplicado e as freqüências das irrigações variam de acordo com o tipo de solo, a topografia da área, as condições do clima e o estádio de desenvolvimento.

A fase crítica ocorre do início da floração até o início da maturação, compreendendo, portanto, todo o desenvolvimento do fruto. $\mathrm{Na}$ fase de desenvolvimento da planta, a irrigação menos freqüente favorece o desenvolvimento das raízes, enquanto na floração, frutificação e maturação, irrigações leves e freqüentes contribuem para o desenvolvimento do fruto e aumentam o teor de suco.

O nível adequado de irrigação deve ser o suficiente para manter úmida a camada de solo explorada pelo sistema radicular, ou seja, deve atingir até 40 $\mathrm{cm}$ de profundidade. O manejo incorreto da irrigação pode ocasionar um excesso de água no solo, cujos efeitos podem ser: crescimento excessivo da planta e retardamento na maturação dos frutos; condução de nutrientes, principalmente o nitrogênio, para longe do alcance das raízes; queda de flores durante a floração; ocorrência de podridão apical; surgimento de doenças cujo agente esteja no solo; ataque de doenças fúngicas nas folhas e desgaste do 
equipamento de irrigação (EMBRAPA, 1995). Assim, uma boa opção para a cultura do tomateiro tem sido a fertirrigação.

Fertirrigação é o nome dado à técnica que consiste na aplicação simultânea de água e fertilizantes por meio de um sistema de irrigação (Frizzone et al., 1985). Vitti et al. (1994) defiiram a fertirrigação como a combinação da fertilização com a irrigação, ou seja, os adubos minerais são dissolvidos na água de irrigação para formar uma "água de irrigação enriquecida". Hernandez (1993) definiu fertirrigação como uma técnica onde é feita a aplicação simultânea de água e fertilizantes no solo, através do sistema de irrigação.

A fertirrigação têm sido adotada pelos agricultores de muitos países, utilizando-se diferentes formas de irrigação. Na região oeste dos Estados Unidos, a fertirrigação foi iniciada no sistema de irrigação por sulco. Na década de 1930, na Califórnia, o sistema de irrigação por aspersão foi utilizado para fertirrigar pomares (Woodward, 1959). Deve-se observar que a irrigação por aspersão é usada desde 1910, mas o seu grande desenvolvimento ocorreu por volta de 1962, quando foram instalados sistemas de cobertura total, na Califórnia (Bernardo, 1978). A partir de então, com o aperfeiçoamento desse sistema de irrigação, foi possível solucionar as deficiências que limitavam a difusão da fertirrigação. Após esse avanço, foi desenvolvido o sistema de irrigação por gotejamento e atualmente, ainda em fase de aperfeiçoamento, surge o sistema de irrigação por microaspersão, utilizado em todo tipo de culturas arbóreas e herbáceas (Frizzone et al., 1985).

No Brasil, a fertirrigação praticamente coincide com a irrigação por gotejamento, tendo sido introduzida na década de 70. A tecnologia da irrigação por gotejamento foi importada de Israel, mas a comercialização foi suspensa anos depois. No final da década de 70 as importações recomeçaram e teve início a fabricação de componentes do sistema de irrigação por gotejamento. A partir de então houve a difusão da técnica, principalmente na região nordeste do país. Durante a década de 80 a técnica apresentou crescimento lento. 
Apenas na década de 90 a irrigação por gotejamento foi intensamente difundida.

A irrigação por pivô central foi outro fator que contribuiu para o desenvolvimento da fertirrigação a partir da década de 80 . Nos anos 90 , a fertirrigação passa a ser efetivamente utilizada como prática alternativa e mais eficiente de aplicação de fertilizantes para as culturas.

Atualmente, a fertirrigação está associada e vem sendo utilizada na fruticultura, principalmente na região Nordeste e Sudeste, com as culturas de citros, manga, mamão, coco, caju, maracujá, uva, abacaxi e acerola. Dentre as hortaliças, o melão, o tomate e o pimentão destacam-se com maiores áreas fertirrigadas (Carrijo et al., 1999).

O sistema de fertirrigação apresenta as seguintes vantagens:

- Economia de mão-de-obra: a aplicação manual é difícil e pouco exata, enquanto a aplicação mecânica é relativamente cara, e em alguns casos provoca a compactação do solo. Já a aplicação de fertilizantes através da irrigação é mais rápida que a forma convencional. Após o preparo da solução, o sistema de irrigação se encarrega de fazer a distribuição do produto. Nos dias atuais, tempo e mão-de-obra são fatores altamente limitantes na agricultura e a fertirrigação facilita o manejo no campo, aplicando com comodidade e eficiência os fertilizantes. Assim, a mão-de-obra pode ser utilizada na execução de outras atividades (Frizzone et al., 1985; Hernandez, 1994).

- Redução dos custos de aplicação: a comparação dos custos entre o sistema convencional e a fertirrigação depende de vários fatores, como a necessidade de suplemento de água no momento da fertirrigação, a quantidade de água necessária para a aplicação do produto, o número de adubações, o tipo de equipamento, além de outros fatores. A análise de custos entre sistemas de quimigação e aplicação convencional, considerando custos anuais e variáveis de operação do sistema, demonstra que quanto maior for o número de aplicações, a quimigação é mais vantajosa, pois seu custo de aplicação varia de 50 a $87 \%$ do custo das aplicações convencionais (Frizzone \& Botrel, 1994). 
- Diminuição da compactação do solo: como não há entrada de máquinas para a aplicação de fertilizantes, diminui-se a compactação do solo e reduz-se os danos às culturas (Frizzone \& Botrel, 1994).

- Economia e eficiência no uso de fertilizantes: com a fertirrigação há um aumento na eficiência do uso dos adubos, pois os nutrientes chegam até as plantas já na forma solúvel. Também permite maior parcelamento, reduzindo perdas por lixiviação e, consequentemente, reduzindo a quantidade de adubo a ser aplicada (Frizzone \& Botrel, 1994; Hernandez, 1994). A aplicação fracionada dos nutrientes aumenta a assimilação dos mesmos pelas plantas e limita as perdas por lixiviação, proporcionando o aproveitamento mais eficiente do fertilizante, isto é, resposta equivalente a uma menor quantidade de fertilizante aplicado em comparação com outros métodos (Frizzone et al., 1985). - Controle da profundidade de aplicação: é possível promover o aprofundamento dos nutrientes localizando-os. Os fertilizantes são aplicados juntos com uma quantidade adequada de água, o que permite a incorporação até a profundidade desejada, para impedir a lixiviação do produto (Frizzone \& Botrel, 1994; Hernandez, 1994).

- Flexibilidade de aplicação: os nutrientes podem ser aplicados em qualquer época, possibilitando maior parcelamento das aplicações e adequando-as às necessidades das culturas (Hernandez, 1994). Com métodos convencionais torna-se difícil coordenar a composição dos nutrientes (a quantidade, a relação entre eles e o momento da aplicação) com as variações nas necessidades específicas nas diferentes etapas de desenvolvimento: crescimento vegetativo, floração e maturação. A fertilização combinada com a irrigação oferece maior versatilidade na época de aplicação de nutrientes, podendo dosar as quantidades de nutrientes e fornecê-los segundo as necessidades das plantas, durante o ciclo vegetativo (Frizzone et al., 1985).

- Aplicação de micronutrientes: a aplicação de micronutrientes geralmente é feita em pequenas quantidades, o que dificulta sua aplicação mecânica. Com a 
fertirrigação é possível aplicá-los com eficiência (Frizzone et al., 1985; Hernandez, 1994).

- Controle e aplicação da quantidade certa: existe maior controle sobre a aplicação dos produtos, estando esta menos sujeita às variações causadas pela interferência humana, como a velocidade inconstante do trator e desregulagem da adubadora.

- Menor poluição do ar e dos cursos de água: a redução nas doses de fertilizantes e o aumento da eficiência podem impedir, protelar ou diminuir a contaminação das fontes de água potável (Frizzone et al., 1985).

- Uniformidade de aplicação.

Pode-se citar como desvantagens da fertirrigação:

- Escolha de fertilizantes: o método é apropriado para fertilizantes aplicados em solução ou para aqueles que são muito solúveis, sendo inadequado para fertilizantes pouco solúveis (Frizzone et al., 1985).

- Corrosão do sistema de irrigação: partes do sistema de irrigação podem ser danificadas pela características corrosivas de alguns fertilizantes, especialmente as partes relacionadas ao equipamento de injeção. Isso exige alguns cuidados, como a lavagem dos equipamentos e da tubulação do sistema (Hernandez, 1994).

- Reação dos fertilizantes na linha de irrigação: alguns fertilizante, especialmente os fosfatados, podem sofrer precipitação na rede de irrigação, como conseqüência do $\mathrm{pH}$ da solução, provocando obstrução dos emissores, especialmente em gotejadores (Frizzone et al., 1985; Hernandez, 1994).

- Contaminação e envenenamento: deve-se tomar cuidado com a segurança humana e ambiental. O retorno do fluxo de solução para dentro da água na fonte de suprimento, quando reinicia-se a fertirrigação, constitui-se em um grande risco ambiental. Esse risco existe independente da fonte de água (subterrânea, reservatório ou rio) e do sistema de irrigação (Hernandez, 1994; Frizzone \& Botrel, 1994). É interessante a colocação de válvulas de retenção e anti-vácuo, o que impede a inversão do fluxo na rede de irrigação. 
- Desuniformidade do potencial de distribuição: fatores como uniformidade de distribuição da água, precipitação química na rede de irrigação $e$ desuniformidade da mistura química ou de injeção podem resultar na desuniformidade de distribuição do produto. Para uma melhor distribuição do fertilizante pelo sistema de irrigação, o tempo de irrigação deve ser longo (Frizzone \& Botrel, 1994).

- Déficit ou excesso de produto aplicado: a inadequada operação do sistema de irrigação durante a fertirrigação resulta em excesso ou déficit no produto aplicado em frações da área, proporcionando baixa uniformidade de aplicação dos produtos, porém o operador deve reconhecer que uma quimigação segura e efetiva requer atenção e cuidado no manejo da irrigação (Frizzone \& Botrel, 1994).

A fertirrigação aumenta a dinâmica dos nutrientes no solo, devido à constante aplicação de água, o que provoca aumento na atividade de microorganismos do solo, na troca catiônica e na absorção dos nutrientes. Para se obter resultados satisfatórios com a fertirrigação, é fundamental o controle do pH e da condutividade elétrica (CE) da solução do solo (Casarini \& Folegatti, 1999).

Das formas existentes para a obtenção da solução do solo, pode-se considerar como a mais prática a que utiliza o extrator de cápsula porosa. $\mathrm{Da}$ solução extraída é possivel obter-se o valor do pH e CE no campo, utilizando-se medidores portáteis. Pode-se também conhecer a concentração dos nutrientes na solução para avaliar a movimentação dos íons no solo.

A aplicação dessas informações permite verificar se estão ocorrendo ou não perdas de nutrientes por lixiviação, se há acúmulo de sais na zona radicular da planta e se as quantidades de nutrientes são adequadas à fase de desenvolvimento em que a planta se encontra.

Para o uso intensivo da fertirrigação, é fundamental que haja disponibilidade de produtos, materiais e equipamentos de boa qualidade e a 
custos suportáveis pelo produtor agrícola, além de um contínuo processo de pesquisa e desenvolvimento (Carrijo et al., 1999). 


\section{MATERIAL E MÉTODOS}

\section{1 Área experimental}

O experimento foi realizado na área experimental do Departamento de Engenharia Rural, localizada na Fazenda Areão, pertencente à Escola Superior de Agricultura "Luiz de Queiroz" (ESALQ), da Universidade de São Paulo (USP) em Piracicaba - SP. As coordenadas geográficas são: longitude: $47^{\circ} 38^{\prime \prime} 00^{\prime} \mathrm{W}$ latitude $22^{\circ} 42^{\prime \prime} 30^{\prime} \mathrm{S}$ e a altitude de 580 metros. A área do experimento abrangeu $1036,80 \mathrm{~m}^{2}(36 \mathrm{~m} \times 28,8 \mathrm{~m})$.

\subsection{Características do solo}

O solo no qual foi instalado o experimento é classificado como Terra Roxa Estruturada. Suas características químicas são apresentadas na Tabela 2, conforme análise efetuada pelo Departamento de Solos e Nutrição de Plantas, ESALQ-USP.

Tabela 2: Características químicas do solo da área experimental.

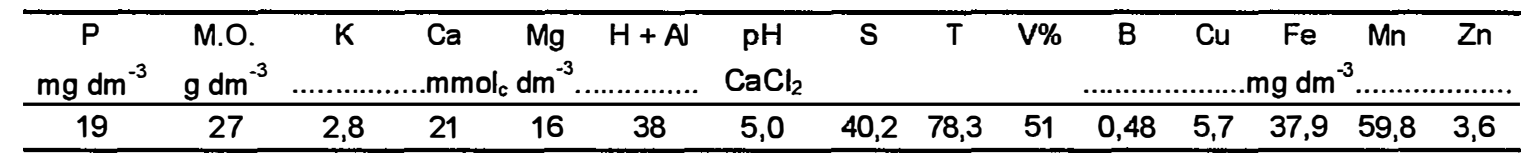

\subsection{Características climáticas}

O clima na região de Piracicaba é caracterizado como Cwa, conforme classificação de KÖPPEN. É um clima subtropical úmido, com verão chuvoso, 
inverno seco e temperatura do mês mais quente superior a $22^{\circ} \mathrm{C}$. As médias anuais são: precipitação de $1247 \mathrm{~mm}$; temperatura do ar de $21,1^{\circ} \mathrm{C}$, umidade relativa do ar de $74 \%$ e velocidade do vento de $2,2 \mathrm{~m} \mathrm{~s}^{-1}$ (dados coletados na Estação Meteorológica do Departamento de Ciências Exatas da ESALQ/USP).

No período em que se 22 outubro de 1999 a 18 janeiro de 2000, época em que foi conduzido o experimento, a precipitação total foi de $509 \mathrm{~mm}$ e a temperatura média foi de $23,86^{\circ} \mathrm{C}$, sendo a média das temperaturas máximas e mínimas diárias de 29,91 e $17,82^{\circ} \mathrm{C}$, respectivamente.

\subsection{Sistema de irrigação}

No sistema de irrigação utilizou-se tubos gotejadores da marca Naan, com espaçamento entre orifícios de $0,33 \mathrm{~m}$ cuja vazão individual é de $2,1 \mathrm{~L} . \mathrm{h}^{-1}$, medidos por meio de teste de campo. A pressão do sistema fói homogeneizada por um regulador de pressão com 15 PSI de saída. Desta forma, foi possivel desconsiderar-se a variabilidade na vazão dos orifícios gotejadores, devido ao fato de seu comprimento ser de apenas $3 \mathrm{~m}$, o que não ocasiona uma perda substancial de carga. A aplicação de fertilizantes foi feita através de uma bomba injetora TMB WP 10.

A largura de $0,70 \mathrm{~m}$ da faixa molhada, perpendicular à linha de irrigação, foi obtida através da determinação da umidade das amostras de solo coletadas na área experimental. A faixa molhada de $0,70 \mathrm{~m}$ proporcionou uma área molhada de $2,08 \mathrm{~m}^{2}$. Considerando-se a vazão e a área molhada, pode-se afirmar que o sistema possibilitou aplicar uma lâmina de água de $9,3 \mathrm{~mm} \mathrm{~h}^{-1}$.

\subsection{Extratores de solução do solo}

Os extratores de solução possuiam em sua extremidade inferior cápsulas porosas de cerâmica de $20 \mathrm{~mm}$ de diâmetro e $50 \mathrm{~mm}$ de comprimento. As cápsulas foram testadas quanto a uma possível contaminação da solução por sais, visto que alguns resíduos poderiam estar presentes nos poros, proporcionando um intercâmbio catiônico (Grover \& Lamborn, 1970). 


\subsection{Fertilizantes}

Foram utilizados os seguintes adubos comerciais: superfosfato simples (20\% de $\left.\mathrm{P}_{2} \mathrm{O}_{5}\right)$, nitrato de potássio $\left(13,5 \% \mathrm{~N}\right.$ e $46 \% \mathrm{~K}_{2} \mathrm{O}$ ), nitrato de amônio $(33 \% \mathrm{~N})$, nitrato de cálcio $(15,5 \% \mathrm{~N}$ e $19 \% \mathrm{Ca})$ e cloreto de potássio $\left(60 \% \mathrm{~K}_{2} \mathrm{O}\right)$. O superfosfato simples foi aplicado em uma única vez, sete dias antes do transplante. Os demais adubos foram aplicados via fertirrigação, que teve início sete dias após o transplante.

\subsection{Cultura}

Utilizou-se o cultivar Carmem, um híbrido F1 longa vida, que possui hábito de crescimento indeterminado, peso médio dos frutos variando entre 200 e 250g, com início de colheita por volta dos 75 dias e ciclo variando entre 115 e 121 dias. As sementes foram cedidas pela empresa Agroflora.

\subsection{Delineamento experimental e tratamentos}

O delineamento experimental foi inteiramente casualizado, composto por três doses de nitrogênio, três doses de potássio e duas freqüências de aplicação, que combinados entre si totalizaram dezoito tratamentos, com quatro repetições. O modelo matemático para a análise de variância foi:

$$
y_{i j}=m+t_{i}+e_{i j}
$$

onde:

yij = é o valor observado referente ao i-ésimo tratamento na j-ésima parcela;

$\mathrm{m}=$ é a média geral

$\mathrm{ti}$ = é o efeito do i-ésimo tratamento e

eij $=$ erro aleatório correspondente às observações. 
Cada parcela era composta por três linhas com quatro plantas, totalizando doze plantas. O espaçamento entre linhas foi de $1,5 \mathrm{~m}$ e entre plantas $0,8 \mathrm{~m}$, portanto, a área de cada parcela era de $14,4 \mathrm{~m}^{2}$. As duas plantas centrais foram consideradas como plantas úteis.

As doses de nitrogênio e potássio foram estabelecidas a partir da soma da adubação de plantio com a adubação de cobertura, obtida em função da análise química do solo conforme a recomendação feita por Raij et al. (1996), sendo cada dose equivalente a 50, 100 e 150\% da recomendação. Assim, obteve-se os tratamentos descritos na Tabela 3:

Tabela 3: Tratamentos e a relação entre potássio e nitrogênio.

\begin{tabular}{|c|c|c|c|c|}
\hline Tratamentos & $\begin{array}{l}\text { Freqüência } \\
\text { de aplicação }\end{array}$ & $\begin{array}{c}\text { Doses } \\
\text { de N }\end{array}$ & $\begin{array}{l}\text { Doses } \\
\text { de K }\end{array}$ & $\begin{array}{l}\text { Relação } \\
\text { KIN }\end{array}$ \\
\hline 1 & 3 & 155 & 190 & 1,23 \\
\hline 2 & 3 & 155 & 380 & 2,45 \\
\hline 3 & 3 & 155 & 570 & 3,68 \\
\hline 4 & 3 & 310 & 190 & 0,61 \\
\hline 5 & 3 & 310 & 380 & 1,23 \\
\hline 6 & 3 & 310 & 570 & 1,84 \\
\hline 7 & 3 & 465 & 190 & 0,41 \\
\hline 8 & 3 & 465 & 380 & 0,82 \\
\hline 9 & 3 & 465 & 570 & 1,23 \\
\hline 10 & 7 & 155 & 190 & 1,23 \\
\hline 11 & 7 & 155 & 380 & 2,45 \\
\hline 12 & 7 & 155 & 570 & 3,68 \\
\hline 13 & 7 & 310 & 190 & 0,61 \\
\hline 14 & 7 & 310 & 380 & 1,23 \\
\hline 15 & 7 & 310 & 570 & 1,84 \\
\hline 16 & 7 & 465 & 190 & 0,41 \\
\hline 17 & 7 & 465 & 380 & 0,82 \\
\hline 18 & 7 & 465 & 570 & 1,23 \\
\hline
\end{tabular}

\subsection{Preparo da área experimental}

Foram aplicadas e incorporadas $2,3 \mathrm{Mg} \mathrm{ha}^{-1}$ de calcário para correção da acidez. Na adubação orgânica foram aplicados e incorporados $3,7 \mathrm{Mg}$ de 
esterco de curral. Em seguida o solo foi arado e gradeado. Os canteiros foram feitos para proporcionar uma distância de $1,5 \mathrm{~m}$ entre linhas. Foram instalados mourões, nos quais foram fixados os arames ( $\left.n^{\circ} 16\right)$ para a condução das plantas com fitilhos.

\subsection{Obtenção de mudas}

A semeadura foi feita em 16 de setembro de 1999, em bandejas de 128 células, utilizando-se substratos comercial (Plantmax da Eucatex S. A.). As mudas foram conduzidas em estufas e a irrigação realizada através nebulizadores. O transplante ocorreu em 22 de outubro de 1999, com 29 dias após a emergência.

\subsection{Tratos culturais}

Conforme as necessidades da cultura, foram realizadas as seguintes práticas:

- Amontoa: realizada a cada duas semanas para manter protegidas as raizes.

- Tutoramento: o fitilho foi amarrado na base de cada planta e esticado até o arame, que se encontravam presos aos mourões a uma distância de $2 \mathrm{~m}$ do chão.

- Desbrota: foram retirados os brotos laterais semanalmente. Na condução foi mantida uma haste por planta.

- Tratamento fitossanitário: foram utilizados os métodos preventivo e curativo, utilizando-se fungicidas e inseticidas conforme as recomendações. Os produtos utilizados e o número de aplicações encontram-se na Tabela 4: 
Tabela 4: Produtos utilizados no controle fitossanitário.

\begin{tabular}{lllc}
\hline \multicolumn{1}{c}{ Nome comercial } & \multicolumn{1}{c}{ Nome técnico } & \multicolumn{1}{c}{ Dosagem } & Aplicações \\
\hline Benlat 500 & Benomil & 1mL por litro de água & 8 \\
Confidor 700 GrDA & Imidacoprid & 0,3g por litro de água & 8 \\
Cuprogarb 500 & Oxicloreto de cobre & 3,5g por litro de água & 10 \\
Decis 25 CE & Detalmethrine & 3g por litro de água & 6 \\
Manzat 800 & Mancozeb & 3g por litro de água & 6 \\
\hline
\end{tabular}

\subsection{Manejo da irrigação}

O manejo da irrigação foi realizado utilizando-se tensiômetros, instalados à 20 e $40 \mathrm{~cm}$ de profundidade, e a curva característica de retenção de água no solo (Figura 1), feita através de regressão exponencial dos resultados obtidos em laboratório, utilizando-se amostras de solo indeformadas e funis de placa porosa conforme a metodologia proposta por Haines (1930) nas tensões de -1 , $-2,-4,-10,-30$ e $-50 \mathrm{kPa}$.

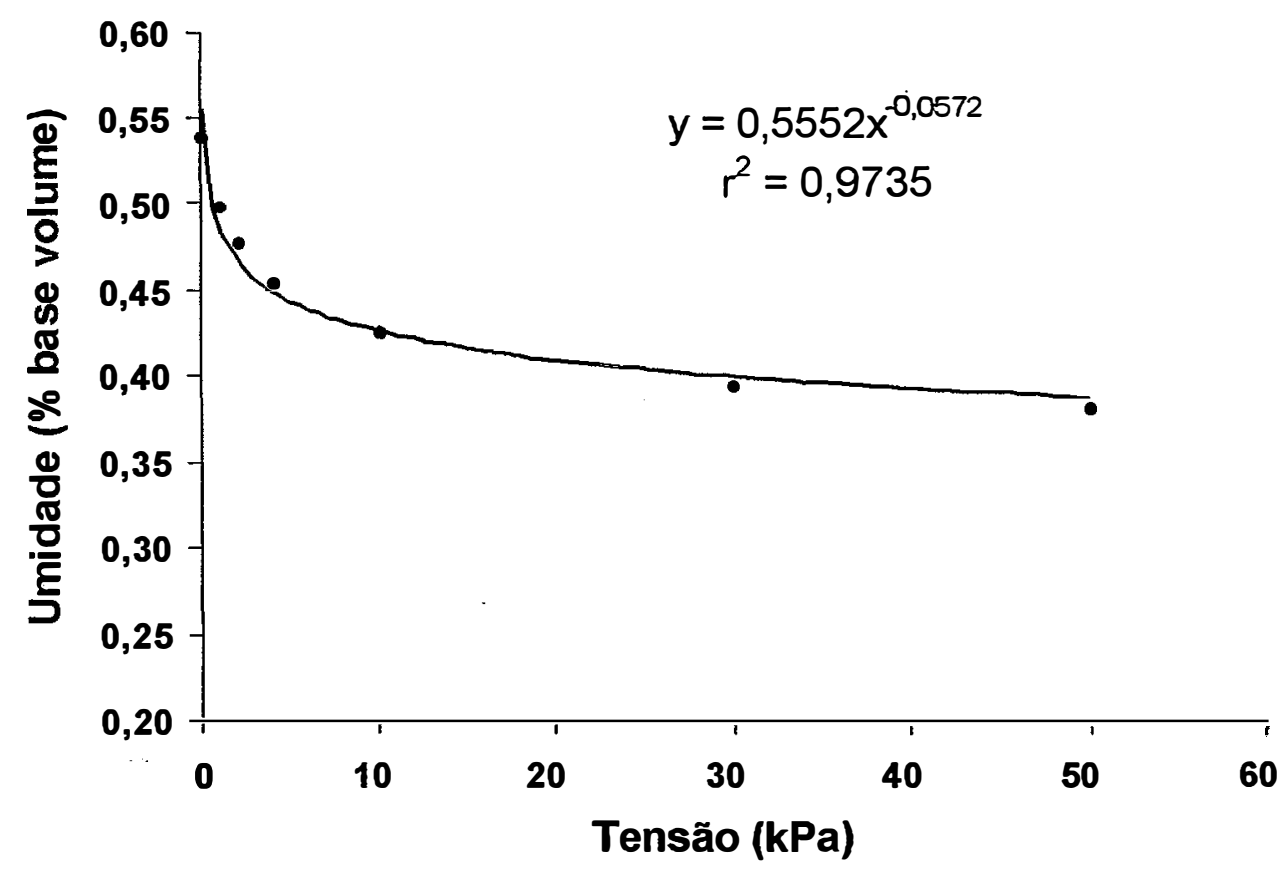

Figura 1: Curva de retenção de água no solo.

As leituras nos tensiômetros foram feitas a cada 3 dias e o momento da irrigação foi baseado nas médias das leituras, sendo realizada a irrigação 
sempre que estes valores atingiram $36 \mathrm{kPa}$. A quantidade de água aplicada na ocasião de cada evento de irrigação foi calculada por meio da utilização da curva de retenção, ou seja, a lâmina de irrigação aplicada era suficiente para elevar o potencial mátrico do solo a $10 \mathrm{kPa}$, sendo este o valor correspondente à umidade máxima de retenção da água pelo solo. Para se conhecer o valor da umidade do solo, utilizou-se a Equação 2:

$$
\phi=\phi c c-\phi \text { atual }
$$

onde:

$\phi$ é a quantidade de água no solo (\% volume);

$\phi$ cc é a quantidade de água no solo (\% volume) em capacidade de campo, e $\phi$ atual é a quantidade água no solo (\% volume) no momento da leitura.

Para a obtenção da lâmina a ser aplicada, multiplicava-se $\phi$ pela profundidade do solo, em milímetros, a ser molhada.

\subsection{Monitoramento da solução do solo}

O monitoramento da solução do solo foi feito ao longo do ciclo a fim de se conhecer a concentração de íons na solução do solo, mais especificamente dos íons potássio e nitrato, bem como da condutividade elétrica, e assim verificar-se a disponibilidade desses nutrientes para as plantas. Os extratores de cápsula porosa foram instalados a uma distância de $10 \mathrm{~cm}$ em relação à planta de tomate e com a cápsula a $20 \mathrm{~cm}$ de profundidade em relação à superfície do solo.

Submeteu-se os extratores de cápsula porosa a um vácuo de aproximadamente $72 \mathrm{kPa}$ por um período de sete dias, quando eram coletadas as soluções e em seguida aplicado novamente, tendo assim, uma freqüência semanal no processo de extração. As leituras de tensão para a verificação dos níveis de umidade do solo foram realizadas no momento em que se aplicava o vácuo nos extratores. Esta prática foi adotada em virtude da pequena variação 
na umidade do solo, ocasionada pela alta freqüência de irrigação e também porque o maior volume de solução do solo succionado pelo extrator ocorre logo após a aplicação do vácuo.

\subsection{Coleta e análise do material vegetal}

A coleta das folhas diagnósticas foi realizada na ocasião do primeiro fruto maduro. A folha coletada com pecíolo foi a primeira abaixo do primeiro cacho. As folhas foram previamente limpas, secadas em estufa até peso constante, pesadas e moídas.

A colheita dos frutos teve início 72 dias após o transplante e foi realizada até o quarto cacho. Os frutos foram pesados, secados em estufa até peso constante, pesados novamente e moídos.

Fez-se a análise química do material através de digestão nitro-perclórica e digestão sulfúrica com determinação de nitrogênio por Micro Kjeldal; fósforo por colorimetria; potássio por fotometria de chama; $\mathrm{Ca}, \mathrm{Mg}, \mathrm{Cu}, \mathrm{Fe}, \mathrm{Mn}$ e $\mathrm{Zn}$ por espectometria de absorção atômica; enxofre por turbidimetria; boro por colorimetria de azometina H, de acordo com Sarruge \& Haag (1974) e Bataglia et al. (1983).

\subsection{Análise estatística}

Utilizou-se o pacote estatístico SAS (Statistical Analysis System). Devido à dificuldade de adequação do sistema de irrigação, cada parcela foi subdividida em quatro partes, simulando as repetições, a fim de obter-se um testador para tratamento no teste $F$. Sabe-se porém que a variabilidade entre essas sub-parcelas, dentro de cada parcela, certamente foi menor do que a variabilidade entre as parcelas, se tivessem sido feitas repetições casualizadas. Esse fato fez necessária uma análise mais sensível que apontou diferenças significativas, mas que elas poderiam não acontecer. Dessa forma, submeteram-se os resultados à análise de variância, empregando-se o teste $\mathrm{F}$ com nível $\alpha$ de significância de 5\% e a comparação entre as médias foi feita 
através do teste de Tukey ao nivel de $1 \%$ de probabilidade. A transformação dos resultados foi aplicada todas as vezes que se fez necessária.

Tabela 5: Esquema da análise da variância e teste $\mathrm{F}$ para os tratamentos.

\begin{tabular}{lcccc}
\hline Causas da variação & G.L. & S.Q. & Q.M. & F \\
\hline Tratamentos & 17 & S.Q. Trat. & Q.M. Trat. & Q.M. Trat./Q.M. Res. \\
Resíduo & 54 & S. Q. Res. & Q.M. Res. & \\
\hline Total & 71 & S. Q. Total & & \\
\hline
\end{tabular}




\section{RESULTADOS E DISCUSSÃO}

\subsection{Monitoramento da solução do solo}

Os valores da concentração de potássio $\left(\mathrm{mmol}_{\mathrm{c}} \mathrm{L}^{-1}\right)$ e da condutividade

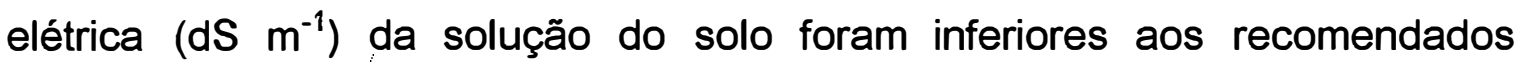
(Figuras 2 e 3). Nota-se que a solução apresentou as maiores concentrações na solução do solo, quando foi aplicada a maior dose de potássio. É recomenda como adequada a concentração de $2,2 \mathrm{mmol}_{\mathrm{c}} \mathrm{L}^{-1}$ de potássio na solução do solo para a cultura do tomateiro. Entretanto, foram encontrados concentrações na solução do solo variando entre 0,4 e 0,8 $\mathrm{mmol}_{\mathrm{c}} \mathrm{L}^{-1}$ para potássio.

A variação na concentração de potássio reflete diretamente nos valores da condutividade elétrica dos tratamentos com freqüência de aplicação a cada 3 dias, enquanto que o mesmo não foi observado nos tratamentos com freqüência de aplicação a cada 7 dias. A concentração de potássio e a condutividade elétrica tendem a ser maiores na freqüência de aplicação a cada 7 dias. Esse fato ocorre devido ao maior controle sobre a irrigação nos tratamentos com freqüência de aplicação a cada 7 dias, pois na freqüência de aplicação a cada 3 dias, o intervalo nem sempre é suficiente para que haja necessidade de irrigação, ou seja, as aplicações a cada 3 dias ocasionaram uma irrigação acima do necessário, provocando, possivelmente, a lixiviação do potássio. 

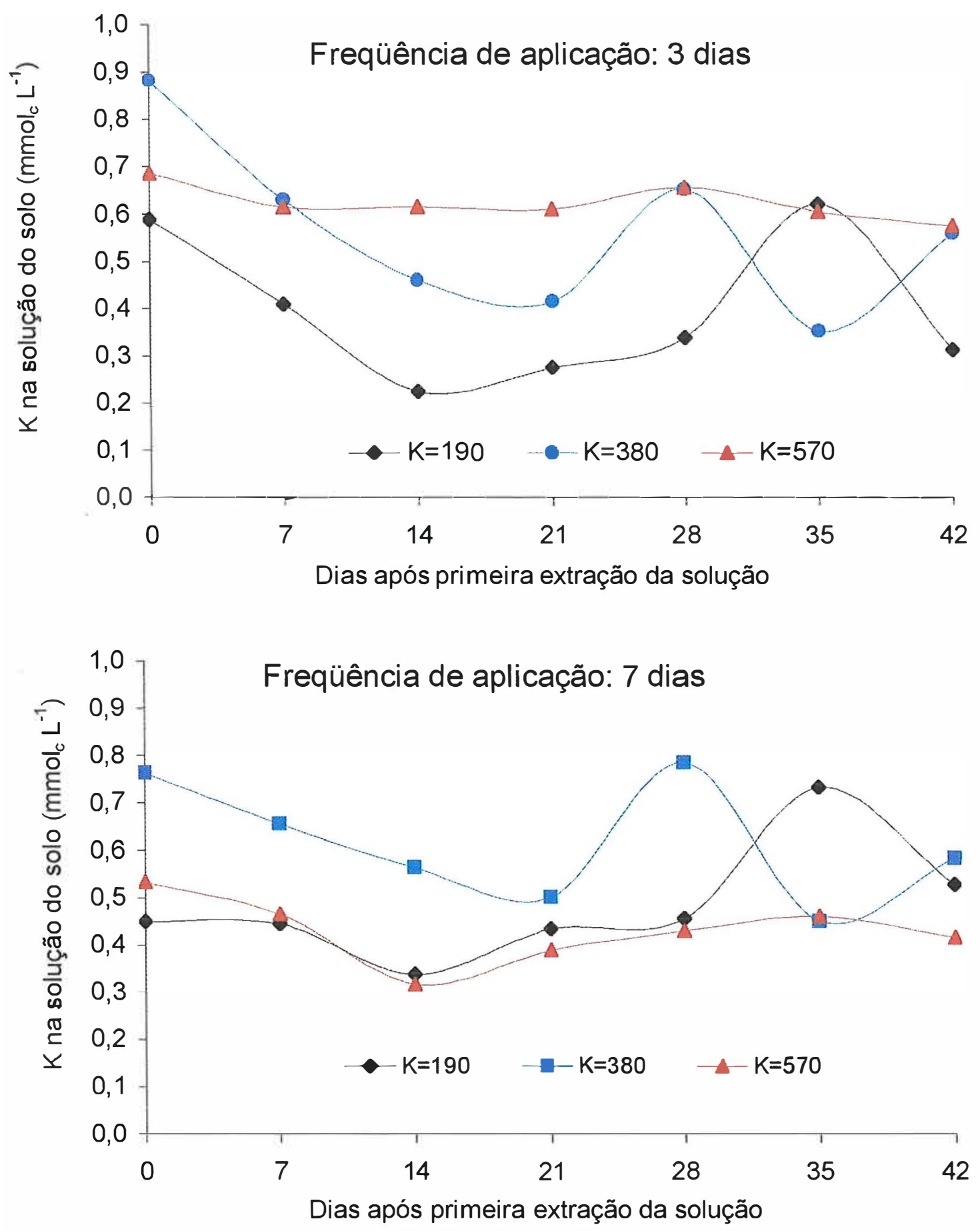

Figura 2: Variação na concentração de potássio $\left(\mathrm{mmol}_{\mathrm{c}} \mathrm{L}^{-1}\right)$ na solução do solo ao longo do ciclo (dias), para as freqüências de aplicação 3 e 7 dias. 

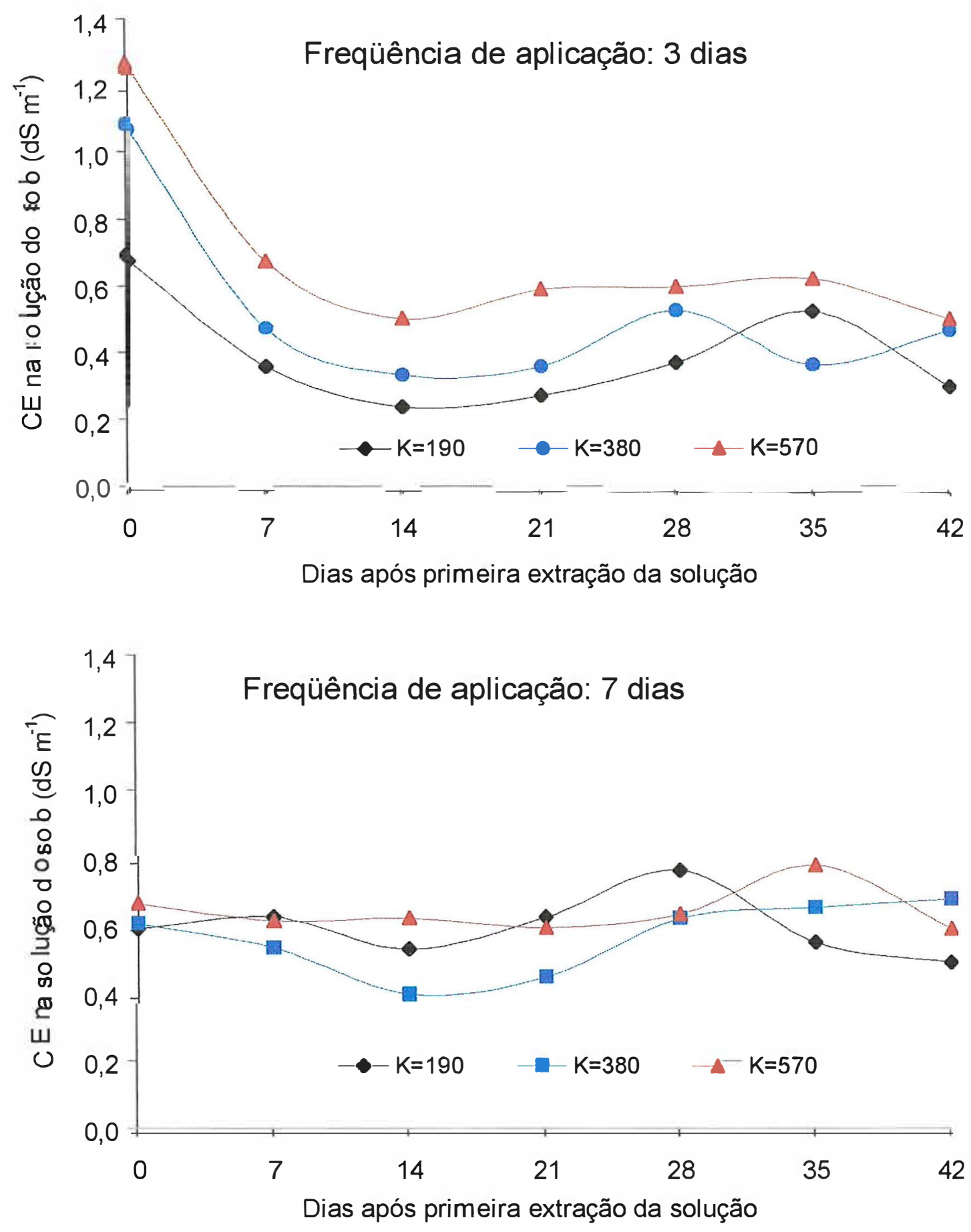

Figura 3: Variação na condutividade elétrica $\left(\mathrm{dS} \mathrm{m}^{-1}\right)$ na solução do solo ao longo do ciclo (dias), para as freqüências de aplicação 3 e 7 dias. 
Para o nitrato é recomendada a concentração de $5 \mathrm{mmol}_{\mathrm{c}} \mathrm{L}^{-1}$ de nitrato na solução do solo para a cultura do tomateiro. A concentração de nitrato ( $m \mathrm{~mol}_{\mathrm{c}} \mathrm{L}^{-1}$ ) e a condutividade elétrica $\left(\mathrm{dS} \mathrm{m}^{-1}\right.$ ) da solução do solo foram inferiores aos valores adequados nos tratamentos com as doses $155 \mathrm{~kg} \mathrm{ha}^{-1}$ aplicadas a cada 3 dias e com as doses 155 e $310 \mathrm{~kg} \mathrm{ha}^{-1}$ aplicadas a cada 7 dias (Figuras 4 e 5 ).

A variação na concentração de nitrato refletiu diretamente sobre os valores da condutividade elétrica nas duas freqüências de aplicação. A concentração de nitrato e a condutividade elétrica tenderam a ser maiores na freqüência de aplicação a cada 3 dias. Mesmo nas aplicações mais freqüêntes, que podem ocasionar a lixiviação do nitrato, a nitrificação pode ter ocorrido pois, em condição de solo ácido ( $\mathrm{pH} 5,0$ ), esse processo é realizado por fungos heterotróficos (Aspergillus niger e Aspergillus wentii). Nos tratamentos com freqüência de aplicação a cada 7 dias, esse processo pode ter sido limitado pela sensibilidade desses fungos a salinidade. 

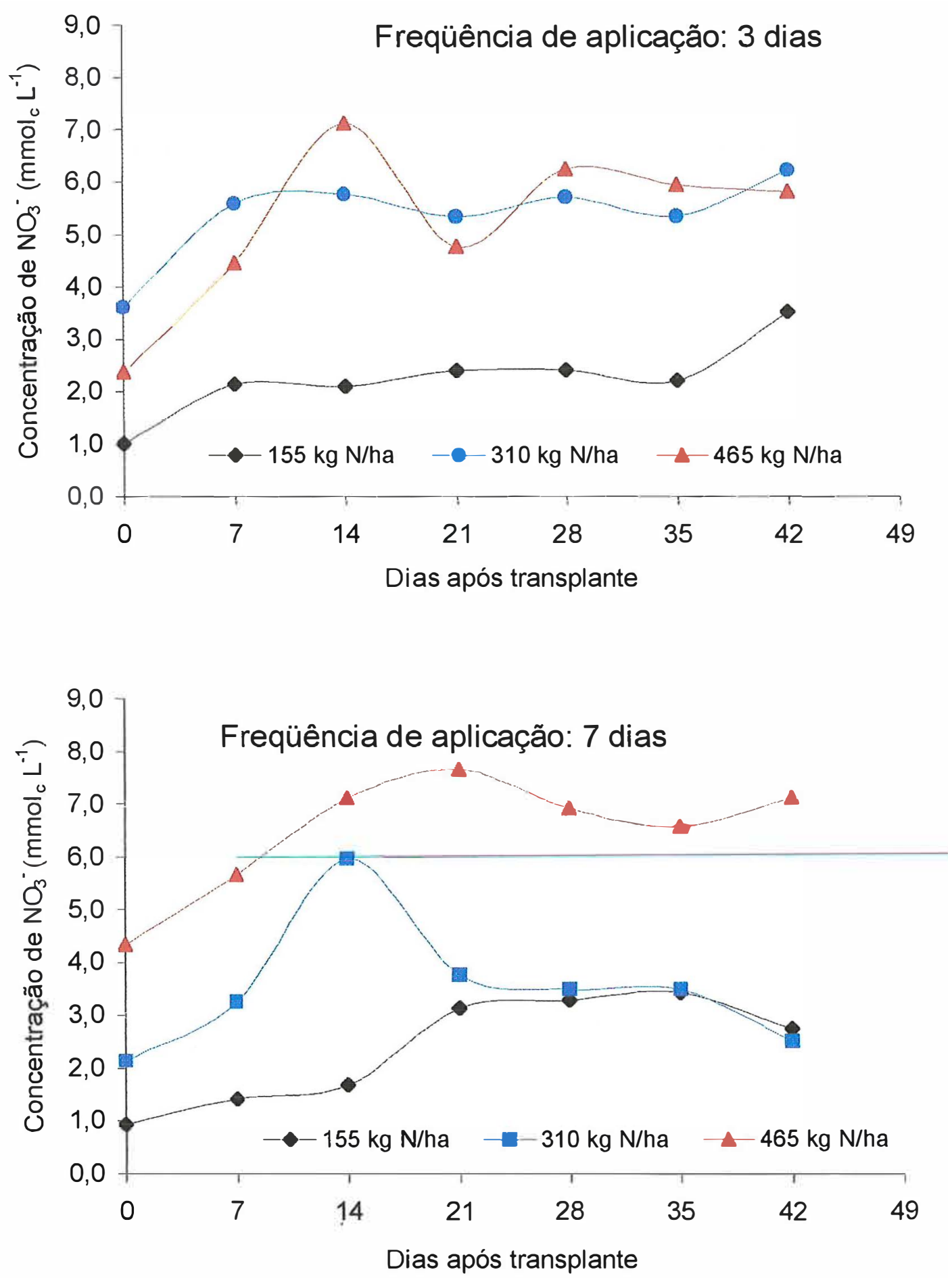

Figura 4: Variação na concentração de nitrato $\left(\mathrm{mmol}_{\mathrm{C}} \mathrm{L}^{-1}\right)$ na solução do solo ao longo do ciclo (dias), para as freqüências de aplicação 3 e 7 dias. 

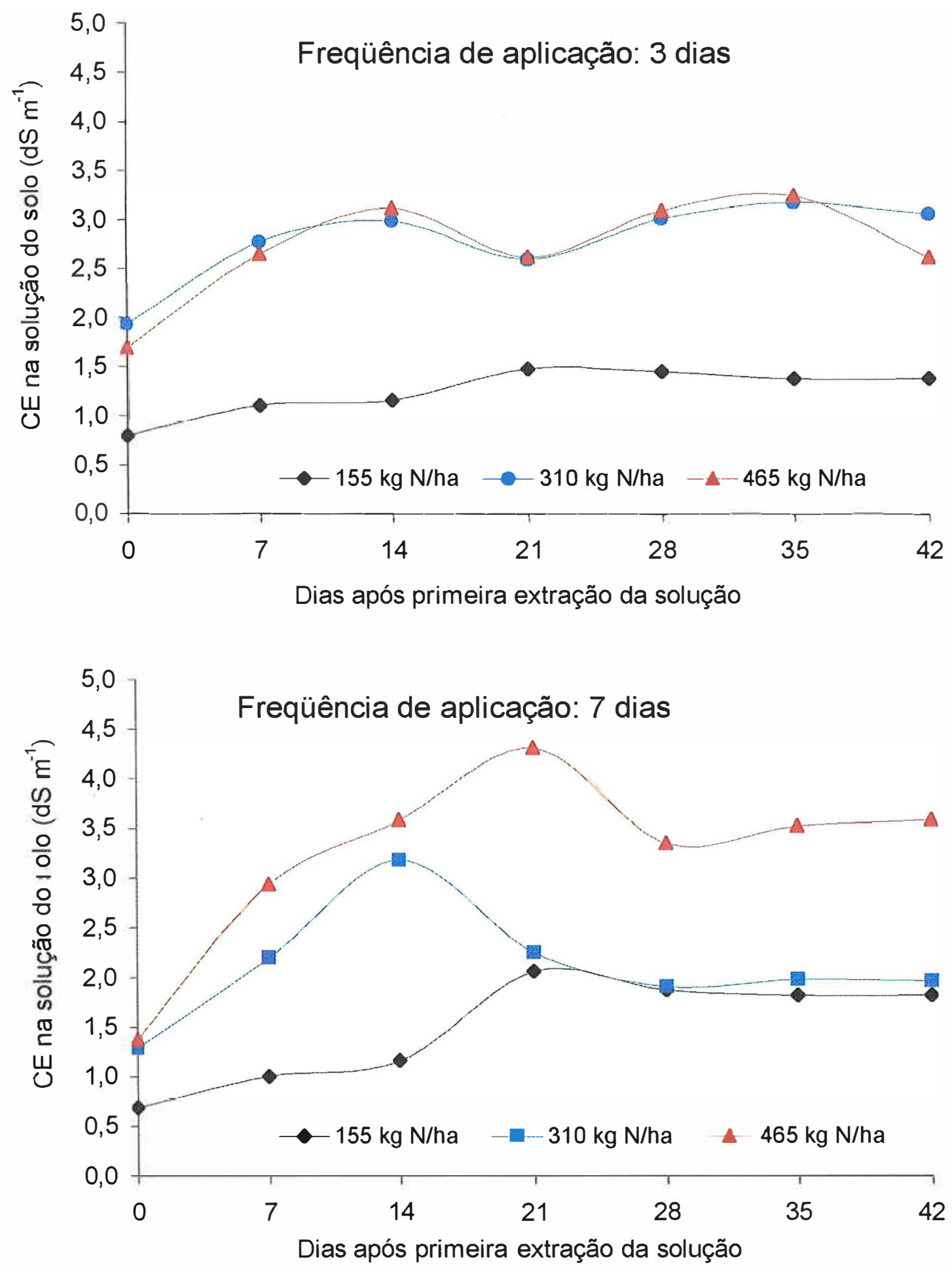

Figura 5: Variação na condutividade elétrica ( $d S \mathrm{~m}^{-1}$ ) na solução do solo ao longo do ciclo (dias), para as freqüências de aplicação 3 e 7 dias. 


\subsection{Efeitos na produção}

\subsubsection{Número de frutos}

A comparação das médias do número de frutos de duas plantas, apresentadas na Tabela 6 mostra que para as doses de potássio, apenas os tratamentos 17 e 18 diferiram entre si. Para as doses de nitrogênio houve diferença entre os tratamentos 15 e 18. Entre as freqüências, ocorreu diferença entre os tratamentos 8 e 17 . Esses resultados foram menores que os encontrados por

Tabela 6: Comparação das médias do número de frutos de duas plantas.

\begin{tabular}{|c|c|c|c|c|c|c|c|c|}
\hline \multirow{2}{*}{$\begin{array}{c}\text { Freqüências de } \\
\text { aplicação }\end{array}$} & \multirow{2}{*}{$\begin{array}{c}\text { Doses de N } \\
\left(\mathrm{kg} \mathrm{ha}^{-1}\right)\end{array}$} & \multicolumn{7}{|c|}{ Doses de K $\left(\mathrm{kg} \mathrm{ha}^{-1}\right)$} \\
\hline & & \multicolumn{2}{|c|}{190} & \multicolumn{3}{|c|}{380} & \multicolumn{2}{|l|}{570} \\
\hline & 155 & 26,26 & aA T1 & 22,75 & $\mathrm{aA}$ & $\mathrm{T} 2$ & 21,00 aA & T3 \\
\hline \multirow[t]{3}{*}{3 dias } & 310 & 27,75 & aA T4 & 26,25 & $\mathrm{aA}$ & T5 & 27,00 aA & T6 \\
\hline & 465 & 22,75 & aA T7 & *20,75 & $\mathrm{aA}$ & T8 & 25,25 aA & T9 \\
\hline & 155 & 26,75 & aA T10 & 24,75 & $\mathrm{aA}$ & T11 & $27,50 \mathrm{aAB}$ & T12 \\
\hline \multirow[t]{2}{*}{7 dias } & 310 & 31,50 & aA T13 & 25,00 & $\mathrm{aA}$ & T14 & 31,75 & T15 \\
\hline & 465 & 24,50 & abA T16 & *32,25 & $\mathrm{aA}$ & T17 & 21,75 bB & T18 \\
\hline
\end{tabular}

Médias seguidas pela mesma letra, minúscula na linha e maiúscula na coluna, nāo diferem entre si pelo teste de Tukey a $1 \%$.

Asteriscos indicam diferenças entre as freqüências de aplicação pelo teste de Tukey a $1 \%$.

As deficiências minerais afetam diretamente desenvolvimento das flores e, consequentemente, a produção de frutos. O nitrogênio e o potássio afetam diretamente a produção de frutos, pois, quando a absorção é insuficiente, provocam o retardamento na abertura floral e aumentam a incidência de abortos florais (Atherton \& Harris, 1986).

A superfície de resposta do número de frutos em função das doses de nitrogênio e potássio aplicadas via fertirrigação a cada 3 dias (Equação 3), é representada na Figura 6. A superfície de resposta apresentou ponto de sela em 25,79 frutos. 
$N F=26,666667+0,073656 D N-0,060307 D K-0,000161 D N^{2}+0,000065789$

$D N D K+0,000048476 D K^{2}$

$\mathrm{R}^{2}=38,84(\%)$ e Prob $>\mathrm{F} 0,0086$

onde:

NF - Número de frutos coletados em duas plantas.

$\mathrm{DN}$ - Doses de nitrogênio, em $\mathrm{kg} \mathrm{ha}^{-1}$, tal que $155 \leq \mathrm{DN} \geq 465$.

DK - Doses de potássio, em $\mathrm{kg} \mathrm{ha}^{-1}$, tal que $190 \leq \mathrm{DK} \geq 570$.

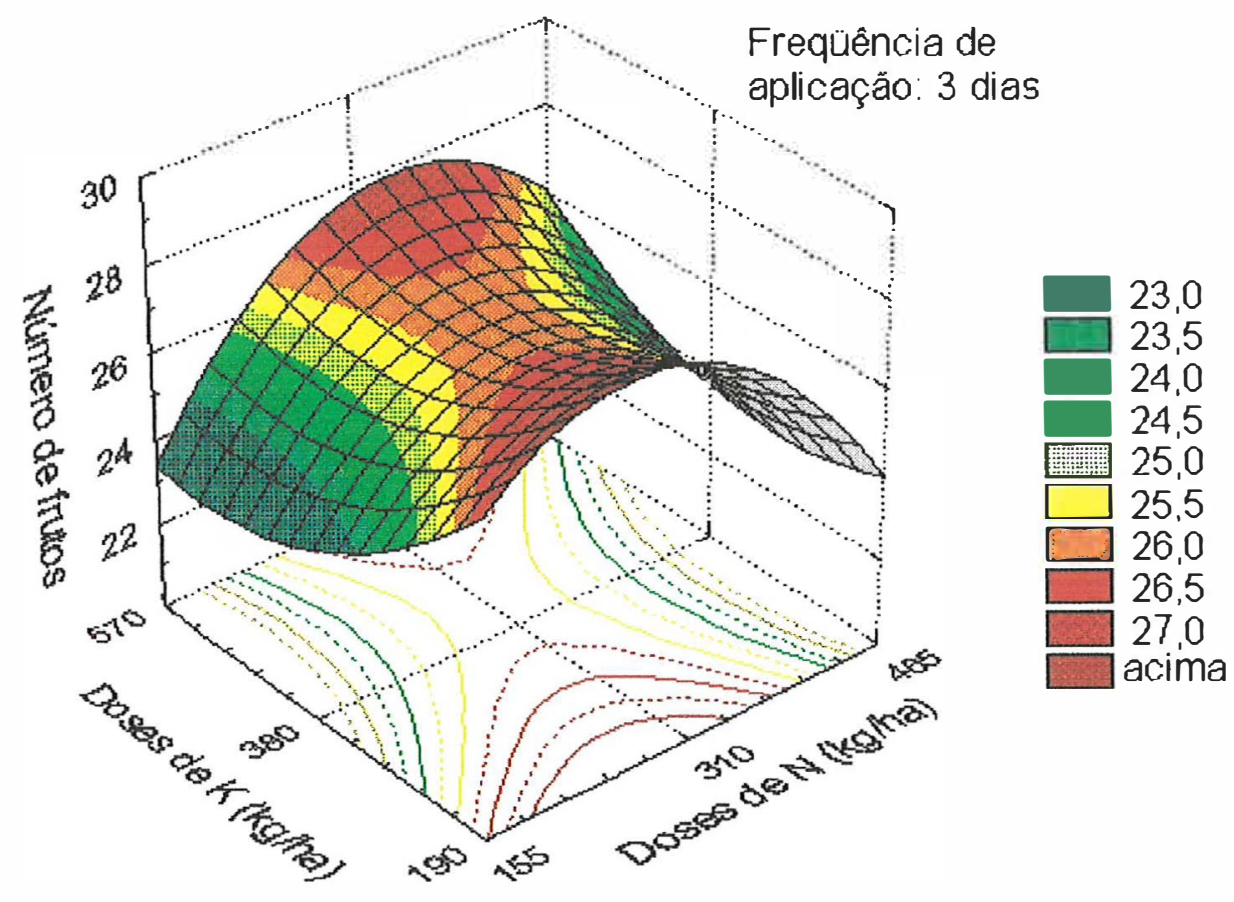

Figura 6: Superfície de resposta do número de frutos em função das doses de nitrogênio e potássio $\left(\mathrm{kg} \mathrm{ha}^{-1}\right)$ aplicadas a cada 3 dias.

\subsubsection{Massa de material fresco dos frutos}

A comparação das médias da massa de material fresco dos frutos $(\mathrm{kg})$ é apresentada na Tabela 7. Para as dose de potássio observou-se diferenças entre os tratamentos 17 e 18. As doses de nitrogênio apresentaram diferença entre os tratamentos 5 e 8 . As freqüências de aplicação apresentaram diferença entre os tratamentos 8 e 17 . 
Tabela 7: Comparação entre as médias da massa de material fresco $(\mathrm{kg})$ dos frutos de duas plantas.

\begin{tabular}{|c|c|c|c|c|c|}
\hline \multirow{3}{*}{$\begin{array}{l}\text { Freqüências de } \\
\text { aplicação }\end{array}$} & \multirow{3}{*}{$\begin{array}{c}\begin{array}{c}\text { Doses de } N \\
\left(\mathrm{~kg} \mathrm{ha}^{-1}\right)\end{array} \\
155\end{array}$} & \multicolumn{4}{|c|}{ Doses de $\mathrm{K}\left(\mathrm{kg} \mathrm{ha}^{-1}\right)$} \\
\hline & & 190 & 380 & \multicolumn{2}{|l|}{570} \\
\hline & & 1,72 aA $\mathrm{T1}$ & 1,59 aAB T2 & 1,63 aA & T3 \\
\hline \multirow[t]{3}{*}{3 dias } & 310 & 1,87 aA T4 & 1,86 aA T5 & 1,89 & T6 \\
\hline & 465 & 1,79 aA T7 & aB T8 & 1,51 aA & T9 \\
\hline & 155 & 1,62 aA $\mathrm{T} 10$ & 1,98 aA T11 & 1,67 aA & $\mathrm{T} 12$ \\
\hline \multirow[t]{2}{*}{7 dias } & 310 & 2,10 aA T13 & aA T14 & 1,83 aA & T15 \\
\hline & 465 & 1,50 abA T16 & *1,99 aA T17 & 1,13 bA & $\mathrm{T} 18$ \\
\hline
\end{tabular}

Os tratamentos que apresentaram diferenças produziram em torno de $1,90 \mathrm{~kg}$ de massa de material fresco de frutos por duas plantas. Isso representa uma produção aproximada de $7918 \mathrm{~kg} \mathrm{ha}^{-1}$ para uma população de 8.333 plantas ha- ${ }^{-1}$ (espaçamento de 0,8 $\mathrm{m} \times 1,5 \mathrm{~m}$ ), e de $11.870 \mathrm{~kg} \mathrm{ha}^{-1}$ para uma população de 12.500 plantas ha-1 (espaçamento de $1,0 \mathrm{~m} \times 0,8 \mathrm{~m}$ ). Esse resultado é muito baixo, quando comparado ao obtido por Fontes et al. (2000), que produziu $86.400 \mathrm{~kg} \mathrm{ha}^{-1}$ com o cultivar Santa Clara e Sampaio et al. (1999), que obteve uma produção de $70.000 \mathrm{~kg} \mathrm{ha}^{-1}$, também com o cultivar Santa Clara. Deve-se considerar que, a produção de massa de material fresco é referente apenas à colheita feita até o quarto cacho, ou seja, se a colheita tivesse sido realizada até o sexto cacho, a produção seria maior, porém, mesmo assim, ainda seria considerada baixa.

O processo de desenvolvimento do fruto é dividido em três fases. A primeira fase ocorre nas primeiras duas a três semanas, sendo um processo lento, no qual o ganho de peso do fruto é inferior a $10 \%$ do peso final. $O$ transporte de assimilados das folhas para os ovários aumenta consideravelmente dentro dos dois dias após a polinização e a razão de acúmulo diário do material seco aumenta de 30 a $150 \mathrm{mg}$ até o final das primeiras duas semanas. A segunda fase é o período de desenvolvimento 
rápido, indo da terceira à quinta semana. $\mathrm{Na}$ metade do período de desenvolvimento a razão de acúmulo diário atinge o máximo, sendo $7 \mathrm{~g} \mathrm{em}$ peso de material fresco ou 0,37 g em peso de material seco ou 2,2 $\mathrm{mL}$ em volume. A terceira fase dura aproximadamente duas semanas, quando o fruto apresenta um baixo ganho de peso, porém onde as trocas metabólicas são intensas (Ho \& Hewitt, 1986). Assim, considerando-se as fases de desenvolvimento dos frutos, é possível afirmar que um dos fatores que afeta a produção da massa de material fresco é a disponibilidade de nutrientes, que nas condições do presente estudo apresentou-se insuficiente.

A superfície de resposta da massa de material fresco dos frutos de duas plantas (valores transformados), em função das doses de nitrogênio e potássio aplicadas via fertirrigação a cada 3 dias (Equação 4), é representada na Figura 7. A superfície de resposta apresentou um ponto de sela em 7,42.

$\operatorname{Ln}(\mathrm{MfF})=7,327645+0,004959 D N-0,003027 D K-0,000007994 D N^{2}-$ $0,0000001171 D N D K+0,000004212 D K^{2}$

$R^{2}=35,06(\%)$ e Prob $>F 0,0186$

onde:

MfF - Massa de material fresco dos frutos em duas plantas $(\mathrm{kg})$.

$\mathrm{DN}$ - Doses de nitrogênio, em kg ha-1 ${ }^{-1}$ tal que $155 \leq \mathrm{DN} \geq 465$.

DK - Doses de potássio, em kg ha-1, tal que $190 \leq \mathrm{DK} \geq 570$. 


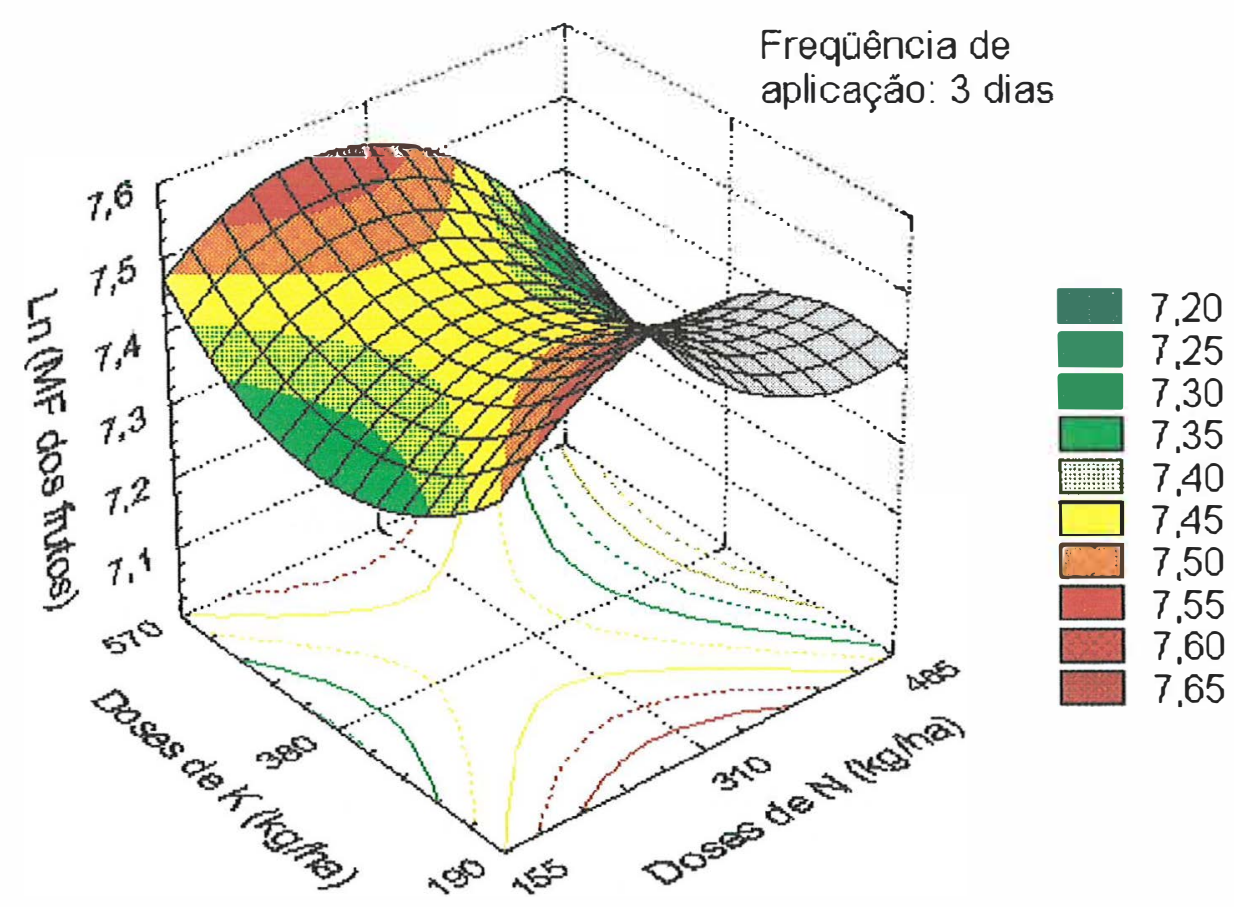

Figura 7: Superfície de resposta da massa de material fresco de frutos em função das doses de nitrogênio e potássio $\left(\mathrm{kg} \mathrm{ha}^{-1}\right)$ aplicadas a cada 3 dias.

\subsection{Efeitos nas concentrações de nutrientes}

\subsubsection{Concentrações de nutrientes na folha diagnóstica}

\subsubsection{Concentrações de nitrogênio}

A comparação das médias das concentrações de nitrogênio $\left(\mathrm{g} \mathrm{kg}^{-1}\right)$ nas folhas diagnósticas encontra-se na Tabela 8 . Não observou-se diferenças entre os tratamentos quando consideradas as doses de potássio aplicadas. Dentro das doses de nitrogênio foi possível observar diferença entre os tratamentos $2 \mathrm{e}$ 8. Houve diferenças entre os tratamentos 2 e 11,3 e 12,5 e 14 , e 9 e 18 quando comparadas as freqüências de aplicação. 
Tabela 8: Comparação entre as médias das concentrações de nitrogênio $\left(\mathrm{g} \mathrm{kg}^{-1}\right)$ nas folhas diagnósticas.

\begin{tabular}{|c|c|c|c|c|c|c|c|}
\hline \multirow{2}{*}{$\begin{array}{c}\text { Freqüências de } \\
\text { aplicação }\end{array}$} & \multirow{3}{*}{$\begin{array}{c}\begin{array}{c}\text { Doses de N } \\
\left(\mathrm{kg} \mathrm{ha}^{-1}\right)\end{array} \\
155\end{array}$} & \multicolumn{6}{|c|}{ Doses de K $\left(\mathrm{kg} \mathrm{ha}^{-1}\right)$} \\
\hline & & \multicolumn{3}{|c|}{190} & 380 & \multicolumn{2}{|l|}{570} \\
\hline & & 29,77 & $\mathrm{aA}$ & $\mathrm{T} 1$ & ${ }^{* 23,99}$ aA T2 & *32,68 aA & T3 \\
\hline \multirow[t]{3}{*}{3 dias } & 310 & 37,71 & $\mathrm{aA}$ & $\mathrm{T} 4$ & $\star 30,70$ aAB T5 & 33,92 aA & T6 \\
\hline & 465 & 30,12 & $\mathrm{aA}$ & $\mathrm{T7}$ & 35,56 aB T8 & $* 28,79$ aA & T9 \\
\hline & 155 & 35,79 & $\mathrm{aA}$ & T10 & $* 35,40$ aA T11 & $* 43,51$ aA & T12 \\
\hline \multirow[t]{2}{*}{7 dias } & 310 & 39,78 & $\mathrm{aA}$ & $\mathrm{T} 13$ & $* 43,88$ aA T14 & 39,36 aA & T15 \\
\hline & 465 & 40,06 & $\mathrm{aA}$ & T16 & 37,96 aA T17 & $* 41,17$ aA & T18 \\
\hline
\end{tabular}

Trani \& Raij (1996) recomendam como concentrações adequadas de nitrogênio em folhas diagnósticas valores entre 40 e $60 \mathrm{~g} \mathrm{~kg}^{-1}$. Mesmo não apresentando diferenças signficativas, os tratamentos com concentrações adequadas foram: 12, 14, 16 e 18. Fernandes et al. (1975) obtiveram resultado semelhante em experimento com tomateiros do Grupo Santa Cruz. Gargantini e Blanco (1963), encontraram concentrações de nitrogênio nas folhas em torno de $55 \mathrm{~g} \mathrm{~kg}^{-1}$, em estudo realizado com para a determinação da marcha de absorção do tomateiro, do Grupo Santa Cruz.

Essa condição pode ter sido ocasionada pelo baixo nível de matéria orgânica no solo, porém a baixa concentração de nitrogênio na solução do solo foi a mais provável causa.

\subsubsection{Concentrações de fósforo}

$\mathrm{Na}$ Tabela 9 apresentam-se as diferenças entre as médias das concentrações de fósforo $\left(\mathrm{g} \mathrm{kg}^{-1}\right)$ das folhas diagnósticas. Para as doses de potássio, os tratamentos 1,2 e 3 diferiram entre si; o tratamento 4 diferiu do tratamento 5; os tratamentos 6,7 e 8 diferiram entre si; o tratamento 11 diferiu dos tratamentos 10 e 12; o tratamento 13 diferiu do tratamento 14 e o tratamento 17 diferiu dos tratamentos 16 e 18. Para as comparações feitas em 
função das doses de nitrogênio, observou-se que os tratamentos 2,5 e 8 diferiram entre si; os tratamentos 3, 6 e 9 diferiram entre si; os tratamentos 11 , 14 e 17 diferem entre si e o tratamento 15 diferiu do tratamento 18. As freqüências de aplicação não apresentaram diferenças somente entre as médias dos tratamentos 3 e 12 .

Tabela 9: Comparação entre as médias das concentrações de fósforo $\left(\mathrm{g} \mathrm{kg}^{-1}\right)$ nas folhas diagnósticas.

\begin{tabular}{|c|c|c|c|c|c|c|c|}
\hline \multirow{3}{*}{$\begin{array}{l}\text { Freqüências de } \\
\text { aplicaçăo }\end{array}$} & \multirow{3}{*}{$\begin{array}{c}\begin{array}{c}\text { Doses de N } \\
\left(\mathrm{kg} \mathrm{ha}^{-1}\right)\end{array} \\
155\end{array}$} & \multicolumn{6}{|c|}{ Doses de K $\left(\mathrm{kg} \mathrm{ha}^{-1}\right)$} \\
\hline & & \multicolumn{3}{|c|}{190} & \multicolumn{2}{|c|}{380} & 570 \\
\hline & & *2,36 & $\mathrm{aA}$ & T1 & $* 1,98$ & bA T2 & 2,86 cA $\quad$ T3 \\
\hline \multirow[t]{3}{*}{3 dias } & 310 & $\star 2,18$ & $\mathrm{aA}$ & T4 & *3,19 & bB T5 & ${ }^{\star} 2,37$ abB T6 \\
\hline & 465 & *2,23 & $\mathrm{aA}$ & T7 & *2,45 & bC T8 & *1,95 cC T9 \\
\hline & 155 & $\star 2,68$ & $\mathrm{aA}$ & $\mathrm{T} 10$ & $\star 2,25$ & bA T11 & 2,82 aAB T12 \\
\hline \multirow[t]{2}{*}{7 dias } & 310 & $\star 2,54$ & $\mathrm{aA}$ & $\mathrm{T} 13$ & *2,93 & bB T14 & *2,74 abA T15 \\
\hline & 465 & *2,77 & $\mathrm{aA}$ & T16 & *3,48 & bC T17 & $\star 3,00$ aB $\quad \mathrm{T} 18$ \\
\hline
\end{tabular}

As concentrações adequados de fósforo nas folhas diagnósticas devem variar entre 4 e $8 \mathrm{~g} \mathrm{~kg}^{-1}$ (Trani \& Raij, 1996). Os resultados indicam que todos os tratamentos apresentam concentrações abaixo do adequado para a cultura do tomateiro estaqueado, mesmo ocorrendo algumas diferenças significativas. A baixa concentração de fósforo é ocasionada, principalmente, pela baixa concentração do nutriente na solução do solo e pela acidez do solo. Fernandes et al. (1975) obteve valores próximos a $3 \mathrm{~g} \mathrm{~kg}^{-1}$, semelhantes aos apresentados na Tabela 9. Porém, Gargantini \& Blanco (1963) apresentaram a quantidade de fósforo como sendo aproximadamente $7,5 \mathrm{~g} \mathrm{~kg}^{-1}$.

A superfície de resposta das concentrações de fósforo nas folhas diagnósticas em função das doses de nitrogênio e potássio aplicadas via fertirrigação a cada 7 dias (Equação 5), é representada na Figura 8. A superfície de resposta apresentou um ponto de sela em é 2,67 
Concentração de $P=2,0875-0,001086 D N+0,002950 D K+0,000003954 D N^{2}$ $+0,000000679 D N D K-0,000003497 D K^{2}$

$\mathrm{R}^{2}=50,54(\%)$ e Prob $>\mathrm{F} 0,0005$

onde:

Concentração de P- Concentração de fósforo nas folhas diagnósticas em $\mathrm{g} \mathrm{kg}^{-1}$. $\mathrm{DN}$ - Doses de nitrogênio, em $\mathrm{kg} \mathrm{ha}^{-1}$, tal que $155 \leq \mathrm{DN} \geq 465$.

DK - Doses de potássio, em kg ha-1, tal que $190 \leq \mathrm{DK} \geq 570$.

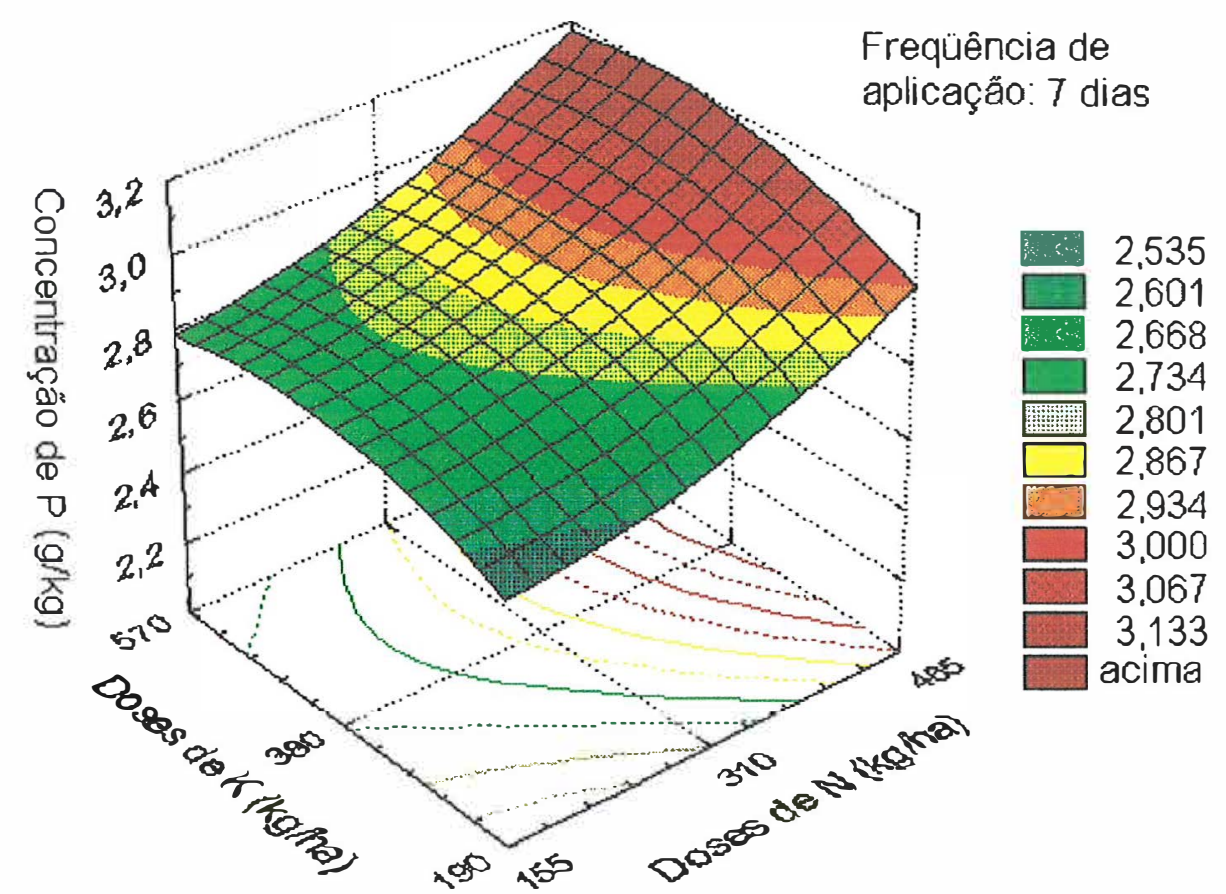

Figura 8: Superfície de resposta das concentrações de fósforo $\left(\mathrm{g} \mathrm{kg}^{-1}\right)$ nas folhas diagnósticas em função das doses de nitrogênio e potássio $\left(\mathrm{kg} \mathrm{ha}^{-1}\right)$ aplicadas a cada 7 dias.

\subsubsection{Concentrações de potássio}

As médias das concentrações de potássio $\left(\mathrm{g} \mathrm{kg}^{-1}\right)$ nas folhas diagnósticas são apresentadas na Tabela 10. Para as doses de potássio os tratamentos 7 e 9 diferiram entre si, o tratamento 12 diferiu dos tratamentos 10 e 11, o tratamento 14 diferiu dos tratamentos 13 e 15 e o tratamento 18 diferiu dos tratamentos 16 e 17 . Considerando-se as doses de nitrogênio, o tratamento 
7 diferiu dos tratamentos 1 e 4, o tratamento 9 diferiu dos tratamentos 3 e 6, o tratamento 14 diferiu dos tratamentos 11 e 17 e o tratamento 15 diferiu dos tratamentos 12 e 18. Para as freqüências de irrigação, o tratamento 4 diferiu do tratamento 13 , o tratamento 7 diferiu do tratamento 16 e o tratamento 9 diferiu do tratamento 18.

Tabela 10: Comparação entre as médias das concentrações de potássio $\left(\mathrm{g} \mathrm{kg}^{-1}\right)$ nas folhas diagnósticas.

\begin{tabular}{|c|c|c|c|c|c|c|c|c|c|c|}
\hline \multirow{2}{*}{$\begin{array}{c}\text { Freqüências de } \\
\text { aplicação }\end{array}$} & \multirow{2}{*}{$\begin{array}{c}\text { Doses de N } \\
\left(\mathrm{kg} \mathrm{ha}^{-1}\right)\end{array}$} & \multicolumn{9}{|c|}{ Doses de K $\left(\mathrm{kg} \mathrm{ha}^{-1}\right)$} \\
\hline & & \multicolumn{3}{|c|}{190} & \multicolumn{3}{|c|}{380} & \multicolumn{3}{|c|}{570} \\
\hline & 155 & 30,98 & $a A$ & T1 & 29,64 & $a A$ & T2 & 32,13 & $\mathrm{aA}$ & T3 \\
\hline \multirow[t]{3}{*}{3 dias } & 310 & *30,60 & $a A$ & T4 & 30,60 & $a A$ & T5 & 28,31 & $\mathrm{aB}$ & T6 \\
\hline & 465 & $\star 25,82$ & $\mathrm{aB}$ & $\mathrm{T7}$ & 28,50 & $a b A$ & T8 & *29,07 & bAB & T9 \\
\hline & 155 & 29,26 & $\mathrm{aA}$ & T10 & 27,16 & $a A$ & T11 & 35,76 & bA & T12 \\
\hline \multirow[t]{2}{*}{7 dias } & 310 & *27,35 & $a A$ & T13 & 34,62 & bB & T14 & 29,45 & $\mathrm{aB}$ & T15 \\
\hline & 465 & *29,26 & $\mathrm{aA}$ & T16 & 28,30 & $\mathrm{aA}$ & T17 & *33,28 & bA & T18 \\
\hline
\end{tabular}

Médiasseguidas pela mesma letra, minúscula na linha e maiúscula na coluna, nāo diferem entre si pelo teste de Tukey a $1 \%$.

Asteriscos indicam diferenças entre as freqüências de aplicação pelo teste de Tukey a $1 \%$.

O teor adequado de potássio nas folhas diagnósticas deve estar entre 30 e $50 \mathrm{~g} \mathrm{~kg}^{-1}$ (Trani \& Raij, 1996). Apesar de existirem diferenças significativas, alguns tratamentos apresentaram concentrações dentro dos limites adequados, independente da relação $\mathrm{K} / \mathrm{N}$. Os fatores que mais contribuem para a baixa concentração de potássio são a lixiviação e a concentração de amônio no meio. $O$ resultado obtido por Fernandes et al.(1975) é de $35 \mathrm{~g} \mathrm{~kg}^{-1}$ de potássio nas folhas. Muito diferente foi o resultado obtido por Gargantini \& Blanco (1963), que foi de $57 \mathrm{mg} \mathrm{kg}^{-1}$.

As superfícies de resposta das concentrações de potássio nas folhas diagnósticas (valores transformados) em função das doses de nitrogênio e potássio aplicadas via fertirrigação a cada 3 dias (Equação 6), e a cada 7 dias (Equação 7), são representadas nas Figuras 9 e 10. A superfície de resposta dos tratamentos com freqüência de aplicação a cada 3 dias apresentou um 
ponto de mínimo em 0,03 , e a superfície de resposta dos tratamentos com freqüência de aplicação a cada 7 dias apresentou um ponto de sela em 0,03.

$1 /($ Concentração de $K)=0,032194+0,000001554 D N-0,000001809 D K+$ $0,000000031298 D N^{2}-0,00000002487 D N D K+0,00000000888 D K^{2}$ $\mathrm{R}^{2}=42,75(\%)$ e Prob $>\mathrm{F} 0,003$

$1 /($ Concentração de $K)=0,036332-0,000004953 D N+0,000001130 D K$ $0,000000002108 D N^{2}+0,00000001820 D N D K+0,00000002386 D K^{2}$ $\mathrm{R}^{2}=33,34(\%)$ e Prob $>\mathrm{F} 0,025$

onde:

Concentração de $\mathrm{K}$ - Concentração de potássio nas folhas diagnósticas em $\mathrm{g}$ $\mathrm{kg}^{-1}$.

$\mathrm{DN}$ - Doses de nitrogênio em $\mathrm{kg} \mathrm{ha}^{-1}$, tal que $155 \leq \mathrm{DN} \geq 465$.

DK - Doses de potássio em $\mathrm{kg} \mathrm{ha}^{-1}$, tal que $190 \leq \mathrm{DK} \geq 570$. 


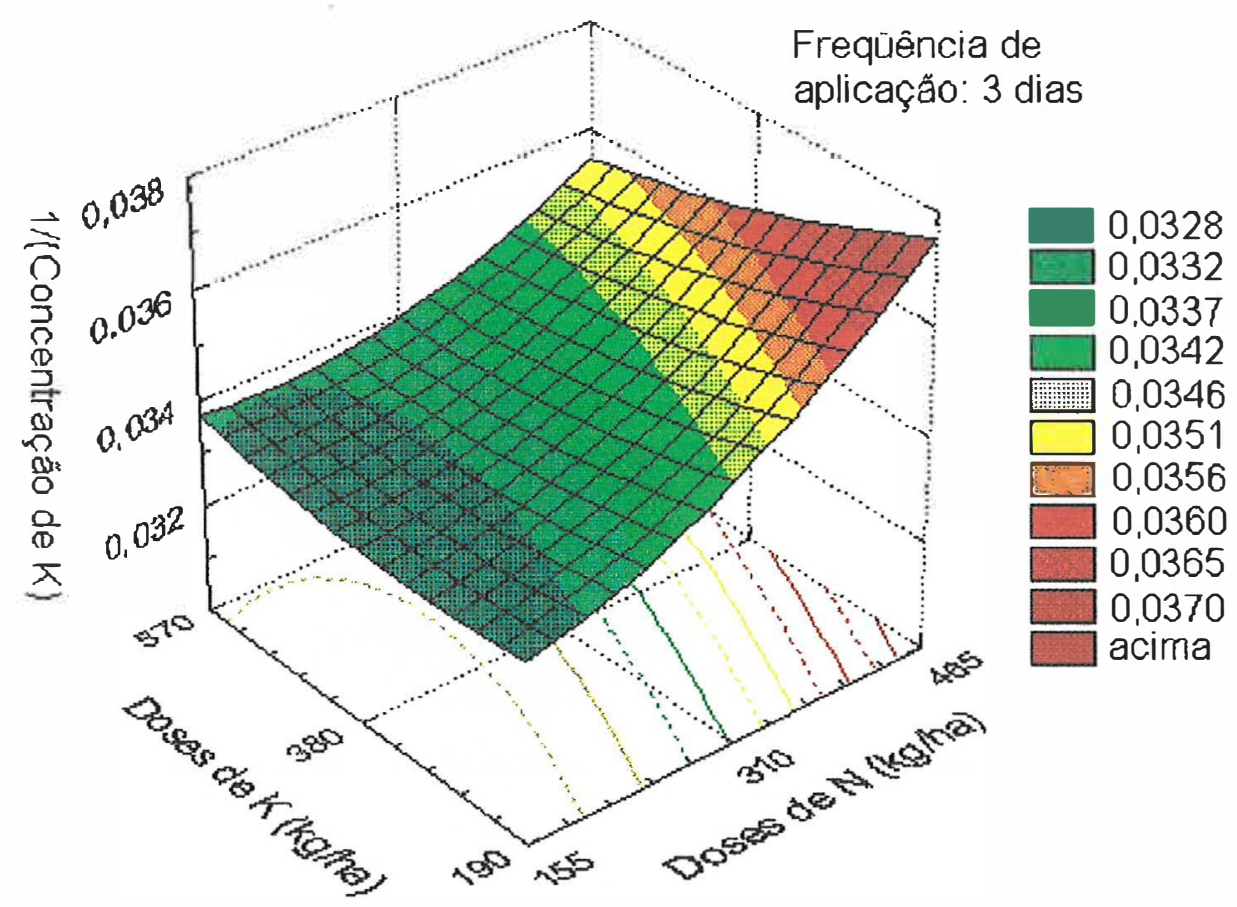

Figura 9: Superfície de resposta das concentrações de potássio nas folhas diagnósticas em função das doses de nitrogênio e potássio $\left(\mathrm{kg} \mathrm{ha}^{-1}\right)$ aplicadas a cada 3 dias.

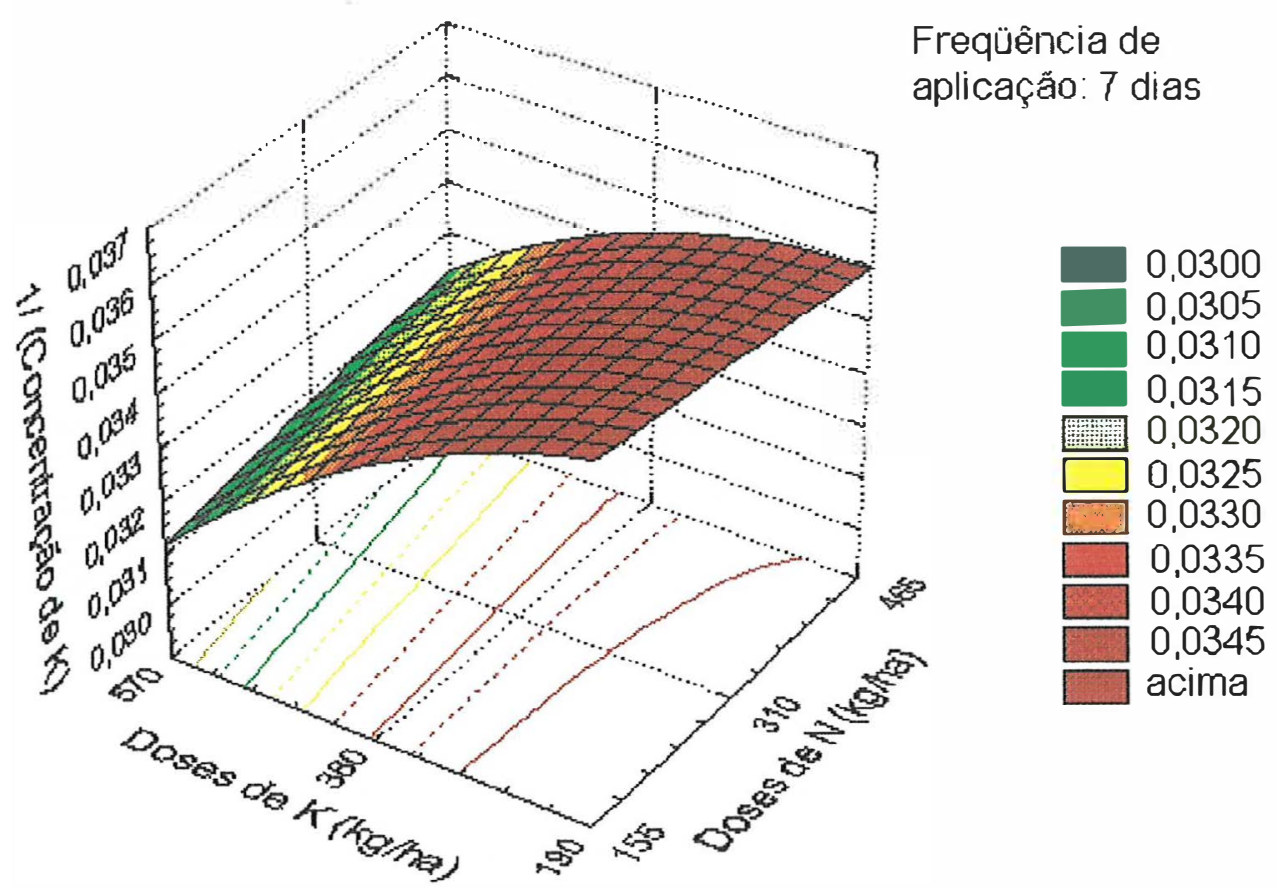

Figura 10: Superfície de resposta das concentrações de potássio nas folhas diagnósticas em função das doses de nitrogênio e potássio $\left(\mathrm{kg} \mathrm{ha}^{-1}\right)$ aplicadas a cada 7 dias. 


\subsubsection{Concentrações de cálcio}

Para as doses de potássio, pode-se observar na Tabela 11, independente da freqüência de aplicação, que o tratamento com a dose de 310 $\mathrm{kg} \mathrm{ha}^{-1}$ de nitrogênio associada à dose $190 \mathrm{~kg} \mathrm{ha}^{-1}$ de potássio diferiu do tratamento com a dose de $310 \mathrm{~kg} \mathrm{ha}^{-1}$ de nitrogênio associada à dose de 380 $\mathrm{kg} \mathrm{ha}^{-1}$ de potássio. $O$ tratamento com a dose $465 \mathrm{~kg} \mathrm{ha}^{-1}$ de nitrogênio associado à dose de $190 \mathrm{~kg} \mathrm{ha}^{-1}$ de potássio diferiu do tratamento com a dose $465 \mathrm{~kg} \mathrm{ha}^{-1}$ de nitrogênio associada à dose de $570 \mathrm{~kg} \mathrm{ha}^{-1}$ de potássio. Para as doses de nitrogênio, o tratamento com a dose $380 \mathrm{~kg} \mathrm{ha}^{-1}$ de potássio associada à dose de $155 \mathrm{~kg} \mathrm{ha}^{-1}$ de nitrogênio diferiu do tratamento com a dose de $380 \mathrm{~kg} \mathrm{ha}^{-1}$ de potássio associado à dose de $310 \mathrm{~kg} \mathrm{ha}^{-1}$ de nitrogênio. $\mathrm{O}$ tratamento com a dose $570 \mathrm{~kg} \mathrm{ha}^{-1}$ de potássio associada à dose $155 \mathrm{~kg} \mathrm{ha}^{-1} \mathrm{de}$ nitrogênio diferiu do tratamento com a dose de $570 \mathrm{~kg} \mathrm{ha}^{-1}$ de potássio associada à dose de $465 \mathrm{~kg} \mathrm{ha}^{-1}$ de nitrogênio.

Tabela 11: Comparação entre as médias das concentrações de cálcio $\left(\mathrm{g} \mathrm{kg}^{-1}\right)$ em função das doses de nitrogênio e potássio $\left(\mathrm{kg} \mathrm{ha}^{-1}\right)$ nas folhas diagnósticas.

\begin{tabular}{cccc}
\hline Doses de $N$ & \multicolumn{3}{c}{ Doses de K $\left(\mathrm{kg} \mathrm{ha}^{-1}\right)$} \\
\cline { 2 - 4 }$\left(\mathrm{kg} \mathrm{ha}^{-1}\right)$ & 190 & 380 & 570 \\
\hline 155 & $26,02 \mathrm{aA}$ & $29,79 \mathrm{aA}$ & $26,65 \mathrm{aA}$ \\
310 & $28,08 \mathrm{aA}$ & $23,05 \mathrm{bB}$ & $25,78 \mathrm{abA}$ \\
465 & $28,61 \mathrm{aA}$ & $25,95 \mathrm{abAB}$ & $23,18 \mathrm{bA}$ \\
\hline
\end{tabular}

Médias seguidas pela mesma letra, minúscula na línha e maiúscula na coluna, não diferem entre si pelo teste de Tukey a $1 \%$.

A comparação das médias das concentrações de cálcio na Tabela 12 mostra que para a freqüência de aplicação a cada 3 dias, não houve diferenças entre as doses de potássio. Para a freqüência de aplicação a cada 7 dias, a dose $190 \mathrm{~kg} \mathrm{ha}^{-1}$ de potássio diferiu das demais doses. Houve efeito da freqüência de aplicação para todas as doses de potássio. 
Tabela 12: Comparação entre as médias da quantidade de cálcio $\left(\mathrm{g} \mathrm{kg}^{-1}\right)$ nas folhas diagnósticas em função das doses de potássio $\left(\mathrm{kg} \mathrm{ha}^{-1}\right) \mathrm{e}$ as freqüências de aplicação (dias).

\begin{tabular}{cccc}
\hline Freqüências de & \multicolumn{3}{c}{ Doses de $\mathrm{K}\left(\mathrm{kg} \mathrm{ha}^{-1}\right)$} \\
\cline { 2 - 4 } aplicação & 190 & 380 & 570 \\
\hline 3 dias & $30,13 \mathrm{aA}$ & $31,57 \mathrm{aA}$ & $30,06 \mathrm{aA}$ \\
7 dias & $25,01 \mathrm{aB}$ & $20,95 \mathrm{bB}$ & $20,35 \mathrm{bB}$ \\
\hline
\end{tabular}

Médias seguidas pela mesma letra, minúscula na linha e maiúscula na coluna, não diferem entre si pelo teste de Tukey a $1 \%$.

A comparação das médias da quantidade de cálcio apresentados na Tabela 13 mostra que o tratamento $155 \mathrm{~kg} \mathrm{ha}^{-1}$ de nitrogênio diferiu do tratamento $310 \mathrm{~kg} \mathrm{ha}^{-1}$ nitrogênio, na freqüência de aplicação a cada 3 dias. Houve efeito das freqüências de aplicação para todas as doses de nitrogênio.

Tabela 13: Comparação entre as médias das concentrações de cálcio $\left(\mathrm{g} \mathrm{kg}^{-1}\right)$ nas folhas diagnósticas em função das doses de nitrogênio ( $\mathrm{kg} \mathrm{ha}^{-}$ ${ }^{1}$ ) e as freqüências de aplicação (dias).

\begin{tabular}{cccc}
\hline Freqüências de & \multicolumn{3}{c}{ Doses $\mathbf{N}\left(\mathrm{kg} \mathrm{ha}^{-1}\right)$} \\
\cline { 2 - 4 } aplicação & 155 & 310 & \multicolumn{1}{c}{465} \\
\hline 3 dias & $33,03 \mathrm{aA}$ & $28,00 \mathrm{bA}$ & $30,70 \mathrm{abA}$ \\
7 dias & $21,91 \mathrm{aB}$ & $23,27 \mathrm{aB}$ & $21,12 \mathrm{aB}$ \\
\hline
\end{tabular}

Médias seguidas pela mesma letra, minúscula na linha e maiúscula na coluna, não diferem entre si pelo teste de Tukey a $1 \%$.

A quantidade de cálcio na folha diagnóstica deve variar entre 14 e $40 \mathrm{~g}$ $\mathrm{kg}^{-1}$ (Trani \& Raij, 1996). Os resultados apresentados nas Tabelas 11,12 e 13 indicam que nenhum dos tratamentos apresentaram deficiência de cálcio, mesmo com a ocorrência de diferenças significativas. Nas condições do ensaio, os fatores que conduziriam a deficiência de cálcio é a aplicação de altas doses de adubos potássicos e amoniacais. Fernandes et al. (1975) observaram que a quantidade de cálcio na folha é de $16 \mathrm{~g} \mathrm{~kg}^{-1}$, valor este semelhante ao encontrado por Gargantini \& Blanco (1963), que observaram $15 \mathrm{~g} \mathrm{~kg}^{-1}$. 
As superfícies de resposta da quantidade de cálcio nas folhas diagnósticas em função das doses de nitrogênio e potássio aplicadas via fertirrigação a cada 3 dias (Equação 8) e a cada 7 dias (Equação 9), são representadas nas Figuras 11 e 12. A superfície de resposta dos tratamentos com freqüência de aplicação a cada 3 dias apresentou um ponto de sela em $28,91 \mathrm{~g} \mathrm{~kg}^{-1}$, e a superfície de resposta para os tratamentos com freqüência de aplicação a cada 7 dias apresentou ponto de sela em $21,59 \mathrm{~g} \mathrm{~kg}^{-1}$.

Concentração de Ca $=35,5125-0,09 D N+0,045504 D K+0,000162 D N^{2}-$ $0,000046795 D N D K-0,000041032 D K^{2}$

$\mathrm{R}^{2}=39,79(\%)$ e Prob $>\mathrm{F} 0,0070$

Concentração de $\mathrm{Ca}=20,876389+0,064046 \mathrm{DN}-0,031371 \mathrm{DK}-0,000072928$

$D N^{2}-0,000056239 D N D K+0,000048072 D K^{2}$

$R^{2}=54,90(\%)$ e Prob $>F 0,0001$

onde:

Concentração de $\mathrm{Ca}$ - Concentração de cálcio nos frutos em $\mathrm{g} \mathrm{kg}^{-1}$.

$\mathrm{DN}$ - Doses de nitrogênio em $\mathrm{kg} \mathrm{ha}^{-1}$, tal que $155 \leq \mathrm{DN} \geq 465$.

DK - Doses de potássio em kg ha-1 ${ }^{-1}$ tal que $190 \leq \mathrm{DK} \geq 570$. 


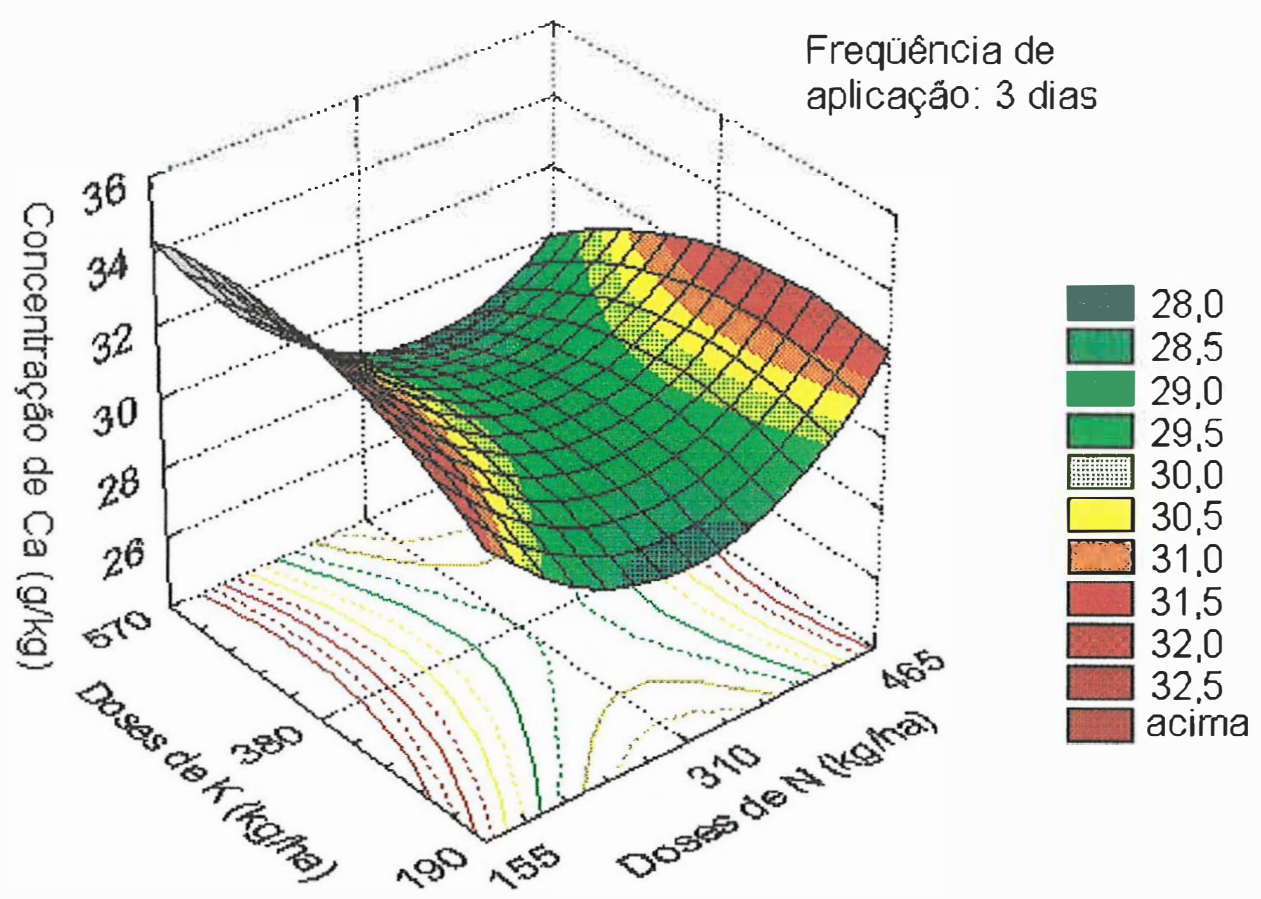

Figura 11: Superfície de resposta das concentrações de cálcio $\left(\mathrm{g} \mathrm{kg}^{-1}\right)$ nas folhas diagnósticas em função das doses de nitrogênio e potássio $\left(\mathrm{kg} \mathrm{ha}^{-1}\right)$ aplicadas a cada 3 dias.

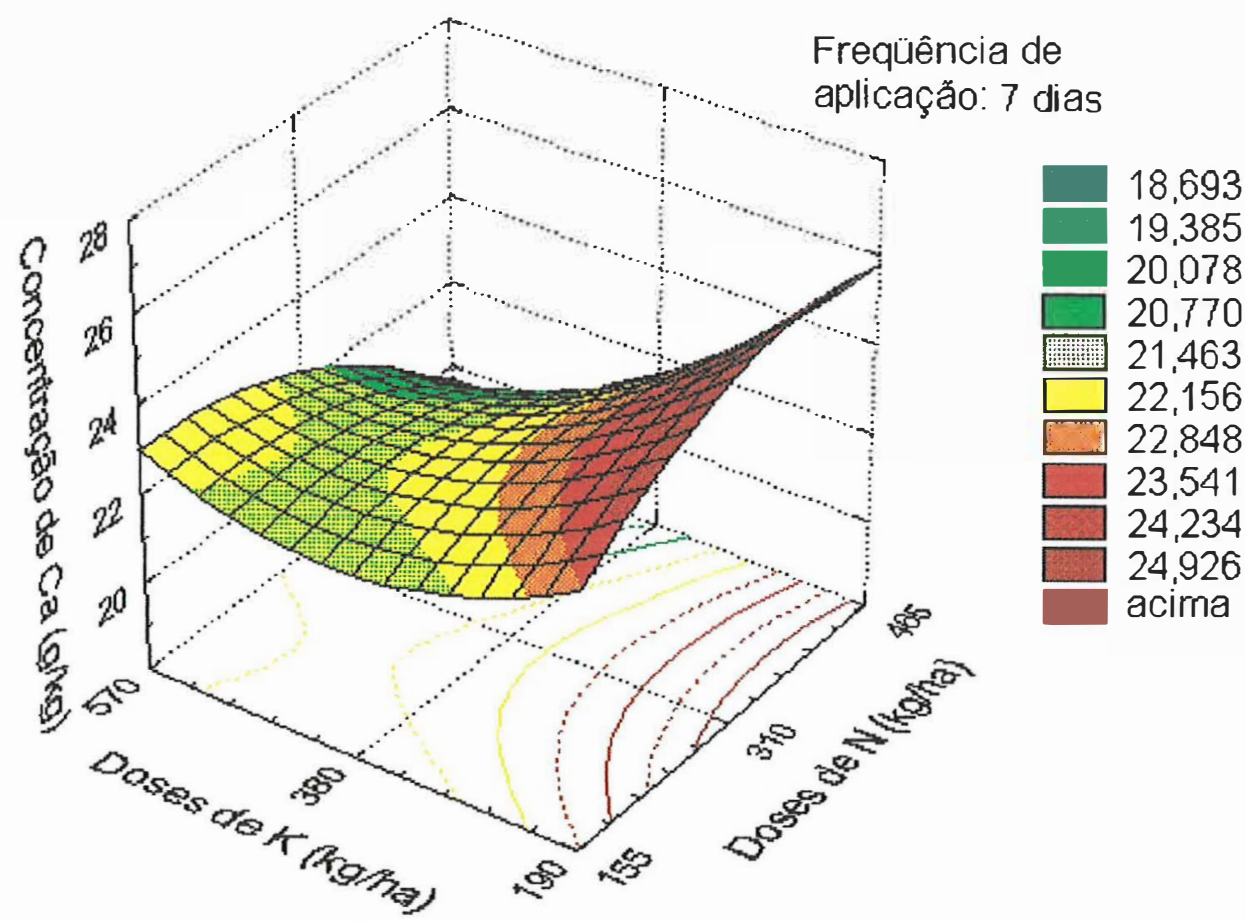

Figura 12: Superfície de resposta das concentrações de cálcio $\left(\mathrm{g} \mathrm{kg}^{-1}\right)$ nas folhas diagnósticas em função das doses de nitrogênio e potássio $\left(\mathrm{kg} \mathrm{ha}^{-1}\right)$ aplicadas a cada 7 dias. 


\subsubsection{Concentrações de magnésio}

As médias das concentrações de magnésio nas folhas diagnósticas são apresentadas na Tabela 14. Para as doses de potássio é possivel observar-se que o tratamento 6 diferiu dos tratamentos 4 e 5; o tratamento 8 diferiu dos tratamentos 7 e 9; o tratamento 13 diferiu dos tratamentos 14 e 15 e o tratamento 16 diferiu dos tratamentos 17 e 18. Para as doses de nitrogênio, os tratamentos 1, 4 e 7 diferiram entre si; o tratamento 5 diferiu dos tratamentos 2 e 8; o tratamento 9 diferiu dos tratamentos 3 e 6; o tratamento 16 diferiu do tratamento 13; o tratamento 17 diferiu dos tratamentos 11 e 14 e o tratamento 18 diferiu dos tratamentos 12 e 15. Para as freqüências de aplicação, o tratamento 1 diferiu do tratamento 10; o tratamento 2 diferiu do tratamento 11 , o tratamento 3 diferiu do tratamento 12 , o tratamento 4 diferiu do tratamento 13 , o tratamento 6 diferiu do tratamento 15, o tratamento 8 diferiu do tratamento $17 \mathrm{e}$ o tratamento 9 diferiu do tratamento 18 .

Tabela 14: Comparação entre as médias das concentrações de magnésio $\left(\mathrm{g} \mathrm{kg}^{-1}\right)$ nas follhas diagnósticas.

\begin{tabular}{|c|c|c|c|c|c|c|c|c|c|}
\hline \multirow{2}{*}{$\begin{array}{c}\text { Freqüências de } \\
\text { aplicação }\end{array}$} & \multirow{3}{*}{$\begin{array}{c}\text { Doses de } N \\
\left(\mathrm{~kg} \mathrm{ha}^{-1}\right)\end{array}$} & \multicolumn{8}{|c|}{ Doses de K $\left(\mathrm{kg} \mathrm{ha}^{-1}\right)$} \\
\hline & & \multicolumn{3}{|c|}{190} & \multicolumn{2}{|c|}{380} & \multicolumn{3}{|c|}{570} \\
\hline & & ${ }^{\star} 6,82$ & $\mathrm{aA}$ & $\mathrm{T} 1$ & $\star 7,09$ & aA T2 & ${ }^{\star} 6,23$ & $\mathrm{aA}$ & T3 \\
\hline \multirow[t]{3}{*}{3 dias } & 310 & *4,67 & $\mathrm{aB}$ & T4 & 5,13 & aB T5 & ${ }^{\star} 6,07$ & bA & T6 \\
\hline & 465 & 5,55 & $\mathrm{aC}$ & $\mathrm{T7}$ & $\star 7,72$ & bA T8 & $\star 5,01$ & $\mathrm{aB}$ & T9 \\
\hline & 155 & ${ }^{\star} 5,18$ & $\mathrm{aAB}$ & 310 & $\star 4,65$ & aA T11 & $\star 5,07$ & $\mathrm{aA}$ & $\mathrm{T} 12$ \\
\hline \multirow[t]{2}{*}{7 dias } & 310 & ${ }^{\star} 5,79$ & $\mathrm{aA}$ & T13 & 4,66 & bA T14 & *4,49 & bA & T15 \\
\hline & 465 & 4,86 & aB & T16 & $\star 3,85$ & bB $\mathrm{T} 17$ & $\star 3,74$ & bB & T18 \\
\hline
\end{tabular}

Trani \& Raij (1996), indicam como adequados, concentrações de magnésio nas folhas de tomateiro variando entre 4 e $8 \mathrm{~g} \mathrm{~kg}^{-1}$. Assim, conforme a recomendação, apenas os tratamentos 17 e 18 apresentaram valores abaixo do adequado, cuja ocorrência no ensaio pode ser devido ao elevado nível de 
cálcio, potássio e amônio. Fernandes et al. (1975) observaram que a quantidade de magnésio nas folhas foi de $9 \mathrm{~g} \mathrm{~kg}^{-1}$, enquanto Gargantini \& Blanco (1963) indicam que a quantidade de magnésio deve estar em torno de $4,5 \mathrm{~g} \mathrm{~kg}^{-1}$.

As superfícies de resposta da quantidade de magnésio nas folhas diagnósticas (valores transformados) em função das doses de nitrogênio e potássio aplicadas via fertirrigação a cada 3 dias (Equação 10) e a cada 7 dias (Equação 11), são representadas nas Figuras 13 e 14. A superfície de resposta dos tratamentos com freqüência de aplicação a cada 3 dias apresentou um ponto de sela em 0,29 , e a superfície de resposta dos tratamentos com freqüência de aplicação a cada 7 dias apresentou um ponto de sela em 0,33.

(Concentração de $M g)^{-0,7}=0,242077+0,001027 D N-0,000605 D K$ $0,000001554 D N^{2}+0,0000000307 D N D K+0,000000765 D K^{2}$ $\mathrm{R}^{2}=50,63(\%)$ e Prob > F 0,0005

(Concentração de $M g)^{-0,7}=0,312216-0,000610 D N+0,000425 D K+$ $0,000000899 D N^{2}+0,000000529 D N D K-0,000000626 D K^{2}$ $\mathrm{R}^{2}=90,29(\%)$ e Prob > F 0,0000

onde:

Concentração de Mg - Concentração de magnésio nas folhas diagnósticas em $\mathrm{g} \mathrm{kg}^{-1}$.

$\mathrm{DN}$ - Doses de nitrogênio em $\mathrm{kg} \mathrm{ha}^{-1}$, tal que $155 \leq \mathrm{DN} \geq 465$.

DK - Doses de potássio em $\mathrm{kg} \mathrm{ha}^{-1}$, tal que $190 \leq \mathrm{DK} \geq 570$. 


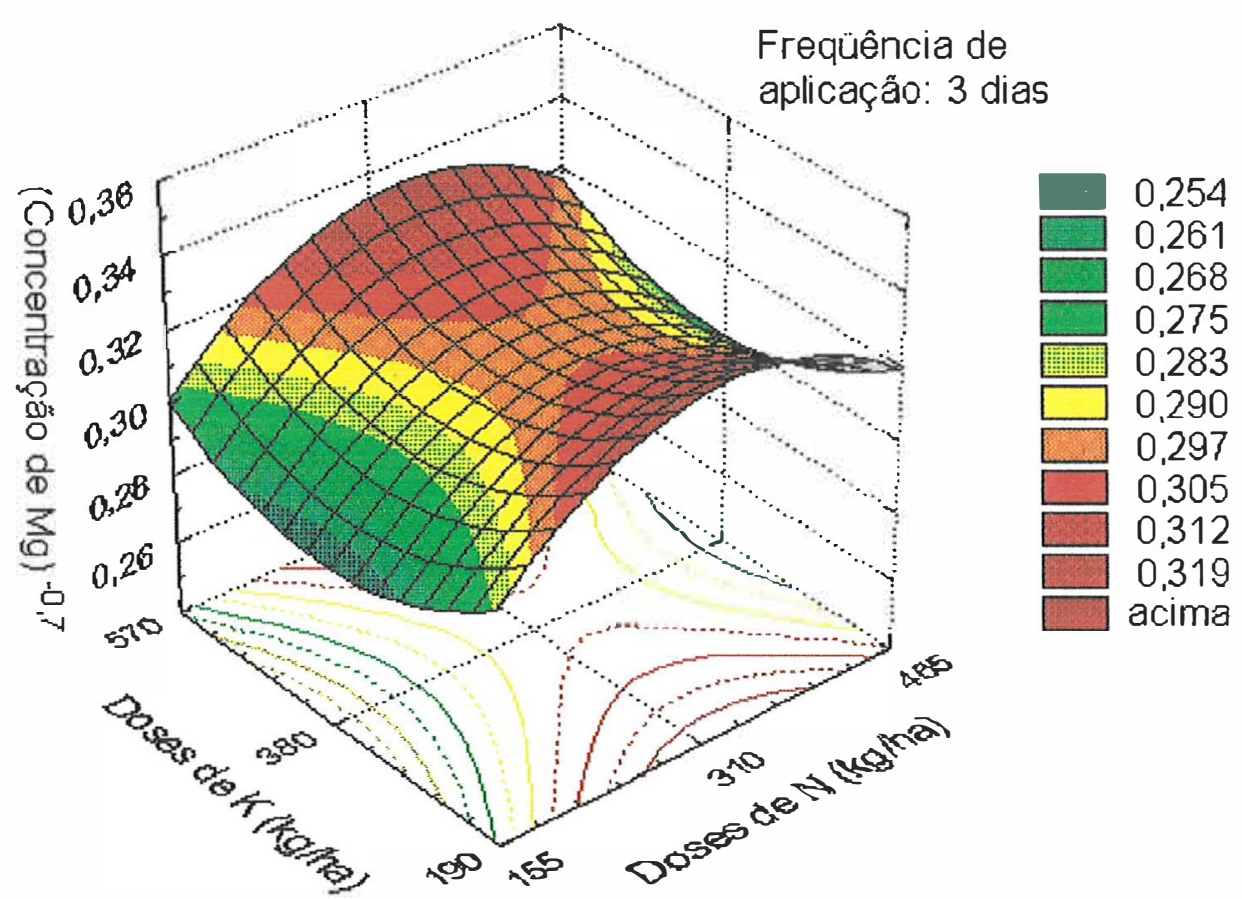

Figura 13: Superfície de resposta das concentrações de magnésio nas folhas diagnósticas em função das doses de nitrogênio e potássio $\left(\mathrm{kg} \mathrm{ha}^{-1}\right)$ aplicadas a cada 3 dias.

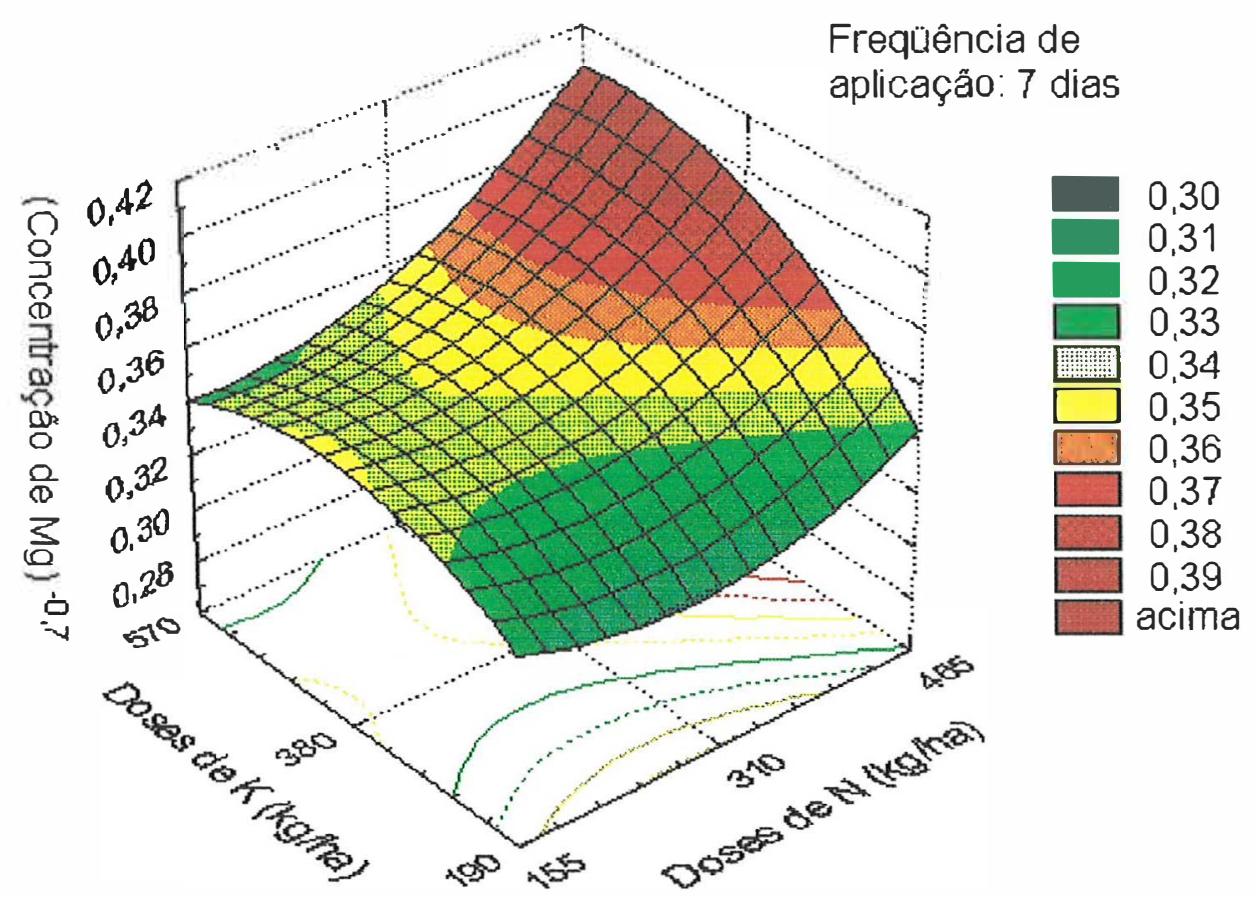

Figura 14: Superfície de resposta das concentrações de magnésio nas folhas diagnósticas em função das doses de nitrogênio e potássio $\left(\mathrm{kg} \mathrm{ha}^{-1}\right)$ aplicadas a cada 7 dias. 


\subsubsection{Concentrações de enxofre}

$\mathrm{Na}$ Tabela 15 apresenta-se a comparação das médias das concentrações de enxofre nas folhas diagnósticas. Para as doses de potássio o tratamento 8 diferiu dos tratamentos 7 e 9 , e o tratamento 11 diferiu do tratamento 10. Quando comparada as médias dos tratamentos em função das doses de nitrogênio, pode-se observar que 0 tratamento 8 diferiu dos tratamentos 2 e 5. Para as freqüências de aplicação o tratamento 2 diferiu do tratamento 11; o tratamento 3 diferiu do tratamento 12; o tratamento 8 diferiu do tratamento 17 e o tratamento 9 diferiu do tratamento 18.

Tabela 15: Comparação entre as médias das concentrações de enxofre $\left(\mathrm{g} \mathrm{kg}^{-1}\right)$ nas folhas diagnósticas.

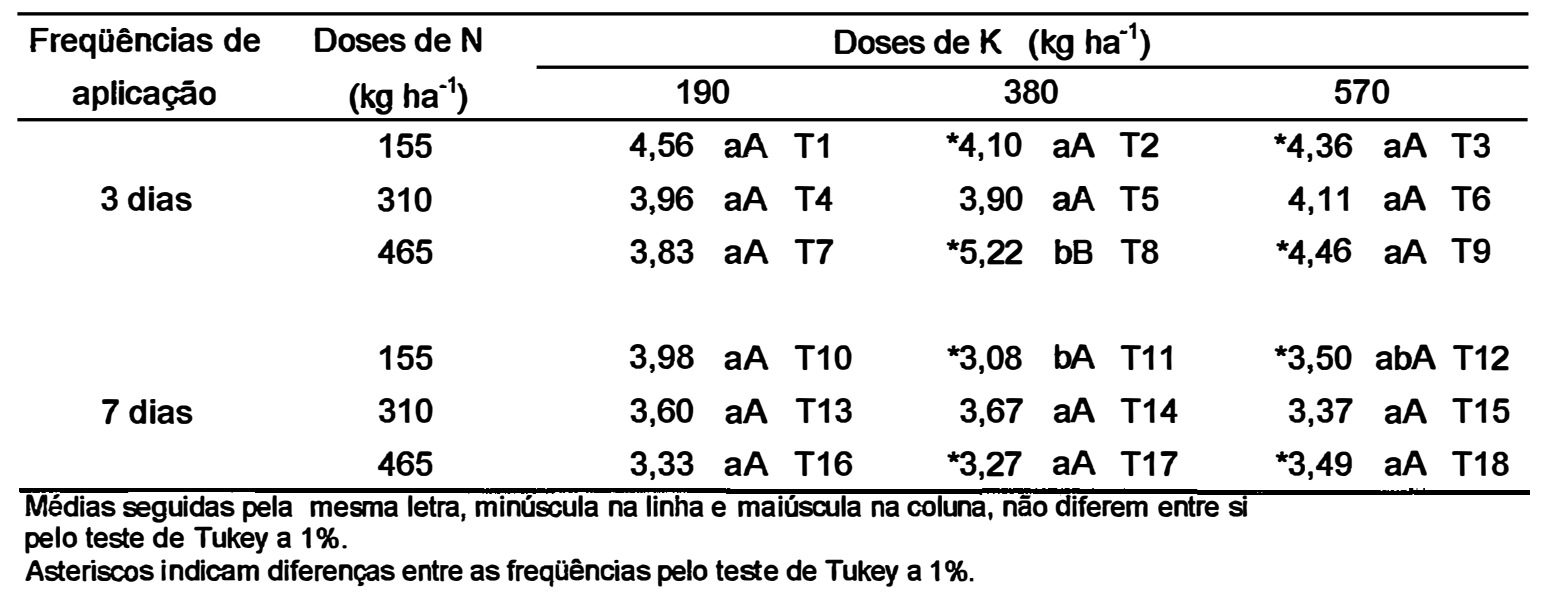

As concentrações de enxofre nas folhas diagnósticas podem variar entre 3 e $10 \mathrm{~g} \mathrm{~kg}^{-1}$ (Trani \& Raij, 1996). Dessa forma, pode-se afirmar que a quantidade de enxofre manteve-se adequado em todos os tratamentos, incluindo ao que se diferenciou significativamente, o tratamento 11. Gargantini \& Blanco (1963) e Fernandes et al. (1975) obtiveram $1,7 \mathrm{~g} \mathrm{~kg}^{-1}$ de enxofre nas folhas, ou seja, quase a metade da recomendação feita por Trani \& Raij (1996).

As superfícies de resposta da quantidade de enxofre nas folhas diagnósticas, em função das doses de nitrogênio e potássio aplicadas via fertirrigação a cada 3 dias (Equação 12) e a cada 7 dias (Equação 13), são 
representadas nas Figuras 15 e 16. A superfície de resposta dos tratamentos com freqüência de aplicação a cada 3 dias apresentou um ponto de sela em $4,12 \mathrm{~g} \mathrm{~kg}^{-1}$, e a superfície de resposta dos tratamentos com freqüência de aplicação a cada 7 dias apresentou ponto de sela em $3,40 \mathrm{~g} \mathrm{~kg}^{-1}$.

Concentração de $S=5,541944-0,013374 D N+0,002485 D K+0,00001824$ $D N^{2}+0,000006728 D N D K-0,000005309 D K^{2}$

$\mathrm{R}^{2}=34,98(\%)$ e Prob > F 0,0189

Concentração de $S=4,783889+0,000231 D N-0,006509 D K-0,000004457$ $D N^{2}+0,000005327 D N D K+0,000005759 D K^{2}$

$\mathrm{R}^{2}=34,78(\%)$ e Prob > F 0,0197

onde:

Concentração de S - Concentração de enxofre nas folhas diagnósticas em $\mathrm{g} \mathrm{kg}^{-1}$.

$\mathrm{DN}$ - Doses de nitrogênio em $\mathrm{kg} \mathrm{ha}^{-1}$, tal que $155 \leq \mathrm{DN} \geq 465$.

DK - Doses de potássio em $\mathrm{kg} \mathrm{ha}^{-1}$, tal que $190 \leq \mathrm{DK} \geq 570$. 


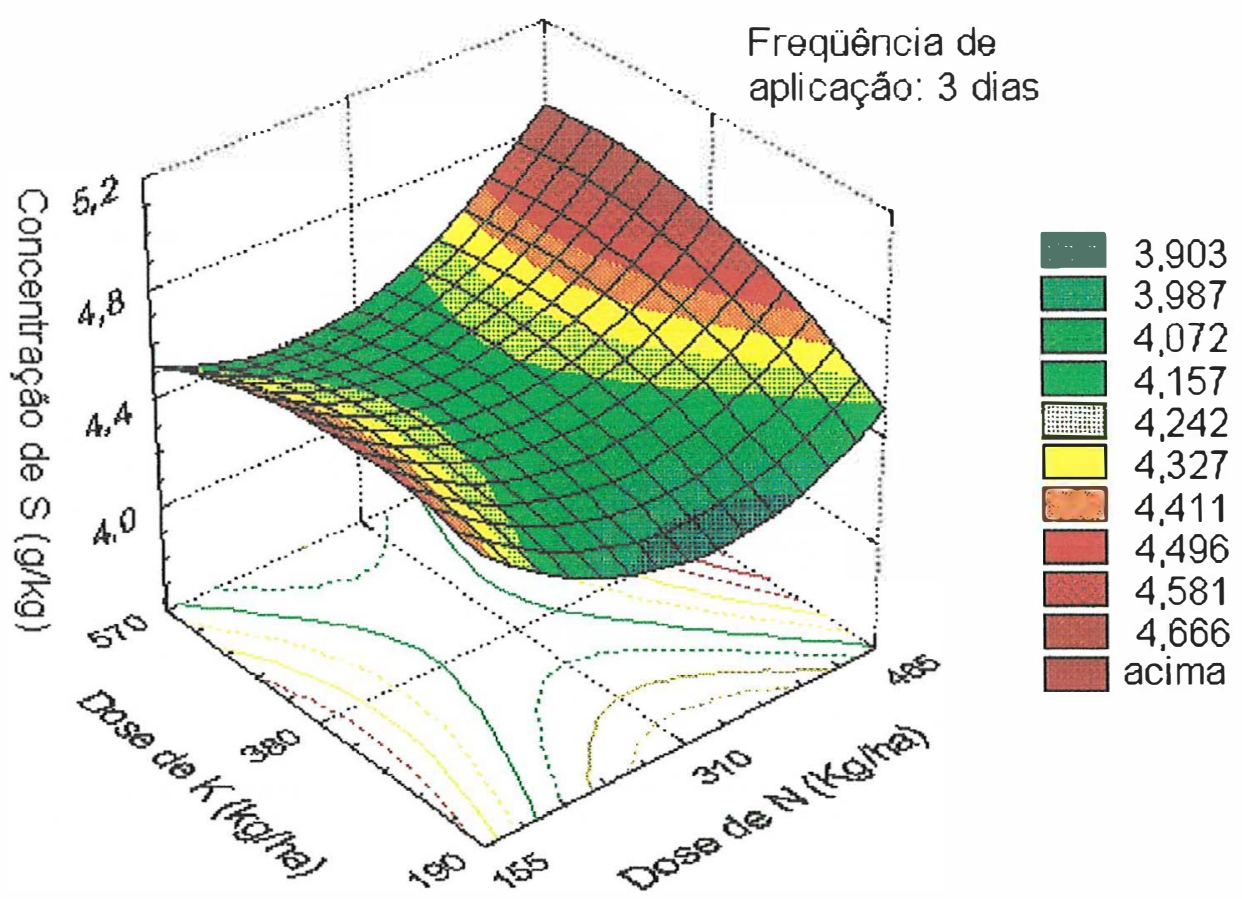

Figura 15: Superfície de resposta das concentrações de enxofre $\left(\mathrm{g} \mathrm{kg}^{-1}\right)$ nas folhas diagnósticas em função das doses de nitrogênio e potássio $\left(\mathrm{kg} \mathrm{ha}^{-1}\right)$ aplicadas a cada 3 dias.

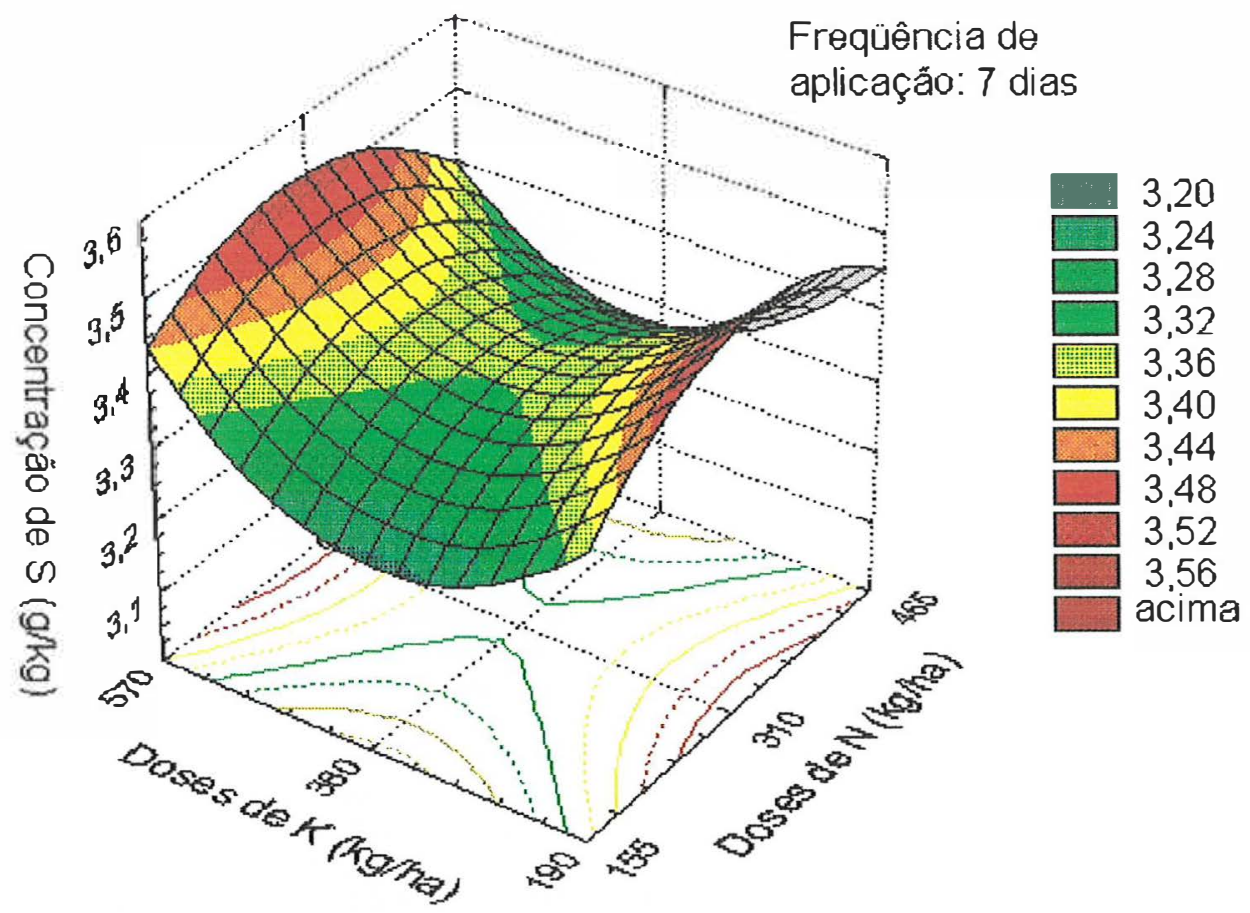

Figura 16: Superfície de resposta das concentrações de enxofre $\left(\mathrm{g} \mathrm{kg}^{-1}\right)$ nas folhas diagnósticas em função das doses de nitrogênio e potássio $\left(\mathrm{kg} \mathrm{ha}^{-1}\right)$ aplicadas a cada 7 dias. 


\subsubsection{Concentrações de boro}

As médias das concentrações de boro $\left(\mathrm{mg} \mathrm{kg}^{-1}\right)$ nas folhas diagnósticas encontram-se na Tabela 16. Comparando as médias em função das doses de potássio não houve diferenças entre os tratamentos. Nas comparações feitas em função das doses de nitrogênio, o tratamento 11 e 14 diferiram entre si. As freqüências de aplicação apresentaram diferença entre os tratamentos 2 e 11.

Tabela 16: Comparação entre as médias das concentrações de boro $\left(\mathrm{mg} \mathrm{kg}^{-1}\right)$ nas folhas diagnósticas.

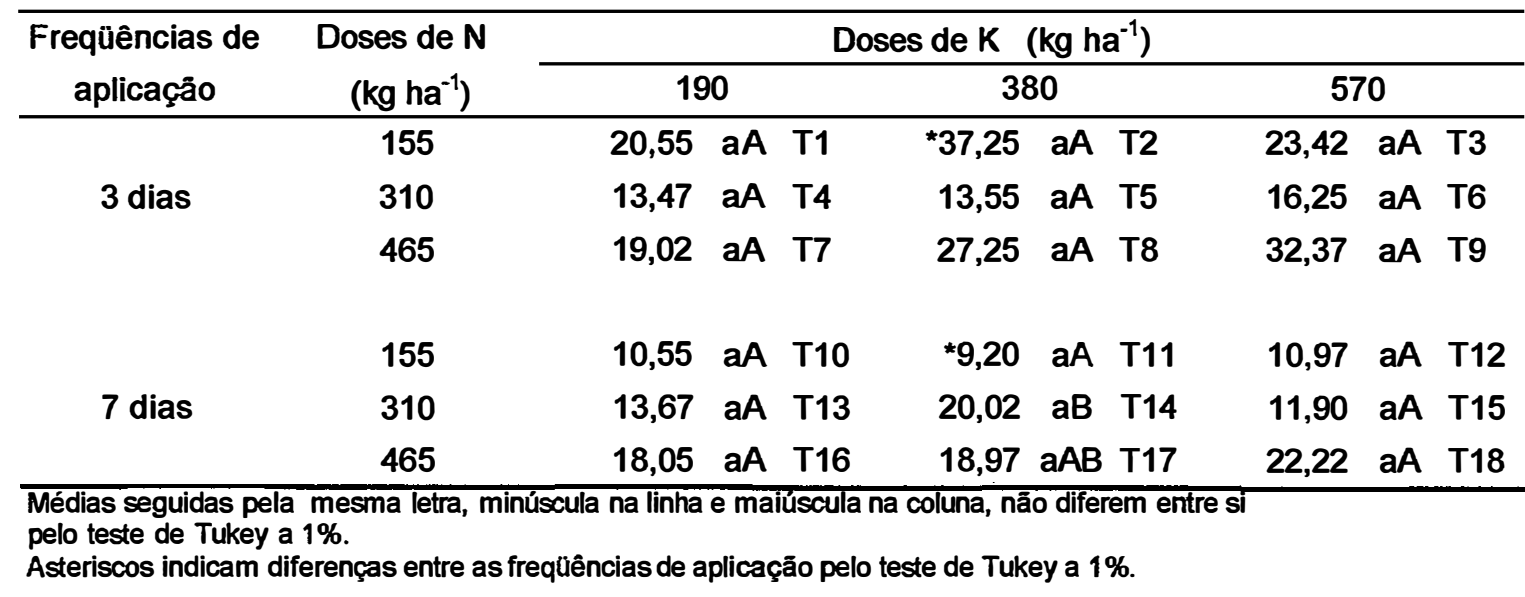

Apesar de ocorrem diferenças significativas, as concentrações de boro nas folhas diagnósticas encontram-se baixas, pois deveriam variar entre $30 \mathrm{e}$ $100 \mathrm{mg} \mathrm{kg}^{-1}$ (Trani \& Raij, 1996). Dos fatores que podem levar a ocorrência de deficiência de boro, a alta taxa de precipitação durante o ciclo da cultura é a mais provável causa do ocorrido. A quantidade de boro nas folhas obtido por Fernandes et al. (1975) foi $44 \mathrm{mg} \mathrm{kg}^{-1}$.

As superfícies de resposta das concentrações de boro nas folhas diagnósticas (valores transformados), em função das doses de nitrogênio e potássio aplicadas via fertirrigação a cada 3 dias (Equação 14) e a cada 7 dias (Equação 15), são representadas pelas Figuras 17 e 18. A superfície de resposta dos tratamentos com freqüência de aplicação a cada 3 dias apresentou um ponto de sela em 0,43 , e a superfície de resposta dos 
tratamentos com freqüência de aplicação a cada 7 dias apresentou ponto de sela em 0,33.

$(\text { Concentração de } B)^{-0,3}=0,198061+0,001903 D N-0,000138 D K$ $0,000002803 D N^{2}-0,000000492 D N D K+0,000000266 D K^{2}$ $\mathrm{R}^{2}=51,20(\%)$ e Prob > F 0,0004

$(\text { Concentração de } B)^{-0,3}=0,586154-0,000370 D N-0,000199 D K+$ $0,000000239 D N^{2}-0,000000190 D N D K+0,000000323 D K^{2}$ $\mathrm{R}^{2}=55,98(\%)$ e Prob $>$ F 0,0001

onde:

Concentração de B - Concentração de boro nas folhas diagnósticas em mg kg ${ }^{-1}$. DN - Doses de nitrogênio em kg ha ${ }^{-1}$, tal que $155 \leq \mathrm{DN} \geq 465$.

DK - Doses de potássio em $\mathrm{kg} \mathrm{ha}^{-1}$, tal que $190 \leq \mathrm{DK} \geq 570$.

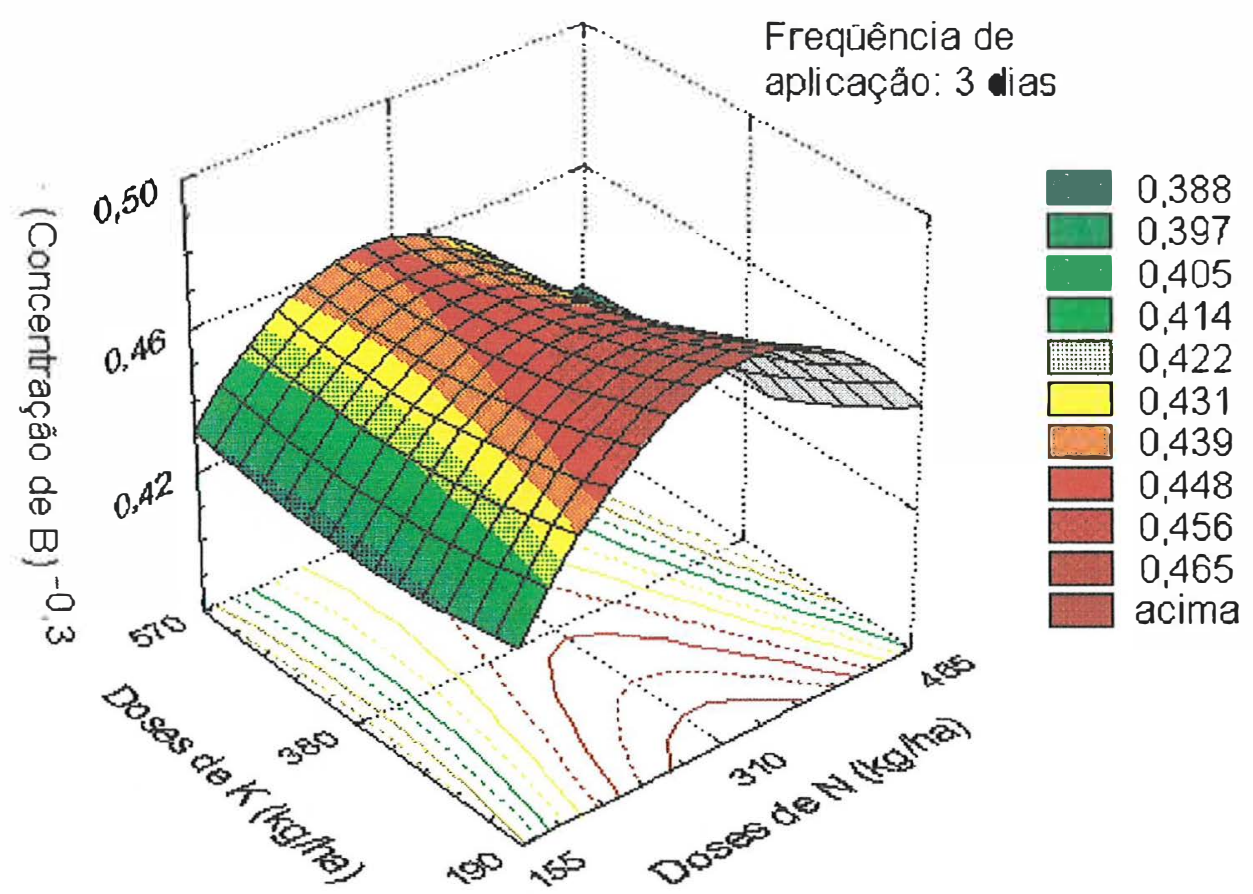

Figura 17: Superfície de resposta das concentrações de boro nas folhas diagnósticas em função das doses de nitrogênio e potássio $\left(\mathrm{kg} \mathrm{ha}^{-1}\right)$ aplicadas a cada 3 dias. 


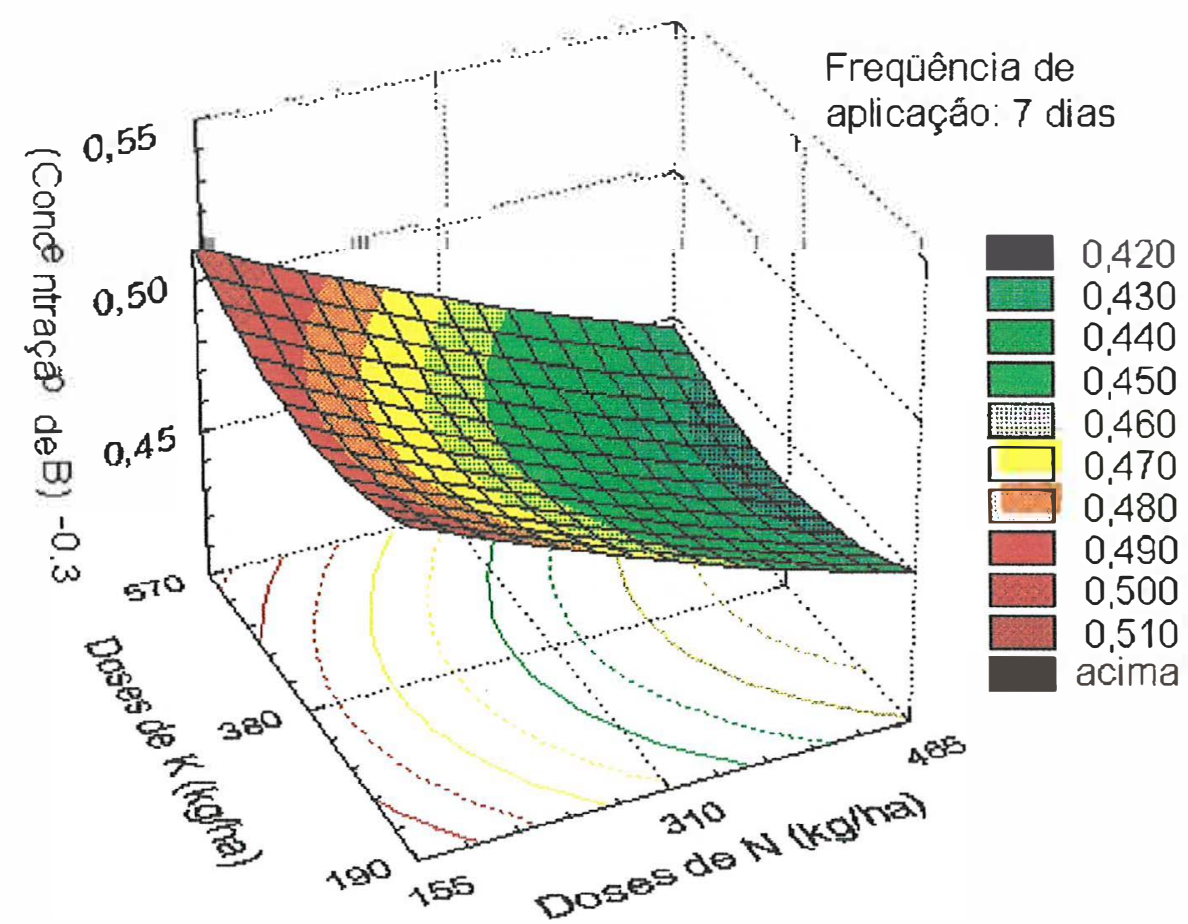

Figura 18: Superfície de resposta das concentrações de boro nas folhas diagnósticas em função das doses de nitrogênio e potássio $\left(\mathrm{kg} \mathrm{ha}^{-1}\right)$ aplicadas a cada 7 dias.

\subsubsection{Concentrações de cobre}

Para as doses de potássio, pode-se observar na Tabela 17, sem considerar a freqüência de aplicação, que não houve diferenças entre os tratamentos para as concentrações de cobre nas folhas diagnósticas. Quando consideradas as doses de nitrogênio, o tratamento com a dose $190 \mathrm{~kg} \mathrm{ha}^{-1}$ de potássio associada à dose $155 \mathrm{~kg} \mathrm{ha}^{-1}$ de nitrogênio diferiu do tratamento com a dose de $190 \mathrm{~kg} \mathrm{ha}^{-1}$ de potássio associado à dose de $310 \mathrm{~kg} \mathrm{ha}^{-1}$ de nitrogênio. 
Tabela 17: Comparação entre as médias das concentrações de cobre $\left(\mathrm{mg} \mathrm{kg}^{-1}\right)$ nas fohas diagnósticas em função das doses de nitrogênio e potássio $\left(\mathrm{kg} \mathrm{ha}^{-1}\right)$.

\begin{tabular}{cccc}
\hline $\begin{array}{c}\text { Doses de } \mathrm{N} \\
\left(\mathrm{kg} \mathrm{ha}^{-1}\right)\end{array}$ & \multicolumn{4}{c}{ Doses de K $\left(\mathrm{kg} \mathrm{ha}^{-1}\right)$} \\
\cline { 2 - 4 } & 190 & 380 & 570 \\
\hline 155 & $29,90 \mathrm{aA}$ & $43,42 \mathrm{aA}$ & $32,28 \mathrm{aA}$ \\
310 & $92,33 \mathrm{aB}$ & $39,62 \mathrm{aA}$ & $30,77 \mathrm{aA}$ \\
465 & $30,60 \mathrm{aAB}$ & $32,23 \mathrm{aA}$ & $36,07 \mathrm{aA}$ \\
\hline
\end{tabular}

Na Tabela 18 pode-se observar que o tratamento com a dose de $190 \mathrm{~kg}$ $\mathrm{ha}^{-1}$ de potássio aplicadas a cada 7 dias diferiu do tratamento com a dose de $380 \mathrm{~kg} \mathrm{ha}^{-1}$ de potássio aplicadas a cada 7 dias. Houve efeito das freqüências de aplicação para todas as doses de potássio.

Tabela 18: Comparação entre as médias das concentrações de cobre $\left(\mathrm{mg} \mathrm{kg}^{-1}\right)$ nas folhas diagnósticas em função das freqüências de aplicação (dias) e doses de potássio $\left(\mathrm{kg} \mathrm{ha}^{-1}\right)$.

\begin{tabular}{cccc}
\hline Freqüências de & \multicolumn{3}{c}{ Doses de $\mathrm{K}\left(\mathrm{kg} \mathrm{ha}^{-1}\right)$} \\
\cline { 2 - 4 } aplicação & 190 & 380 & 570 \\
\hline 3 & $66,16 \mathrm{aA}$ & $54,94 \mathrm{aA}$ & $37,83 \mathrm{aA}$ \\
7 & $35,72 \mathrm{aB}$ & $21,91 \mathrm{bB}$ & $28,25 \mathrm{abB}$ \\
\hline
\end{tabular}

Médias seguidas pela mesma letra, minúscula na linha e maiúscula na coluna, não diferem entre si pelo teste de Tukey a $1 \%$.

A faixa adequada da quantidade de cobre em folhas diagnósticas do tomateiro deve variar entre 5 e $15 \mathrm{mg} \mathrm{kg}^{-1}$ (Trani \& Raij, 1996). Todos os tratamentos apresentaram concentrações muito acima do adequado, mesmo ocorrendo diferenças significativas. A ocorrência desse fato pode ser devido ao intenso uso de fungicida cúprico.

A superfície de resposta das concentrações de cobre nas folhas diagnósticas (valores transformados), em função das doses de nitrogênio e 
potássio aplicadas via fertirrigação a cada 7 dias (Equação 16), é representada na Figura 19. A superfície de resposta apresentou ponto de sela em 0,0018.

(Concentrações de Cu $)^{-0,2}=0,001086-0,000012535 D N+0,000013150 D K+$ $0,00000001996 D N^{2}+0,000000001371 D N D K-0,00000001687 D K^{2}$

$R^{2}=38,33(\%)$, Prob $>$ F 0,0096

onde:

Concentração de $\mathrm{Cu}$ - Concentração de cobre nas folhas diagnósticas em $\mathrm{mg} \mathrm{kg}^{-1}$.

DN - Doses de nitrogênio em $\mathrm{kg} \mathrm{ha}^{-1}$, tal que $155 \leq \mathrm{DN} \geq 465$.

DK - Doses de potássio em $\mathrm{kg} \mathrm{ha}^{-1}$, tal que $190 \leq \mathrm{DK} \geq 570$.

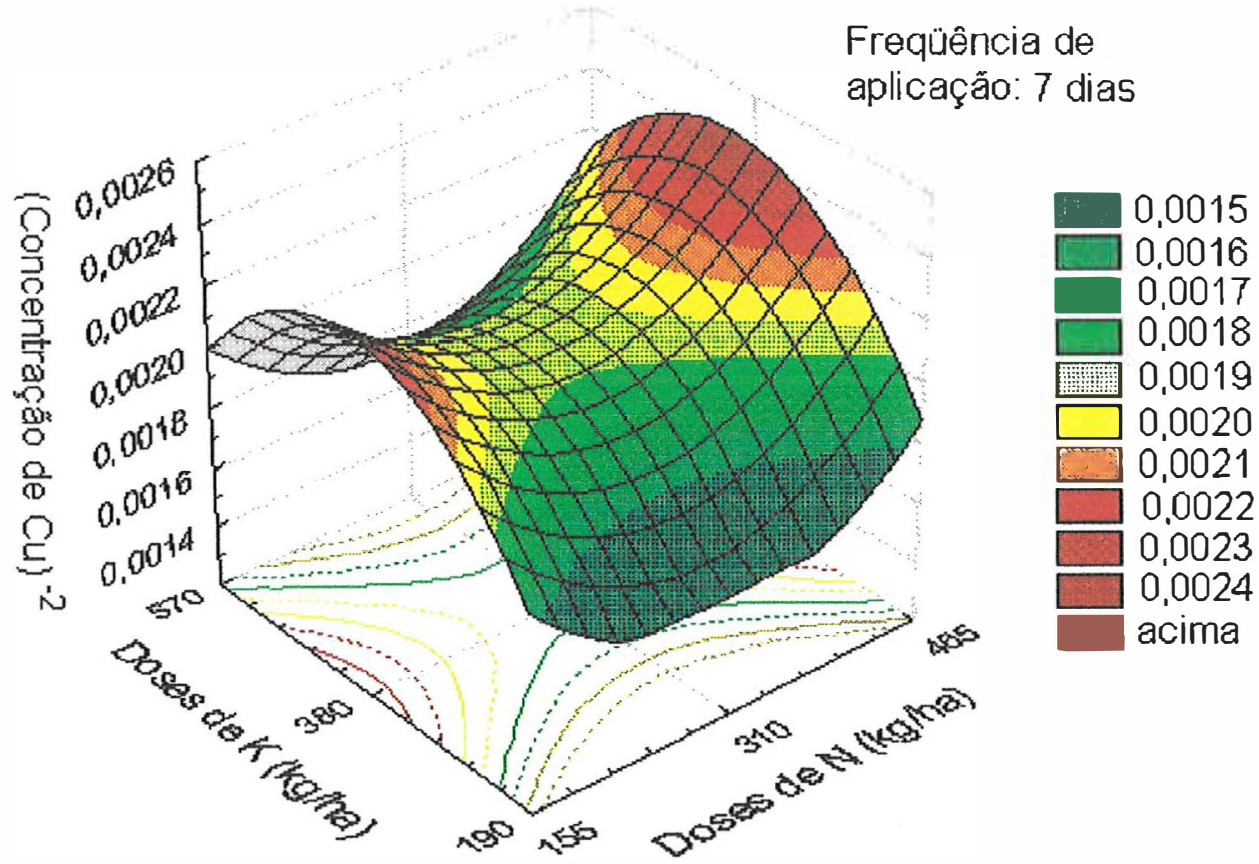

Figura 19: Superfície de resposta das concentrações de cobre nas folhas diagnósticas em função das doses de nitrogênio e potássio $\left(\mathrm{kg} \mathrm{ha}^{-1}\right)$ aplicadas a cada 7 dias.

\subsubsection{Concentrações de ferro}

A comparação das médias das concentrações de ferro nas folhas dagnósticas se encontram na Tabela 19. Para as doses de potássio, é possível 
observar-se que os tratamentos 1, 2 e 3 diferiram entre si; o tratamento 4 diferiu dos tratamentos 5 e 6; o tratamento 8 diferiu dos tratamentos 7 e 9; o tratamento 11 diferiu dos tratamentos 10 e 12; o tratamento 15 diferiu dos tratamentos 13 e 14 , e os tratamentos 16,17 e 18 diferiram entre si. Comparando-se as médias em função das doses de nitrogênio, nota-se que os tratamentos 1, 4 e 7 diferiram entre si; os tratamentos 2, 5 e 8 diferiram entre si; os tratamentos 3 diferiram dos tratamentos 6 e 9; os tratamentos 10, 13 e 16 diferiram entre si; o tratamento 10 diferiu dos tratamentos 14 e 17 , e os tratamentos 12,15 e 18 diferiram entre si.

Tabela 19: Comparação entre as médias das concentrações de ferro $\left(\mathrm{mg} \mathrm{kg}^{-1}\right)$ nas folhas diagnósticas.

\begin{tabular}{|c|c|c|c|c|c|c|c|c|c|c|}
\hline \multirow{3}{*}{$\begin{array}{c}\text { Freqüências de } \\
\text { aplicação }\end{array}$} & \multirow{3}{*}{$\begin{array}{c}\begin{array}{c}\text { Doses de N } \\
\left(\mathrm{kg} \mathrm{ha}^{-1}\right)\end{array} \\
155\end{array}$} & \multicolumn{9}{|c|}{ Doses de K $\left(\mathrm{kg} \mathrm{ha}^{-1}\right)$} \\
\hline & & \multicolumn{3}{|c|}{190} & \multicolumn{3}{|c|}{380} & \multicolumn{3}{|c|}{570} \\
\hline & & $* 453,25$ & aA & T1 & 626,72 & bA & T2 & *922,32 & $\mathrm{cA}$ & T3 \\
\hline \multirow[t]{3}{*}{3 dias } & 310 & *369,32 & $\mathrm{aB}$ & T4 & 492,17 & bB & T5 & *530,05 & bB & T6 \\
\hline & 465 & *576,15 & $\mathrm{aC}$ & T7 & ${ }^{*} 1435,25$ & bC & T8 & *538,00 & $\mathrm{aB}$ & T9 \\
\hline & 155 & *1295,03 & $\mathrm{aA}$ & T10 & 704,47 & bA & T11 & *1481,20 & $\mathrm{aA}$ & T12 \\
\hline \multirow[t]{2}{*}{7 dias } & 310 & ${ }^{\star} 473,30$ & $\mathrm{aB}$ & T13 & 476,87 & $\mathrm{aB}$ & T14 & *406,60 & bB & T15 \\
\hline & 465 & *899,02 & $\mathrm{aC}$ & T16 & *424,57 & bB & T17 & *646,37 & $\mathrm{cC}$ & T18 \\
\hline
\end{tabular}

$\mathrm{Na}$ cultura do tomateiro, as concentrações de ferro nas folhas diagnósticas devem estar entre 100 e $300 \mathrm{mg} \mathrm{kg}^{-1}$ (Trani \& Raij, 1996). Os resultados obtidos indicam que todos os tratamentos se encontram com valores acima do adequado, mesmo ocorrendo diferenças significativas. Esses resultados podem ser explicados pela alta concentração de ferro no solo e pelo uso de defensivos que contêm ferro. Também acima da faixa recomendada para a concentração de ferro nas folhas, foi o resultado $706 \mathrm{mg} \mathrm{kg}^{-1}$ obtido por Fernandes et al. (1975). 
As superfícies de resposta das concentrações de ferro nas folhas diagnósticas (valores transformados), em função das doses de nitrogênio e potássio aplicadas via fertirrigação a cada 3 dias (Equação 17) e a cada 7 dias (Equação 18), são representadas nas Figuras 20 e 21 . A superfície de resposta dos tratamentos com freqüência de aplicação a cada 3 dias apresentou ponto de sela em 0,0018 , e a superfície de resposta dos tratamentos com freqüência de aplicação a cada 7 dias apresentou ponto de máximo em 0,0026.

$1 /($ Concentração de $\mathrm{Fe})=0,003123+0,000012805 \mathrm{DN}-0,000014794 \mathrm{DK}-$ $0,0000000281 D N^{2}+0,000000010461 D N D K-0,00000001312 D K^{2}$

$R^{2}=81,89(\%)$ e Prob > F 0,0000

$1 /($ Concentração de $\mathrm{Fe})=-0,003531+0,00002412 \mathrm{DN}-0,00000994 \mathrm{DK}-$ $0,0000000379 D N^{2}+0,00000000448 D N^{*} D K-0,00000001412 D K^{2}$ $R^{2}=83,70(\%)$ e Prob > F 0,0000

onde:

Concentração de Fe - Concentração de ferro nas folhas diagnósticas em $\mathrm{mg} \mathrm{kg}^{-1}$.

$\mathrm{DN}$ - Doses de nitrogênio $\mathrm{kg} \mathrm{ha}^{-1}$, tal que $155 \leq \mathrm{DN} \geq 465$.

DK - Doses de potássio em $\mathrm{kg} \mathrm{ha}^{-1}$, tal que $190 \leq \mathrm{DK} \geq 570$. 


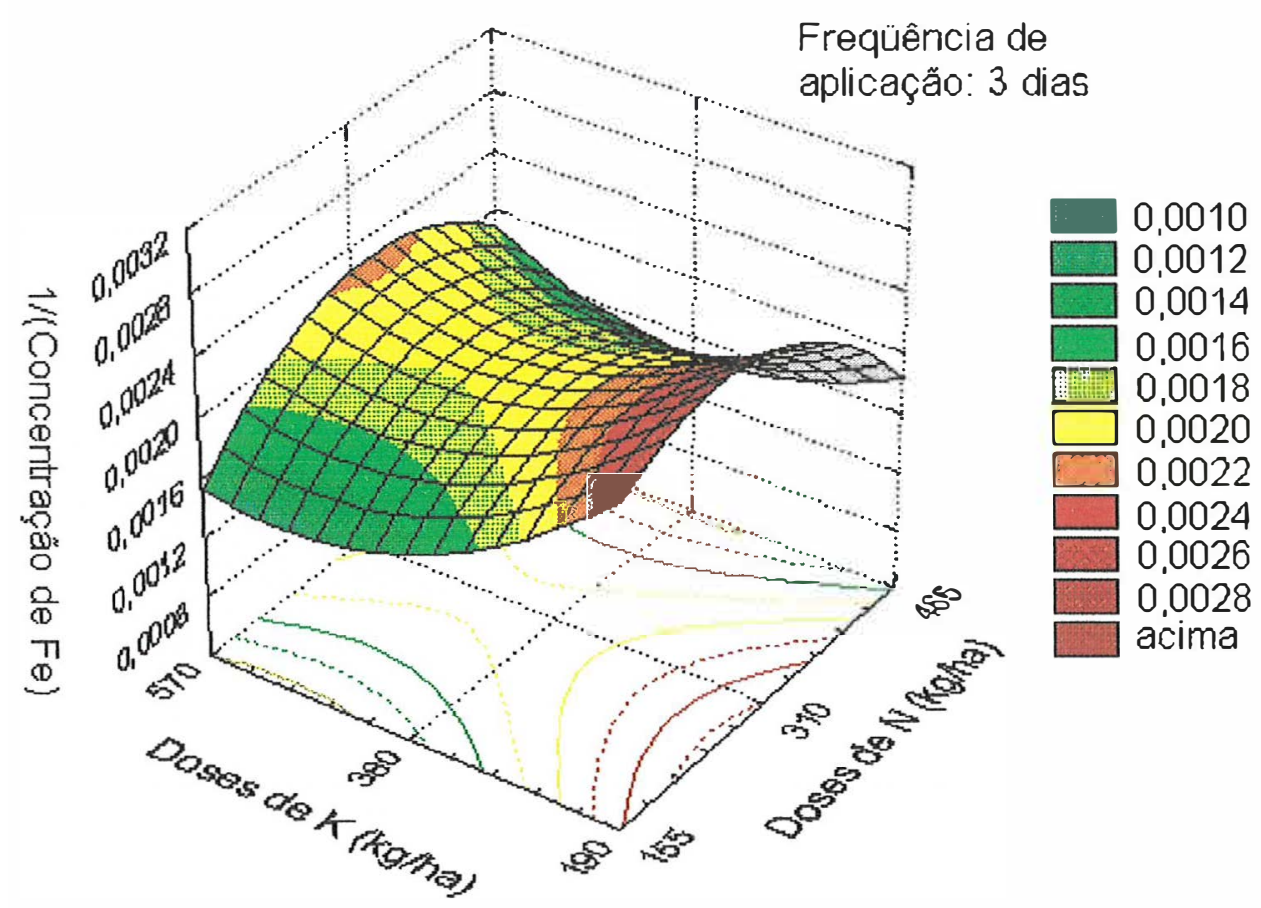

Figura 20: Superfície de resposta das concentrações de ferro nas folhas diagnósticas em função das doses de nitrogênio e potássio $\left(\mathrm{kg} \mathrm{ha}^{-1}\right)$ aplicadas a cada 3 dias.

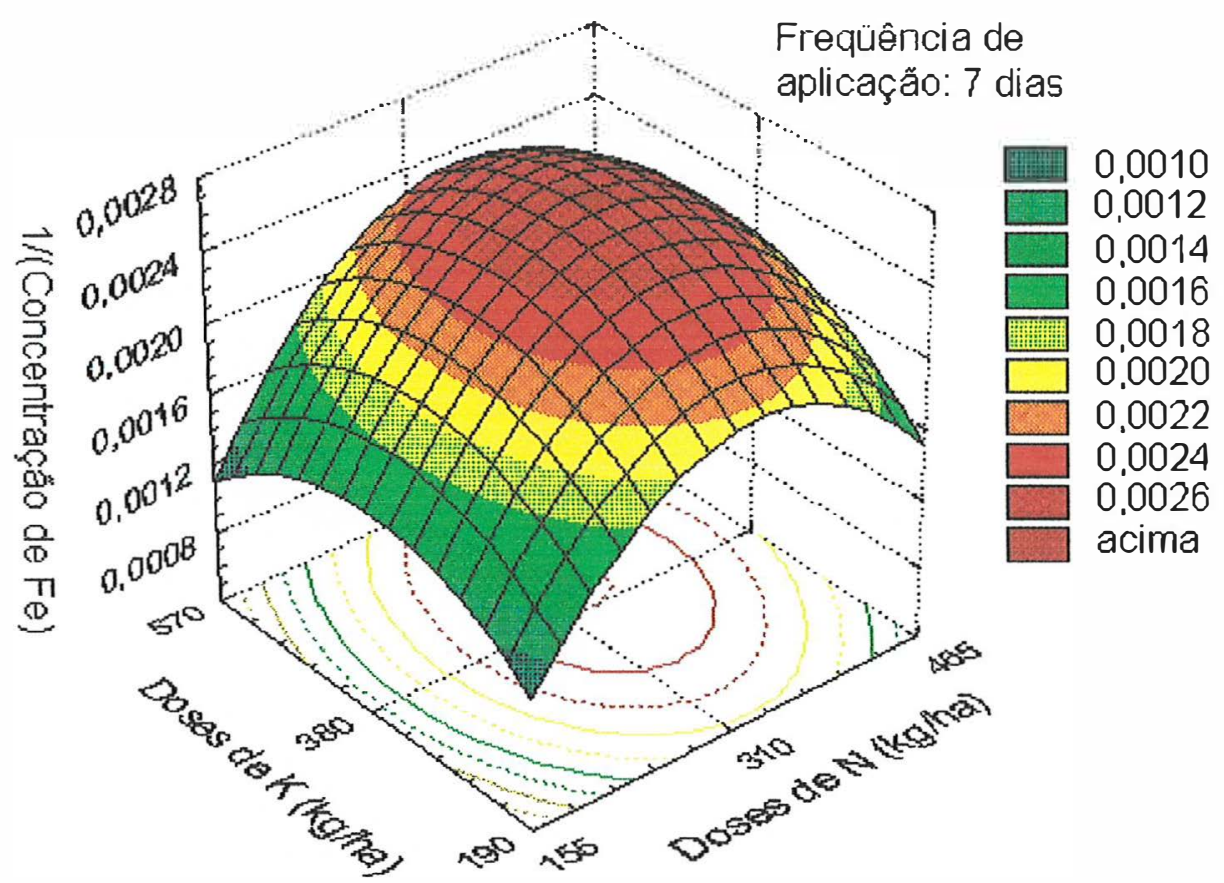

Figura 21: Superfície de resposta das concentrações de ferro nas folhas diagnósticas em função das doses de nitrogênio e potássio $\left(\mathrm{kg} \mathrm{ha}^{-1}\right)$ aplicadas a cada 7 dias. 


\subsubsection{Concentrações de manganês}

$\mathrm{Na}$ Tabela 20 encontra-se a comparação entre as médias das concentrações de manganês nas folhas diagnósticas. As comparações feitas em função das doses de potássio aplicadas mostram que o tratamento 1 diferiu do tratamento 3; o tratamento 5 diferiu do tratamento 4 e 6 ; o tratamento 8 diferiu dos tratamentos 7 e 9; o tratamento 10 diferiu do tratamento 11; os tratamentos 13,14 e 15 diferiram entre si, e o tratamento 18 diferiu dos tratamentos 16 e 17. Nas comparações feitas em função das doses de nitrogênio observa-se que os tratamentos 1,4 e 7 diferiram entre si; os tratamentos 2, 5 e 8 diferiram entre si; os tratamentos 3,6 e 9 diferiram entre si; o tratamento 10 diferiu dos tratamentos 13 e 16; os tratamentos 11,14 e 17 diferiram entre si, e o tratamento 12 diferiu dos tratamentos 15 e 18 . Não houve efeito das freqüências de aplicação apenas entre os tratamentos 4 e 13.

Tabela 20: Comparação entre as médias das concentrações de manganês (mg $\mathrm{kg}^{-1}$ ) nas folhas diagnósticas.

\begin{tabular}{|c|c|c|c|c|c|c|c|c|c|c|}
\hline \multirow{2}{*}{$\begin{array}{c}\text { Freqüências de } \\
\text { aplicação }\end{array}$} & \multirow{2}{*}{$\begin{array}{c}\text { Doses de N } \\
\left(\mathrm{kg} \mathrm{ha}^{-1}\right)\end{array}$} & \multicolumn{9}{|c|}{ Doses de K $\left(\mathrm{kg} \mathrm{ha}^{-1}\right)$} \\
\hline & & 190 & & & 380 & & & 570 & & \\
\hline & 155 & *127,67 & $\mathrm{aA}$ & $\mathrm{T1}$ & *122,50 & $a b A$ & T2 & $\star 107,17$ & bA & T3 \\
\hline \multirow[t]{3}{*}{3 dias } & 310 & 165,22 & $a B$ & T4 & *220,42 & bB & T5 & *179,87 & $\mathrm{aB}$ & T6 \\
\hline & 465 & ${ }^{\star} 257,52$ & $\mathrm{aC}$ & $\mathrm{T7}$ & *190,97 & bC & T8 & ${ }^{\star} 244,42$ & $\mathrm{ac}$ & T9 \\
\hline & 155 & *86,65 & $\mathrm{aA}$ & T10 & $\star 76,10$ & $\mathrm{bA}$ & $\mathrm{T} 11$ & *79,42 & $a b A$ & $\mathrm{~T} 12$ \\
\hline \multirow[t]{2}{*}{7 dias } & 310 & 172,92 & $\mathrm{aB}$ & $\mathrm{T} 13$ & $* 124,77$ & bB & T14 & *98,05 & $\mathrm{cB}$ & $\mathrm{T} 15$ \\
\hline & 465 & *161,42 & $a B$ & T16 & *152,77 & $\mathrm{ac}$ & T17 & *105,55 & bB & T18 \\
\hline
\end{tabular}

Trani \& Raij (1996), recomendam que as concentrações de manganês nas folhas diagnósticas sejam entre 50 e $250 \mathrm{mg} \mathrm{kg-1}$, assim os resultados mostraram-se adequados, apesar da ocorrência de diferenças significativas. Fernandes et al. (1975) obtiveram $302 \mathrm{mg} \mathrm{kg}^{-1}$ de manganês nas folhas. 
As superfícies de resposta das concentrações de manganês nas folhas diagnósticas (valores transformados), em função das doses de nitrogênio e potássio aplicadas via fertirrigação a cada 3 dias (Equação 19) e a cada 7 dias (Equação 20), são representadas nas Figuras 22 e 23. A superfície de resposta dos tratamentos com freqüência de aplicação a cada 3 dias apresentou um ponto de máximo em 5,46, e a superfície de resposta dos tratamentos com freqüência de aplicação a cada 7 dias apresentou um ponto de máximo em 40,93 .

Ln (Concentração de $M n)=4,219432+0,004975 D N-0,000315 D K-$ $0,000005246 D N^{2}+0,000001046 D N D K-0,000000176 D K^{2}$

$\mathrm{R}^{2}=85,90(\%)$ e Prob $>$ F 0,0000

$\operatorname{Ln}$ (Concentração de $M n)=3,517193+0,007930 D N+0,000143 D K-$ $0,000008249 D N^{2}-0,000002873 D N D K-0,000000261 D K^{2}$

$\mathrm{R}^{2}=92,29(\%)$ e Prob > F 0,0000

onde:

Concentração de Mn - Concentração de manganês nas folhas diagnósticas em $\mathrm{mg} \mathrm{kg}^{-1}$.

$\mathrm{DN}$ - Doses de nitrogênio em $\mathrm{kg} \mathrm{ha}^{-1}$, tal que $155 \leq \mathrm{DN} \geq 465$.

DK - Doses de potássio em $\mathrm{kg} \mathrm{ha}^{-1}$, tal que $190 \leq \mathrm{DK} \geq 570$. 


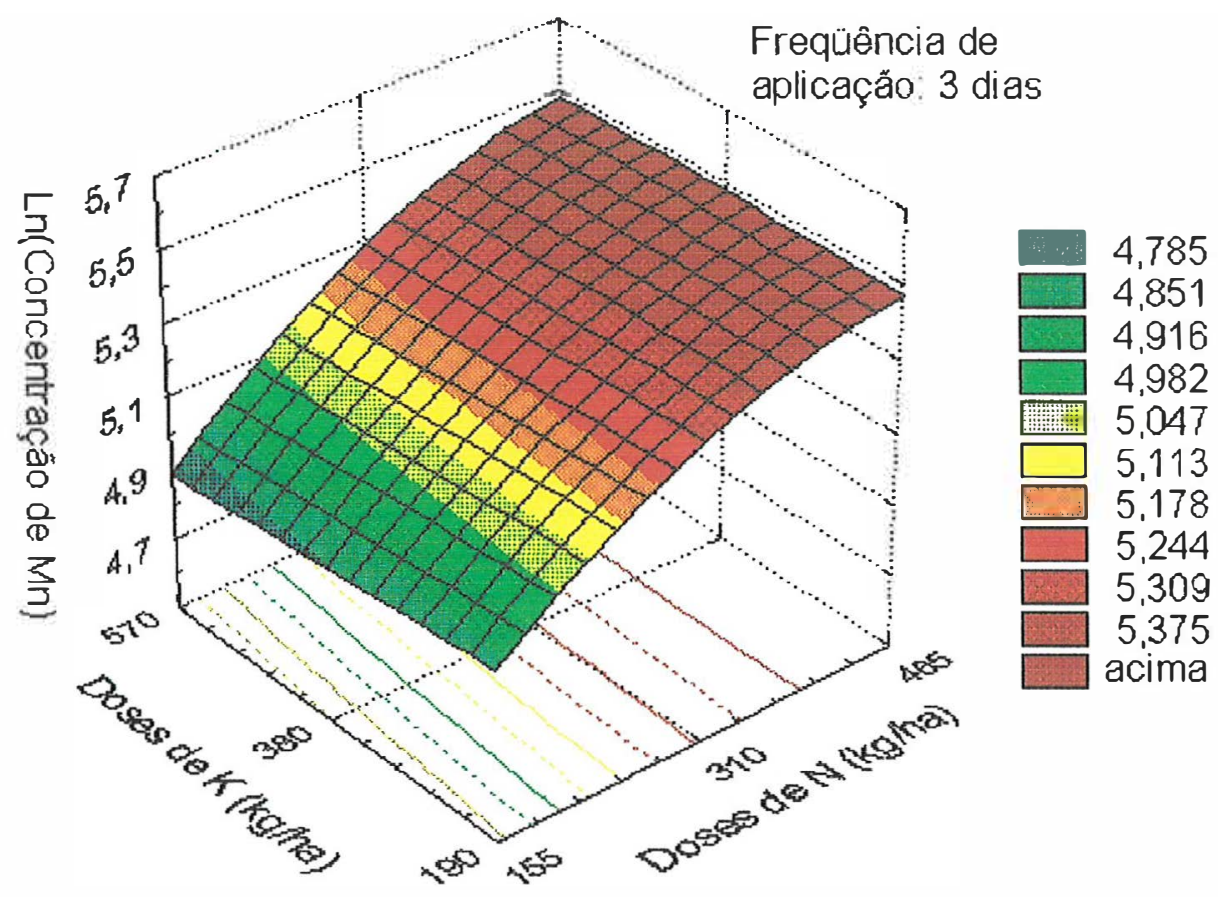

Figura 22: Superfície de resposta das concentrações de manganês nas folhas diagnósticas em função das doses de nitrogênio e potássio $\left(\mathrm{kg} \mathrm{ha}^{-1}\right)$ aplicadas a cada 3 dias.

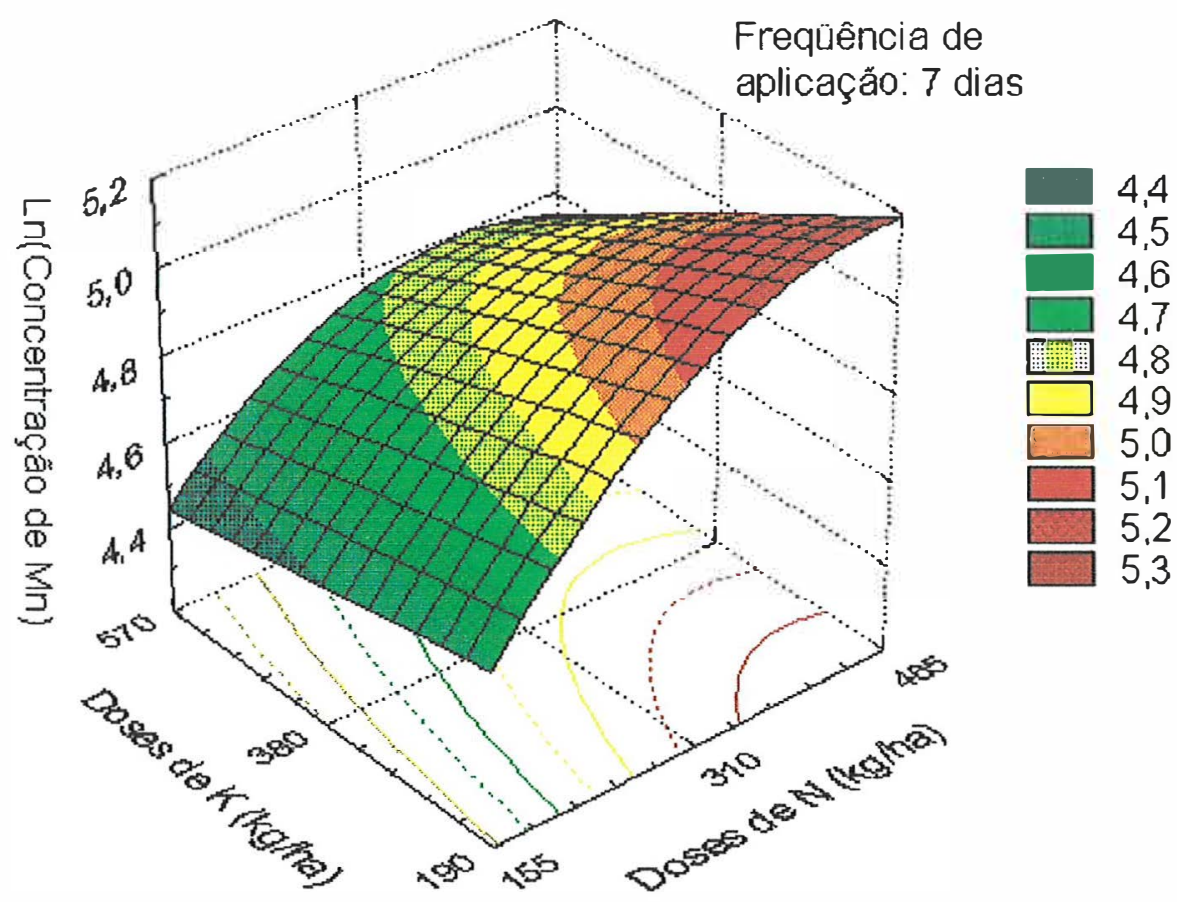

Figura 23: Superfície de resposta das concentrações de manganês nas folhas diagnósticas em função das doses de nitrogênio e potássio $\left(\mathrm{kg} \mathrm{ha}^{-1}\right)$ aplicadas a cada 7 dias. 


\subsubsection{Concentrações de zinco}

A comparação entre as médias das concentrações de zinco nas folhas diagnósticas, apresentada na Tabela 21, mostra que, quando comparadas em função das doses de potássio aplicadas, o tratamento 4 diferiu dos tratamentos 5 e 6; o tratamento 9 diferiu dos tratamentos 7 e 8 , e o tratamento 13 diferiu dos tratamentos 14 e 15. Para as doses de nitrogênio estudadas, o tratamento 4 diferiu dos tratamentos 1 e 7 ; o tratamento 8 diferiu dos tratamentos 2 e 5 ; o tratamento 13 diferiu dos tratamentos 10 e 16, e o tratamento 11 diferiu dos tratamentos 14 e 17. Houve efeito das freqüências de aplicação para todos os tratamentos.

Tabela 21: Comparação das médias das concentrações de zinco $\left(\mathrm{mg} \mathrm{kg}^{-1}\right)$ nas folhas diagnósticas.

\begin{tabular}{|c|c|c|c|c|c|c|c|c|c|c|}
\hline \multirow{3}{*}{$\begin{array}{l}\text { Freqüências de } \\
\text { aplicação }\end{array}$} & \multirow{3}{*}{$\begin{array}{c}\text { Doses de N } \\
\left(\mathrm{kg} \mathrm{ha}^{-1}\right)\end{array}$} & \multicolumn{9}{|c|}{ Doses de K $\left(\mathrm{kg} \mathrm{ha}^{-1}\right)$} \\
\hline & & \multicolumn{3}{|c|}{190} & \multicolumn{3}{|c|}{380} & \multicolumn{3}{|c|}{570} \\
\hline & & $\star 46,45$ & $\mathrm{aA}$ & T1 & *41,45 & $\mathrm{aA}$ & T2 & $\star 39,67$ & $\mathrm{aA}$ & T3 \\
\hline \multirow[t]{3}{*}{3 dias } & 310 & $\star 30,90$ & aB & T4 & *38,20 & bA & T5 & *40,75 & bA & T6 \\
\hline & 465 & *47,35 & aA & $\mathrm{T7}$ & ${ }^{\star} 60,75$ & $\mathrm{aB}$ & T8 & *36,07 & bA & T9 \\
\hline & 155 & *28,65 & $\mathrm{aA}$ & T10 & *24,75 & $\mathrm{aA}$ & T11 & ${ }^{\star} 27,65$ & $\mathrm{aA}$ & T12 \\
\hline \multirow[t]{2}{*}{7 dias } & 310 & *39.57 & aB & T13 & $\star 28,87$ & bB & T14 & $\star 27,02$ & bA & T15 \\
\hline & 465 & $\star 29,20$ & aA & T16 & *29,27 & $\mathrm{aB}$ & T17 & *29,70 & aA & T18 \\
\hline
\end{tabular}

Médias seguidas pela mesma letra, minúscula na linha e maiúscula na coluna, não diferem entre si pelo teste de Tukey a $1 \%$.

Asteriscos indicam diferenças entre as freqüências de aplicação pelo teste de Tukey a $1 \%$.

A recomendação feita por Trani \& Raij (1996) é que a quantidade de zinco nas folhas diagnósticas deve variar entre 30 e $100 \mathrm{mg} \mathrm{kg}^{-1}$. Apesar da análise estatística apresentaar diferenças significativas entre as médias, é importante notar que os resultados mostram que todos os tratamentos com freqüência de aplicação a cada 3 dias (tratamentos 1 ao 9) apresentaram concentrações adequadas, enquanto que para os tratamentos com freqüência de aplicação a cada 7 dias (tratamento 10 ao 18) quase todos apresentaram 
concentraçōes abaixo do adequado. Fernandes et al. (1975) obtiveram $34 \mathrm{mg}$ $\mathrm{kg}^{-1}$ de zinco nas folhas, resultado semelhante aos resultados desse trabalho.

As superfícies de resposta das concentrações de zinco nas folhas diagnósticas (valores transformados), em função das doses de nitrogênio e potássio aplicadas via fertirrigação a cada 3 dias (Equação 21) e a cada 7 dias (Equação 22), são representadas nas Figuras 24 e 25 . A superfície de resposta dos tratamentos com freqüência de aplicação a cada 3 dias apresentou um ponto de sela em 0,025 , e a superfície de resposta dos tratamentos com freqüência de aplicação a cada 7 dias apresentou ponto de sela igual a 0,034.

$1 /($ Concentração de $\mathrm{Zn})=0,022185+0,000114 D N-0,000072033 D K-$ $0,000000209 D N^{2}+0,00000002428 D N D K+0,0000000877 D K^{2}$

$R^{2}=42,12(\%)$ e Prob > F 0,0042

$1 /($ Concentração de $Z n)=0,033476-0,00008889 D N+0,000073961 D K+$ $0,000000138 D N^{2}-0,00000001636 D N D K-0,00000007675 D K^{2}$ $R^{2}=49,49(\%)$ e Prob > F 0,0007

onde:

Concentração de $\mathrm{Zn}$ - Concentração de zinco nas folhas diagnósticas em $\mathrm{mg} \mathrm{kg}^{-1}$.

$\mathrm{DN}$ - Doses de nitrogênio em $\mathrm{kg} \mathrm{ha}^{-1}$, tal que $155 \leq \mathrm{DN} \geq 465$.

DK - Doses de potássio em $\mathrm{kg} \mathrm{ha}^{-1}$, tal que $190 \leq \mathrm{DK} \geq 570$. 


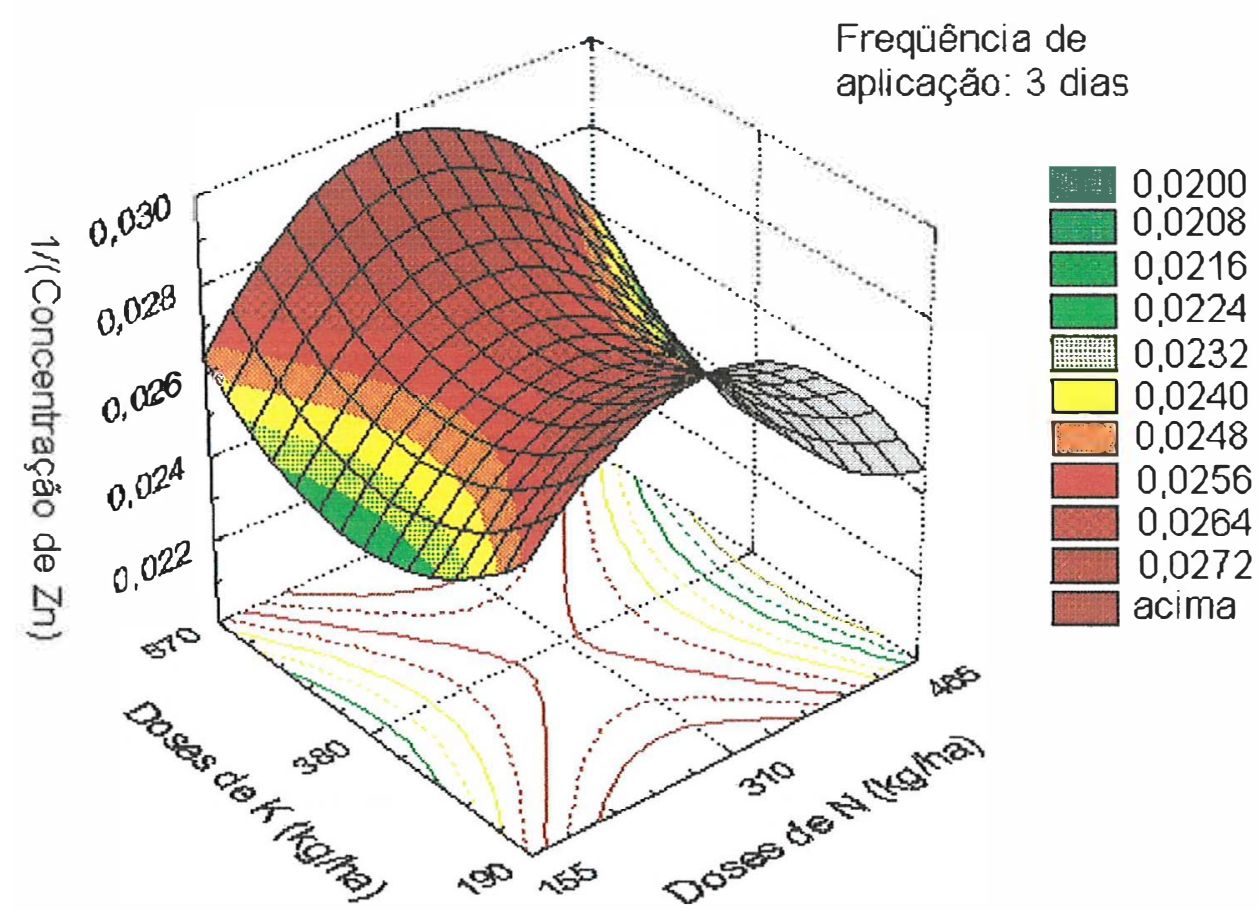

Figura 24: Superfície de resposta das concentrações de zinco nas folhas diagnósticas em função das doses de nitrogênio e potássio $\left(\mathrm{kg} \mathrm{ha}^{-1}\right)$ aplicadas a cada 3 dias.

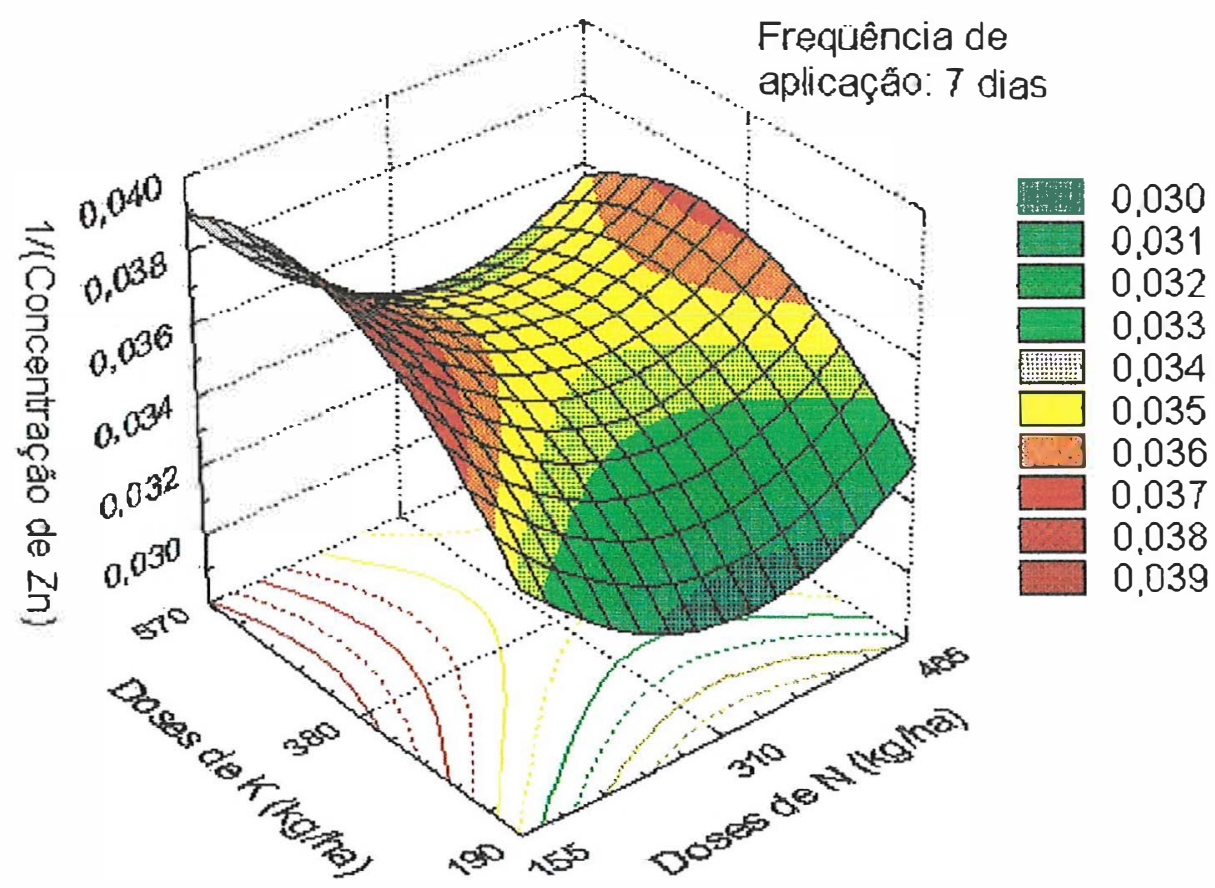

Figura 25: Superfície de resposta das concentrações de zinco nas folhas diagnósticas em função das doses de nitrogênio e potássio $\left(\mathrm{kg} \mathrm{ha}^{-1}\right)$ aplicadas a cada 7 dias. 


\subsubsection{Extração de nutrientes pelos frutos}

\subsubsection{Extração de nitrogênio}

A comparação entre as médias das quantidades de nitrogênio extraído (mg) pelos frutos de duas plantas encontra-se na Tabela 22. Para as doses de potássio aplicadas pode-se observar que o tratamento 14 diferiu dos tratamentos 13 e 15, e o tratamento 17 diferiu do tratamento 18. Fazendo-se comparações em função das doses de nitrogênio aplicadas é possível observarse que $\circ$ tratamento 14 diferiu dos tratamentos 11 e 17 , e o tratamento 15 diferiu do tratamento 18. Considerando-se as freqüências de aplicação, o tratamento 8 diferiu do tratamento 17.

Tabela 22: Comparação entre as médias das quantidades de nitrogênio extraídas $(\mathrm{mg})$ pelos frutos de duas plantas.

\begin{tabular}{|c|c|c|c|c|c|c|}
\hline \multirow{2}{*}{$\begin{array}{l}\text { Freqüências de } \\
\text { aplicação }\end{array}$} & \multirow{2}{*}{$\begin{array}{l}\text { Doses de N } \\
\left(\mathrm{kg} \mathrm{ha}^{-1}\right)\end{array}$} & \multicolumn{5}{|c|}{ Doses de K $\left(\mathrm{kg} \mathrm{ha}^{-1}\right)$} \\
\hline & & 190 & \multicolumn{2}{|c|}{380} & \multicolumn{2}{|l|}{570} \\
\hline & 155 & 2270,26 aA $\mathrm{T1}$ & 1941,77 & $\begin{array}{ll}\mathrm{aA} & \mathrm{T} 2\end{array}$ & 1989,04 aA & T3 \\
\hline \multirow[t]{3}{*}{3 dias } & 310 & 2551,32 aA T4 & 2453,03 & aA T5 & 2600,98 aA & T6 \\
\hline & 465 & 2295,93 aA T7 & *1707,97 & aA T8 & 2104,88 & T9 \\
\hline & 155 & 2622,14 aA T10 & 3070,25 & aA T11 & 2119,76 aАB & T12 \\
\hline \multirow[t]{2}{*}{7 dias } & 310 & 3284,95 aA T13 & 1796,84 & bB T14 & 3148,26 aA & T15 \\
\hline & 465 & 1988,98 abA T16 & *3172,28 & aA T17 & 1627,23 bB & T18 \\
\hline \multicolumn{7}{|c|}{$\begin{array}{l}\text { Médias seguidas pela mesma letra, minúscula na linha e maiúscula na coluna, não diferem entre si } \\
\text { pelo teste de Tukey a } 1 \% \text {. } \\
\text { Asteriscos indicam diferenças entre as frequeências de aplicaçäo pelo teste de Tukey a } 1 \% .\end{array}$} \\
\hline \multicolumn{7}{|c|}{ O tratamento que apresentou menor extração de nitrogênio pelos frutos } \\
\hline \multicolumn{7}{|c|}{ de duas plantas foi o tratamento 18 , com $1627,23 \mathrm{mg}$ e que representa uma } \\
\hline \multicolumn{7}{|c|}{ extração de $13,59 \mathrm{~kg} \mathrm{ha}^{-1}$ de nitrogênio. Esse valor é muito abaixo dos $5656 \mathrm{mg}$} \\
\hline \multicolumn{7}{|c|}{ obtido por Fayad (1998), mas superior aos 664,74 mg obtidos por Fernandes et } \\
\hline
\end{tabular}


A superfície de resposta da extração de nitrogênio pelos frutos de duas plantas (valores transformados), em função das doses de nitrogênio e potássio aplicadas via fertirrigação a cada 3 dias (Equação 23), é representada pela Figura 26. A superfície de resposta apresentou um ponto de sela em 0,021.

Ln(Quant. de $N)=0,022662-0,000052658 D N+0,000032523 D K+$ $0,000000088 D N^{2}-0,00000000289 D N D K-0,0000000394 D K^{2}$ $\mathrm{R}^{2}=33,72(\%)$ e Prob $>\mathrm{F} 0,0241$

onde:

Quant. de N - Quantidade de nitrogênio extraído $(\mathrm{mg})$ pelos frutos de duas plantas.

$\mathrm{DN}$ - Doses de nitrogênio em $\mathrm{kg} \mathrm{ha}^{-1}$, tal que $155 \leq \mathrm{DN} \geq 465$.

DK - Doses de potássio em $\mathrm{kg} \mathrm{ha}^{-1}$, tal que $190 \leq \mathrm{DK} \geq 570$.

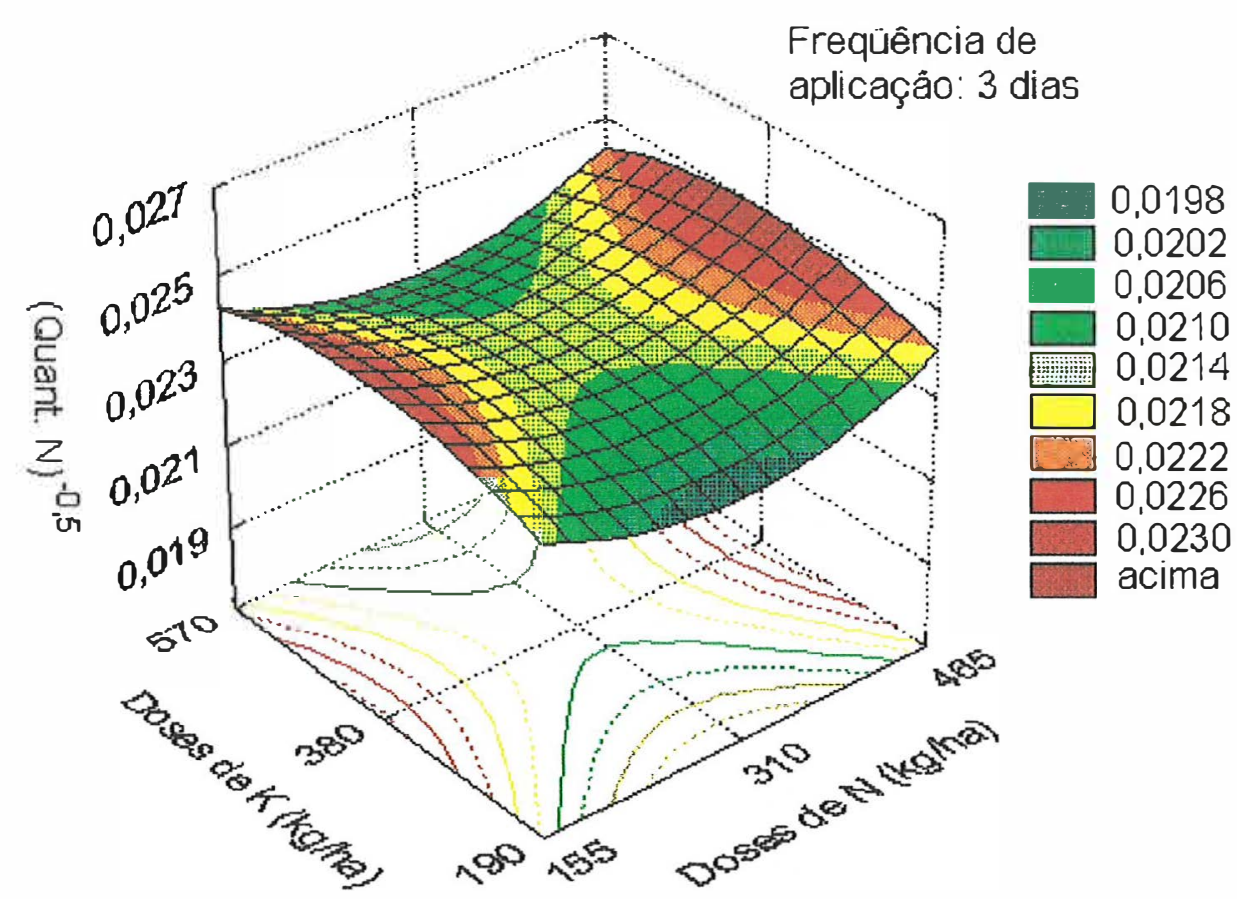

Figura 26: Superfície de resposta das extrações de nitrogênio pelos frutos de duas plantas em função das doses de nitrogênio e de potássio $\left(\mathrm{kg} \mathrm{ha}^{-1}\right)$ aplicadas a cada 3 dias. 


\subsubsection{Extração de fósforo}

A Tabela 23 mostra a comparação entre as médias das quantidades de fósforo extraído $(\mathrm{mg})$ pelos frutos de duas plantas. Para as doses de potássio, pode-se observar que o tratamento 14 diferiu dos tratamentos 13 e 15 , e o tratamento 17 diferiu do tratamento 18. Comparando-se as doses de nitrogênio, observa-se que o tratamento 13 diferiu do tratamento 16; o tratamento 14 diferiu do tratamento 17 , e o tratamento 15 diferiu do tratamento 18. Para as freqüências de aplicação, o tratamento 8 diferiu do tratamento 17.

Tabela 23: Comparação entre as médias das quantidades de fósforo extraídas (mg) pelos frutos de duas plantas.

\begin{tabular}{|c|c|c|c|c|c|c|}
\hline \multirow{3}{*}{$\begin{array}{c}\text { Freqüências de } \\
\text { aplicação } \\
\end{array}$} & \multirow{3}{*}{$\begin{array}{c}\text { Doses de N } \\
\left(\mathrm{kg} \mathrm{ha}^{-1}\right)\end{array}$} & \multicolumn{5}{|c|}{ Doses de K $\left(\mathrm{kg} \mathrm{ha}^{-1}\right)$} \\
\hline & & 190 & \multicolumn{2}{|c|}{380} & \multicolumn{2}{|l|}{570} \\
\hline & & 312,18 aA $\mathrm{T1}$ & 270,84 & aA T2 & 294,26 aA & T3 \\
\hline \multirow[t]{3}{*}{3 dias } & 310 & 389,92 aA T4 & 288,94 & aA T5 & 330,98 aA & T6 \\
\hline & 465 & 327,35 aA T7 & *226,54 & aA T8 & 264,95 aA & T9 \\
\hline & 155 & 362,36 aAB T10 & 376,70 & aAB T11 & 248,60 aAB & T12 \\
\hline \multirow[t]{2}{*}{7 dias } & 310 & 426,16 aA T13 & 226,64 & bA T14 & 404,10 aA & T15 \\
\hline & 465 & 245,90 abB T16 & *408,34 & aB $\quad \mathrm{T} 17$ & 205,73 bB & T18 \\
\hline
\end{tabular}

A menor extração de fósforo ocorreu no tratamento 18. A quantidade extraída por duas plantas foi de $205,73 \mathrm{mg}$, o que corresponde a uma extração pelos frutos de $1,71 \mathrm{~kg} \mathrm{ha}^{-1}$ de fósforo. Essa quantidade de fósforo extraída pelos frutos é muito baixa quando comparada aos valores de $869 \mathrm{mg}$ por planta obtidos por Fayad (1998) e de 489,92 mg obtidos por Rodrigues (1996).

A superfície de resposta das extrações de fósforo pelos frutos de duas plantas (valores transformados), em função das doses de nitrogênio e potássio aplicadas via fertirrigação a cada 3 dias (Equação 24), é representada na Figura 27. A superfície de resposta apresentou um ponto de sela em 5,66. 
$\operatorname{Ln}($ Quant. de $P)=5,837417+0,004668 D N-0,004111 D K-0,000007061 D N^{2}-$ $0,000001463 D N D K+0,000005501 D K^{2}$

$\mathrm{R}^{2}=49,11(\%)$ e Prob $>\mathrm{F} 0,0010$

onde:

Quant. de P - Quantidade de fósforo extraído $(\mathrm{mg})$ pelos frutos de duas plantas.

$\mathrm{DN}$ - Doses de nitrogênio em $\mathrm{kg} \mathrm{ha}^{-1}$, tal que $155 \leq \mathrm{DN} \geq 465$.

DK - Doses de potássio em $\mathrm{kg} \mathrm{ha}^{-1}$, tal que $190 \leq \mathrm{DK} \geq 570$.

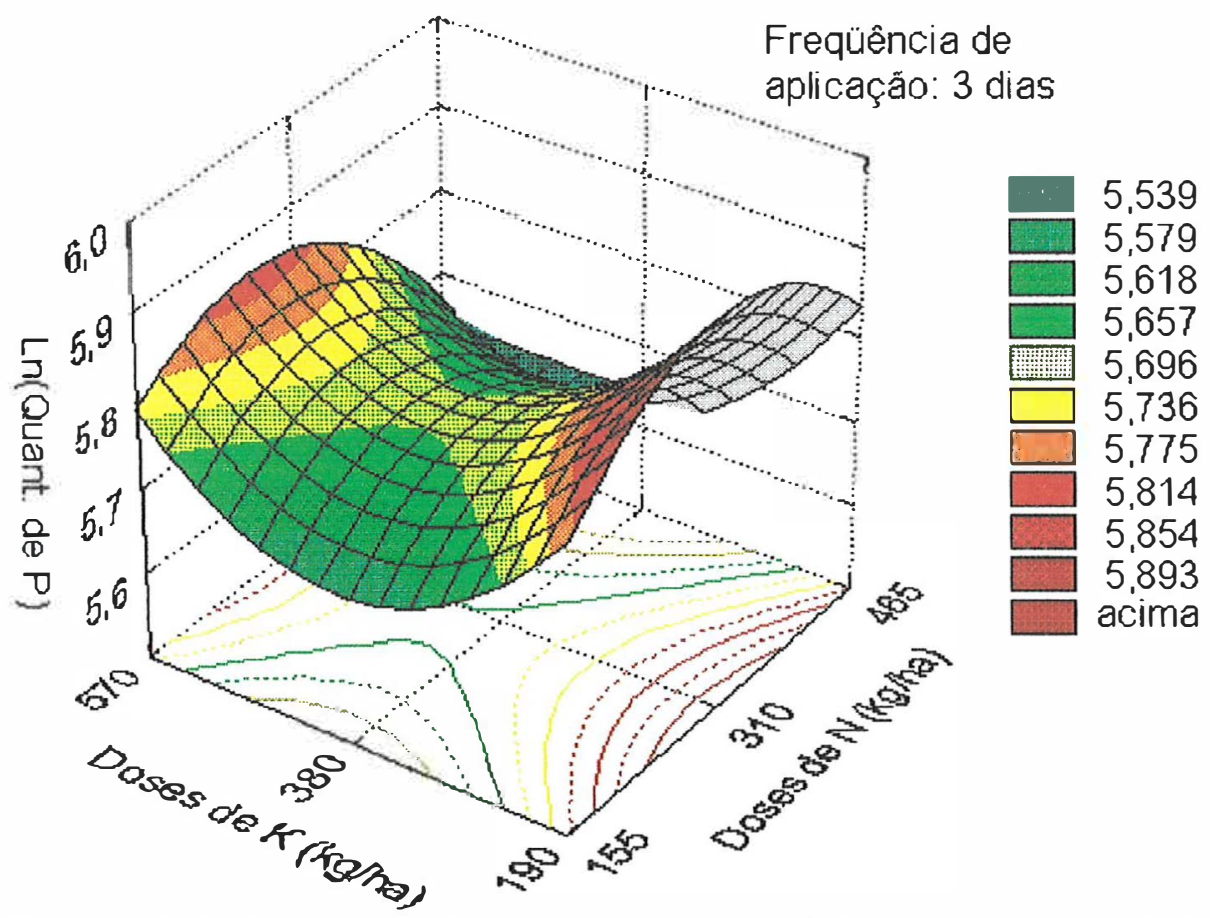

Figura 27: Superfície de resposta das quantidades de fósforo extraído pelos frutos de duas plantas em função das doses de nitrogênio e potássio $\left(\mathrm{kg} \mathrm{ha}^{-1}\right)$ aplicadas a cada 3 dias.

\subsubsection{Extração de potássio}

A comparação entre as médias das quantidades de potássio extraído (mg) pelos frutos de duas plantas encontra-se na Tabela 24. Para as doses de nitrogênio aplicadas, observa-se que o tratamento 14 diferiu dos tratamentos 13 e 15, e o tratamento 17 diferiu do tratamento 18. Para as doses de nitrogênio 
aplicadas, é possível notar que o tratamento 13 diferiu do tratamento 16 ; 0 tratamento 14 diferiu do tratamento 17 , e o tratamento 15 diferiu do tratamento 18. Considerando-se as freqüências de aplicação, o tratamento 8 diferiu do tratamento 17.

Tabela 24: Comparação entre as médias das quantidades de potássio extraídas (mg) pelos frutos de duas plantas.

\begin{tabular}{|c|c|c|c|c|c|c|c|}
\hline \multirow{2}{*}{$\begin{array}{c}\text { Freqüências de } \\
\text { aplicação }\end{array}$} & \multirow{2}{*}{$\begin{array}{c}\text { Doses de } N \\
\left(\mathrm{~kg} \mathrm{ha}^{-1}\right)\end{array}$} & \multicolumn{6}{|c|}{ Doses de K $\left(\mathrm{kg} \mathrm{ha}^{-1}\right)$} \\
\hline & & \multicolumn{2}{|l|}{190} & \multicolumn{2}{|c|}{380} & \multicolumn{2}{|l|}{570} \\
\hline & 155 & 2661,36 aA & T1 & 2236,17 aA & T2 & 2351,66 aA & T3 \\
\hline \multirow[t]{3}{*}{3 dias } & 310 & 2727,98 aA & T4 & 2548,93 aA & T5 & 2735,52 aA & T6 \\
\hline & 465 & $2642,10 \mathrm{aA}$ & T7 & *1717,27 aA & T8 & 2283,25 aA & T9 \\
\hline & 155 & $2865,22 \mathrm{aAB}$ & T10 & $3263,55 \mathrm{aAB}$ & T11 & 2073,75 aAB & T12 \\
\hline \multirow[t]{2}{*}{7 dias } & 310 & 3724,61 aA & T13 & 1837,12 bA & T14 & 3532,54 aA & T15 \\
\hline & 465 & $2079,24 a b B$ & T16 & *3653,97 aB & T17 & 1690,10 bB & T18 \\
\hline
\end{tabular}

Das diferenças significativas ocorridas, é possivel observar que a menor extração de potássio ocorreu no tratamento 18 , sendo a quantidade extraída pelos frutos de duas plantas igual a $1690,10 \mathrm{mg}$. Tal valor corresponde a uma extração pelos frutos de $14,08 \mathrm{~kg} \mathrm{ha}^{-1}$ de potássio. Esse resultado foi inferior de Fayad (1998), que obteve uma extração pelos frutos igual a $10001 \mathrm{mg}$ de potássio por planta e por Rodrigues (1996), cujo valor obtido foi de $11329,92 \mathrm{mg}$ de potássio por planta.

\subsubsection{Extração de cálcio}

A Tabela 25 contém as médias das quantidades cálcio extraídas ( $\mathrm{mg}$ ) pelos frutos de duas plantas. 0 tratamento 17 diferiu do tratamento 18 , quando comparadas as doses de potássio. Para as doses de nitrogênio e as freqüências de aplicação não houve efeito dos tratamentos. 
Tabela 25: Comparação entre as médias das quantidades de cálcio extraídoas $(\mathrm{mg})$ pelos frutos de duas plantas.

\begin{tabular}{|c|c|c|c|c|c|c|c|c|c|}
\hline \multirow{3}{*}{$\begin{array}{c}\text { Freqüências de } \\
\text { aplicação }\end{array}$} & \multirow{3}{*}{$\begin{array}{c}\begin{array}{c}\text { Doses de N } \\
\left(\mathrm{kg} \mathrm{ha}^{-1}\right)\end{array} \\
155\end{array}$} & \multicolumn{8}{|c|}{ Doses de $\mathrm{K}\left(\mathrm{kg} \mathrm{ha}^{-1}\right)$} \\
\hline & & \multicolumn{2}{|c|}{190} & \multicolumn{3}{|c|}{380} & \multicolumn{3}{|c|}{570} \\
\hline & & 89,70 & $\mathrm{aA}$ T1 & 69,32 & $\mathrm{aA}$ & T2 & 88,44 & $\mathrm{aA}$ & T3 \\
\hline \multirow[t]{3}{*}{3 dias } & 310 & 99,05 & aA T4 & 86,92 & $a A$ & T5 & 85,47 & $\mathrm{aA}$ & T6 \\
\hline & 465 & 108,69 & aA T7 & 65,92 & $a A$ & T8 & 84,36 & $\mathrm{aA}$ & T9 \\
\hline & 155 & 88,88 & aA T10 & 91,61 & $a A$ & T11 & 76,10 & $\mathrm{aA}$ & $\mathrm{T} 12$ \\
\hline \multirow[t]{2}{*}{7 dias } & 310 & 148,27 & aA T13 & 74,14 & $\mathrm{aA}$ & T14 & 105,46 & $\mathrm{aA}$ & T15 \\
\hline & 465 & 95,24 & abA T16 & 120,17 & aA & T17 & 56,09 & bA & T18 \\
\hline
\end{tabular}

Médias seguidas pela mesma letra, minúscula na linha e maiüscula na coluna, não diferem entre si pelo teste de Tukey a $1 \%$.

Asteriscos indicam diferenças entre as frequêencias de aplicação pelo teste de Tukey a 1\%.

A menor extração de cálcio pelos frutos de duas plantas foi de $56,09 \mathrm{mg}$, que ocorreu no tratamento 18. Esse valor corresponde a uma extração de 0,46 $\mathrm{kg} \mathrm{ha}^{-1}$. O resultado obtido é maior ao de Fernandes et al. (1975), que observaram uma extração de cálcio pelos frutos igual a $38,08 \mathrm{mg}$ e muito inferior ao de Fayad (1998), cujo resultado foi a extração de 494 mg.

\subsubsection{Extração de magnésio}

A comparação entre as médias das quantidades de magnésio extraídas (mg) pelos frutos de duas plantas encontra-se na Tabela 26. Comparando-se em função das doses de potássio, pode-se observar que o tratamento 14 diferiu do tratamento 15, e o tratamento 17 diferiu do tratamento 18. Para as doses de nitrogênio, os tratamentos 15 e 18 diferiram entre si. Considerando-se as freqüências de aplicação, o tratamento 8 diferiu do tratamento 17. 
Tabela 26: Comparação entre as médias das quantidades de magnésio extraídas (mg) pelos frutos de duas plantas.

\begin{tabular}{|c|c|c|c|c|c|}
\hline \multirow{2}{*}{$\begin{array}{c}\text { Freqüências de } \\
\text { aplicação }\end{array}$} & \multirow{2}{*}{$\begin{array}{c}\text { Doses de N } \\
\left(\mathrm{kg} \mathrm{ha}^{-1}\right)\end{array}$} & \multicolumn{4}{|c|}{ Doses de K $\left(\mathrm{kg} \mathrm{ha}^{-1}\right)$} \\
\hline & & 190 & \multicolumn{2}{|c|}{380} & 570 \\
\hline & 155 & 118,89 aA $\mathrm{T1}$ & 99,54 aA & T2 & 103,92 aA T3 \\
\hline \multirow[t]{3}{*}{3 dias } & 310 & 124,11 aA T4 & 116,88 aA & T5 & 124,24 aA T6 \\
\hline & 465 & 116,38 aA T7 & *72,88 aA & T8 & 104,63 aA T9 \\
\hline & 155 & 129,06 aA T10 & 134,56 aA & T11 & 100,40 aАВ T12 \\
\hline \multirow[t]{2}{*}{7 dias } & 310 & 163,29 aA T13 & 88,16 bA & T14 & 152,44 abA T15 \\
\hline & 465 & 94,64 abA T16 & *151,88 aA & T17 & 76,66 bB T18 \\
\hline
\end{tabular}

Médias seguidas pela mesma letra, minúscula na linha e maiúscula na coluna, nāo diferem entre si pelo teste de Tukey a $1 \%$.

Asteriscos indicam diferenças entre as freqüências de aplicação pelo teste de Tukey a $1 \%$.

O tratamento 18 apresentou a menor extração de magnésio pelos frutos de duas plantas, sendo igual a 76,66mg, correspondendo a uma extração pelos frutos de $0,63 \mathrm{~kg} \mathrm{ha}^{-1}$. Fernandes et al. (1975) obtiveram uma extração de magnésio pelos frutos de uma planta igual a $62,63 \mathrm{mg}$, valor este semelhante ao apresentado nesta pesquisa.

\subsubsection{Extração de enxofre}

A comparação entre as médias das quantidades de enxofre extraídas (mg) pelos frutos de duas plantas, presente na Tabela 27, mostra que o tratamento 14 diferiu dos tratamentos 13 e 15 , e os tratamentos 17 e 18 diferram entre si, quando comparada as doses de potássio. Para comparações feitas em função das doses de nitrogênio, observa-se que o tratamento 14 diferiu do tratamento 17 , e o tratamento 15 diferiue do tratamento 18. Para as freqüências de aplicação houve diferença entre os tratamentos 8 e 17. 
Tabela 27: Comparação entre as médias das quantidades de enxofre extraído (mg) pelos frutos de duas plantas.

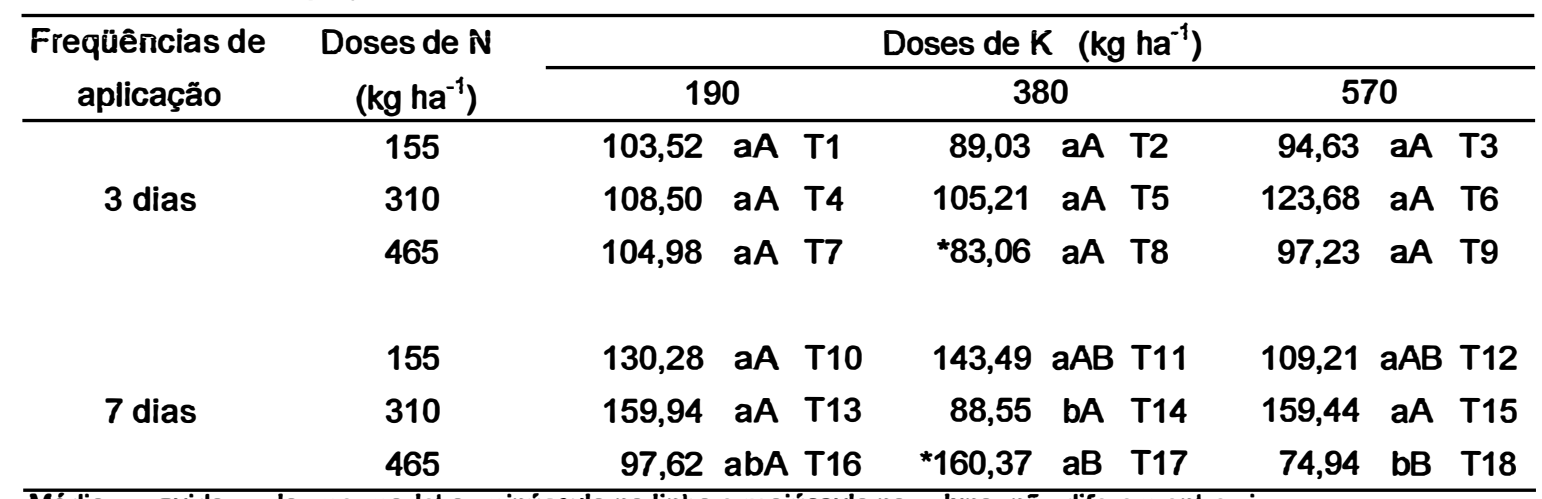

Médias seguidas pela mesma letra, minúscula na linha e maiúscula na coluna, não diferem entre si pelo teste de Tukey a $1 \%$.

Asteriscos indicam diferenças entre as freqüências de aplicação pelo teste de Tukey a 1\%.

O tratamento 18 apresentou a menor extração de enxofre pelos frutos de duas plantas, valor esse igual a 74,94mg, que corresponde a uma extração de $0,62 \mathrm{~kg} \mathrm{ha}^{-1}$. A extração observada por Rodrigues (1996), foi de $350,08 \mathrm{mg}$ de enxofre por planta, muito acima dos resultados deste trabalho. Fernandes et al. (1975) observaram uma extração de $39,65 \mathrm{mg}$ de enxofre pelos frutos de uma planta, resultado que se apresenta muito abaixo do valor aqui apresentado.

\subsubsection{Extração de boro}

A Tabela 28 contém a comparação entre as médias das quantidades de boro extraídas pelos frutos de duas plantas, onde é possivel observar que não há diferença entre os tratamentos. 
Tabela 28: Comparação entre as médias das quantidades de boro extraídas $(\mu \mathrm{g})$ pelos frutos de duas plantas.

\begin{tabular}{|c|c|c|c|c|c|c|c|c|c|c|}
\hline \multirow{2}{*}{$\begin{array}{c}\text { Freqüências de } \\
\text { aplicação }\end{array}$} & \multirow{2}{*}{$\begin{array}{c}\text { Doses de } N \\
\left(\mathrm{~kg} \mathrm{ha}^{-1}\right)\end{array}$} & \multicolumn{9}{|c|}{ Doses de $\mathrm{K}\left(\mathrm{kg} \mathrm{ha}^{-1}\right)$} \\
\hline & & \multicolumn{3}{|c|}{190} & \multicolumn{3}{|c|}{380} & \multicolumn{3}{|c|}{570} \\
\hline & 155 & 776,75 & $\mathrm{aA}$ & $\mathrm{T} 1$ & 780,29 & $\mathrm{aA}$ & T2 & 580,33 & $\mathrm{aA}$ & T3 \\
\hline \multirow[t]{3}{*}{3 dias } & 310 & 621,01 & $\mathrm{aA}$ & T4 & 693,81 & $\mathrm{aA}$ & T5 & 873,66 & $\mathrm{aA}$ & T6 \\
\hline & 465 & 1405,71 & $\mathrm{aA}$ & T7 & 689,68 & $\mathrm{aA}$ & T8 & 984,43 & $\mathrm{aA}$ & T9 \\
\hline & 155 & 1135,98 & $\mathrm{aA}$ & T10 & 1348,85 & $\mathrm{aA}$ & T11 & 538,35 & $\mathrm{aA}$ & T12 \\
\hline \multirow[t]{2}{*}{7 dias } & 310 & 1000,84 & $\mathrm{aA}$ & T13 & 626,43 & $\mathrm{aA}$ & T14 & 772,65 & $\mathrm{aA}$ & T15 \\
\hline & 465 & 647,75 & $a A$ & T16 & 767,64 & $\mathrm{aA}$ & T17 & 855,62 & $a A$ & T18 \\
\hline
\end{tabular}

Médias seguidas pela mesma letra, minúscula na linha e maiúscula na coluna, não diferem entre si pelo teste de Tukey a $1 \%$.

Asteriscos indicam diferenças entre as frequiências de aplicação pelo teste de Tukey a 1\%.

Obteve-se maior extração de boro pelo fruto de duas plantas no tratamento 7 , sendo a quantidade $1405,71 \mu \mathrm{g}$, o que equivale a uma extração de $5,86 \mathrm{~g} \mathrm{ha}^{-1}$. Fernandes et al. (1975) obtiveram resultado semelhante, igual a $520 \mu \mathrm{g}$ de boro extraído pelos frutos de uma planta.

\subsubsection{Extração de cobre}

Não houve diferenças entre as médias das quantidades de cobre extraídas pelos frutos de duas plantas, conforme mostra a Tabela 29.

Tabela 29: Comparação entre as médias das quantidades de cobre extraídas $(\mu \mathrm{g})$ pelos frutos de duas plantas.

\begin{tabular}{|c|c|c|c|c|c|c|c|c|c|c|}
\hline \multirow{2}{*}{$\begin{array}{c}\text { Freqüências de } \\
\text { aplicação } \\
\end{array}$} & \multirow{3}{*}{$\begin{array}{c}\text { Doses de N } \\
\left(\mathrm{kg} \mathrm{ha}^{-1}\right)\end{array}$} & \multicolumn{9}{|c|}{ Doses de $\mathrm{K}\left(\mathrm{kg} \mathrm{ha}^{-1}\right)$} \\
\hline & & \multicolumn{3}{|c|}{190} & \multicolumn{3}{|c|}{380} & \multicolumn{3}{|c|}{570} \\
\hline & & 897,05 & $\mathrm{aA}$ & T1 & 1365,72 & $\mathrm{aA}$ & T2 & 848,95 & $\mathrm{aA}$ & T3 \\
\hline \multirow[t]{3}{*}{3 dias } & 310 & 1122,45 & $\mathrm{aA}$ & T4 & 1055,57 & aA & T5 & 1219,08 & $\mathrm{aA}$ & T6 \\
\hline & 465 & 1202,94 & $\mathrm{aA}$ & $\mathrm{T7}$ & 840,35 & aA & T8 & 1129,83 & $\mathrm{aA}$ & T9 \\
\hline & 155 & 1185,65 & $\mathrm{aA}$ & T10 & 1786,21 & $\mathrm{aA}$ & T11 & 1075,51 & $\mathrm{aA}$ & $\mathrm{T} 12$ \\
\hline \multirow[t]{2}{*}{7 dias } & 310 & 1831,90 & aA & T13 & 982,60 & $\mathrm{aA}$ & T14 & 3073,09 & $\mathrm{aA}$ & T15 \\
\hline & 465 & 1804,65 & $\mathrm{aA}$ & T16 & 1797,49 & aA & T17 & 927,09 & $\mathrm{aA}$ & T18 \\
\hline
\end{tabular}

Médias seguidas pela mesma letra, minúscula na linha e maiúscula na coluna, nāo diferem entre si pelo teste de Tukey a $1 \%$.

Asteriscos indicam diferenças entre as freqüências de aplicação pelo teste de Tukey a 1\%. 
A maior extração de cobre pelos frutos de duas plantas foi observada no tratamento 15 , de $3073,09 \mu \mathrm{g}$, sendo a extração total pelos frutos é igual a $12,80 \mathrm{~g} \mathrm{ha}^{-1}$. Esse resultado é inferior ao obtido por Fayad (1998), que obteve $3871 \mu \mathrm{g}$ extraídos pelos frutos de duas plantas.

\subsubsection{Extração de ferro}

A Tabela 30 mostra que não houve efeito de tratamentos para as quantidades de ferro extraído pelos frutos de duas plantas.

Tabela 30: Comparação entre as médias da quantidade de ferro extraídas ( $\mu \mathrm{g})$ pelos frutos de duas plantas.

\begin{tabular}{|c|c|c|c|c|c|c|c|c|c|c|}
\hline \multirow{2}{*}{$\begin{array}{c}\text { Freqüências de } \\
\text { aplicação }\end{array}$} & \multirow{2}{*}{$\begin{array}{c}\text { Doses de } N \\
\left(\mathrm{~kg} \mathrm{ha}^{-1}\right)\end{array}$} & \multicolumn{9}{|c|}{ Doses de K $\left(\mathrm{kg} \mathrm{ha}^{-1}\right)$} \\
\hline & & \multicolumn{3}{|c|}{190} & \multicolumn{3}{|c|}{380} & \multicolumn{3}{|c|}{570} \\
\hline & 155 & 16611,44 & $\mathrm{aA}$ & T1 & 10243,78 & $\mathrm{aA}$ & T2 & 11935,14 & $\mathrm{aA}$ & T3 \\
\hline \multirow[t]{3}{*}{3 dias } & 310 & 13720,01 & $\mathrm{aA}$ & T4 & 14316,27 & $a A$ & T5 & 16173,49 & $\mathrm{aA}$ & T6 \\
\hline & 465 & 16036,46 & $\mathrm{aA}$ & $\mathrm{T7}$ & 9773,07 & $\mathrm{aA}$ & T8 & 8141,06 & $\mathrm{aA}$ & T9 \\
\hline & 155 & 9080,14 & $\mathrm{aA}$ & T10 & 11608,95 & $\mathrm{aA}$ & T11 & 18698,15 & $\mathrm{aA}$ & $\mathrm{T} 12$ \\
\hline \multirow[t]{2}{*}{7 dias } & 310 & 13226,04 & $\mathbf{a A}$ & T13 & 9702,54 & $\mathrm{aA}$ & T14 & 8840,70 & $\mathrm{aA}$ & T15 \\
\hline & 465 & 19955,22 & $\mathrm{aA}$ & T16 & 8953,35 & $a A$ & T17 & 14756,12 & $\mathrm{aA}$ & T18 \\
\hline
\end{tabular}

Médias seguidas pela mesma letra, minúscula na linha e maiúscula na coluna, nảo diferem entre si pelo teste de Tukey a $1 \%$.

Asteriscos indicam diferenças entre as freqüências de aplicação pelo teste de Tukey a $1 \%$.

O tratamento 16 apresentou a maior extração de ferro por duas plantas, $19955,22 \mu \mathrm{g}$, que equivale a $83,14 \mathrm{~g} \mathrm{ha} \mathrm{g}^{-1}$. O valor obtido é intermediário aos observados por Fayad (1998), de $22592 \mu \mathrm{g}$ por planta e o por Fernandes et al.

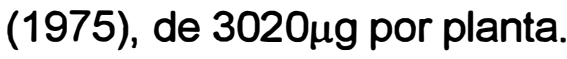

A superfície de resposta das quantidades de ferro extraídas pelos frutos de duas plantas (valores transformados), em função das doses de nitrogênio e potássio aplicadas via fertirrigação a cada 7 dias (Equação 25), é representada na Figura 28. A superfície de resposta apresentou ponto de mínimo em 9,04. 
Ln(Quant. de Fe $)=9,982631-0,001884 D N-0,003620 D K+0,000008425 D N^{2}$

- 0,000007870 DN DK + 0,000007939DK

$\mathrm{R}^{2}=38,39(\%)$ e Prob $>\mathrm{F} 0,0095$

onde:

Quant. de Fe - Quantidade de ferro extraído $(\mu \mathrm{g})$ pelos frutos de duas plantas.

$\mathrm{DN}$ - Doses de nitrogênio em $\mathrm{kg} \mathrm{ha}^{-1}$, tal que $155 \leq \mathrm{DN} \geq 465$.

DK - Doses de potássio em $\mathrm{kg} \mathrm{ha}^{-1}$, tal que $190 \leq \mathrm{DK} \geq 570$.

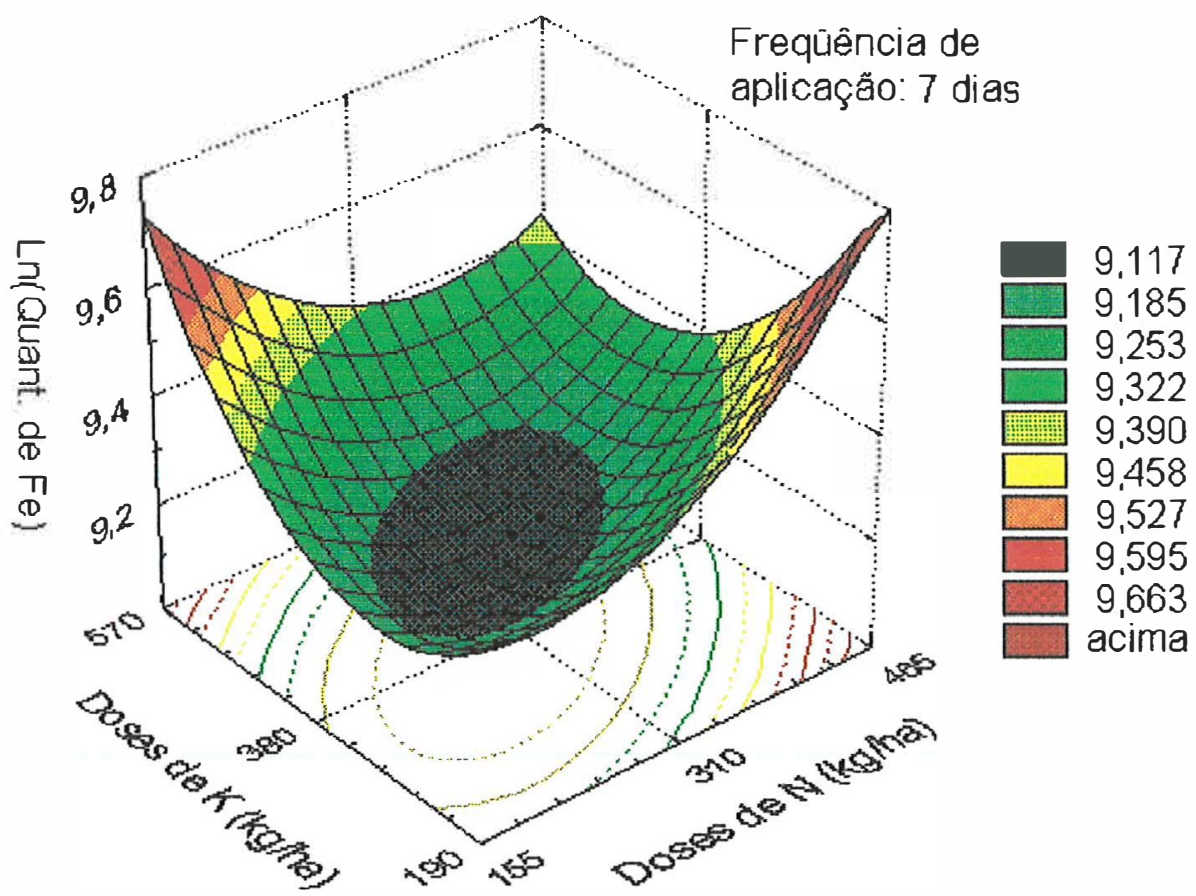

Figura 28: Superfície de resposta das quantidades de ferro extraídas pelos frutos de duas plantas em função das doses de nitrogênio e potássio $\left(\mathrm{kg} \mathrm{ha}^{-1}\right)$ aplicadas a cada 7 dias.

\subsubsection{Extração de manganês}

Não houve efeito dos tratamentos sobre as quantidades de manganês extraídas pelos frutos de duas plantas, como mostra a Tabela 31. 
Tabela 31: Comparação entre as médias da quantidade de manganês extraídas $(\mu \mathrm{g})$ pelos frutos de duas plantas.

\begin{tabular}{|c|c|c|c|c|c|c|c|c|c|c|}
\hline \multirow{2}{*}{$\begin{array}{l}\text { Freqüências de } \\
\text { aplicação }\end{array}$} & \multirow{2}{*}{$\begin{array}{c}\text { Doses de N } \\
\left(\mathrm{kg} \mathrm{ha}^{-1}\right)\end{array}$} & \multicolumn{9}{|c|}{ Doses de K $\left(\mathrm{kg} \mathrm{ha}^{-1}\right)$} \\
\hline & & \multicolumn{3}{|c|}{190} & \multicolumn{3}{|c|}{380} & \multicolumn{3}{|c|}{570} \\
\hline & 155 & 1561,47 & $\mathrm{aA}$ & $\mathrm{T1}$ & 1099,33 & $a A$ & $\mathrm{~T} 2$ & 1068,76 & $\mathrm{aA}$ & T3 \\
\hline \multirow[t]{3}{*}{3 dias } & 310 & 1462,84 & aA & T4 & 1476,33 & $\mathrm{aA}$ & T5 & 1462,49 & $\mathrm{aA}$ & T6 \\
\hline & 465 & 1664,15 & $\mathrm{aA}$ & $\mathrm{T7}$ & 989,09 & $a A$ & T8 & 1306,64 & $\mathrm{aA}$ & T9 \\
\hline & 155 & 1355,60 & $a A$ & T10 & 1428,19 & $\mathrm{aA}$ & T11 & 1267,05 & $a A$ & $\mathrm{~T} 12$ \\
\hline \multirow[t]{2}{*}{7 dias } & 310 & 1801,90 & $\mathrm{aA}$ & T13 & 1244,95 & $\mathrm{aA}$ & $\mathrm{T} 14$ & 1556,53 & aA & T15 \\
\hline & 465 & 1632,67 & $\mathrm{aA}$ & T16 & 1772,57 & $\mathrm{aA}$ & T17 & 1135,41 & $\mathrm{aA}$ & T18 \\
\hline
\end{tabular}

Médias seguidas pela mesma letra, minúscula na linha e maiúscula na coluna, não diferem entre si

pelo teste de Tukey a $1 \%$.

Asteriscos indicam diferenças entre as freqüências de aplicação pelo teste de Tukey a 1\%.

A maior extração de manganês pelos frutos de duas plantas é de $1801,90 \mu \mathrm{g}$, observada no tratamento 13. Esse valor corresponde a uma extração total pelos frutos de $7,51 \mathrm{~g} \mathrm{ha}^{-1}$. O resultado obtido por Rodrigues (1996) foi maior, pois obteve uma extração de $12016 \mu \mathrm{g}$ de manganês por planta.

\subsubsection{Extração de zinco}

A Tabela 32 mostra a comparação entre as médias da quantidade de zinco extraído pelos frutos de duas plantas. Para as comparações feitas em função das doses de potássio aplicadas, nota-se que o tratamento 14 diferiu dos tratamentos 13 e 15 , e o tratamento 17 diferiu dos tratamentos 16 e 18 . Considerando-se as doses de nitrogênio estudadas, pode-se observar que o tratamento 16 diferiu dos tratamentos 10 e 13; o tratamento 14 diferiu dos tratamentos 11 e 17 , e o tratamento 15 diferiu dos tratamentos 12 e 18. Para as freqüências de aplicação nota-se que houve diferenças entre os tratamentos $1 \mathrm{e}$ $10 ; 2$ e $11 ; 4$ e $13 ; 6$ e 15 , e 8 e 17. 
Tabela 32: Comparação entre as médias das quantidades de zinco extraído $(\mu \mathrm{g})$ pelos frutos de duas plantas.

\begin{tabular}{|c|c|c|c|c|c|c|c|c|c|c|}
\hline \multirow{2}{*}{$\begin{array}{c}\text { Freqüências de } \\
\text { aplicação } \\
\end{array}$} & \multirow{2}{*}{$\begin{array}{c}\text { Doses de } N \\
\left(\mathrm{~kg} \mathrm{ha}^{-1}\right)\end{array}$} & \multicolumn{9}{|c|}{ Doses de K $\left(\mathrm{kg} \mathrm{ha}^{-1}\right)$} \\
\hline & & \multicolumn{3}{|c|}{190} & \multicolumn{3}{|c|}{380} & \multicolumn{3}{|c|}{570} \\
\hline & 155 & $\star 21663,18$ & $\mathrm{aA}$ & T1 & *51206,66 & $\mathrm{aA}$ & T2 & 46466,68 & $\mathrm{aA}$ & T3 \\
\hline \multirow[t]{3}{*}{3 dias } & 310 & *35195,69 & aA & T4 & 32166,26 & $\mathrm{aA}$ & T5 & *28893,72 & $\mathrm{aA}$ & T6 \\
\hline & 465 & 46974,18 & $\mathrm{aA}$ & $\mathrm{T7}$ & *31341,29 & $\mathrm{aA}$ & T8 & 50130,29 & $\mathrm{aA}$ & T9 \\
\hline & 155 & *2939,6 & $\mathrm{aA}$ & T10 & *2631,73 & $a A$ & T11 & 45442,57 & bA & T12 \\
\hline \multirow[t]{2}{*}{7 dias } & 310 & *4305,23 & aA & T13 & 50653,33 & bB & T14 & $\star 3665,38$ & $\mathrm{aB}$ & T15 \\
\hline & 465 & 57892,18 & $\mathrm{aB}$ & T16 & *6291,80 & bA & T17 & 45791,23 & $\mathrm{aA}$ & T18 \\
\hline
\end{tabular}

A extração de $50653,33 \mu \mathrm{g}$ de zinco pelos frutos de duas plantas foi observada no tratamento 14 e foi a maior entre todos os tratamentos. Essa extração equivale a 422,09 $\mathrm{g} \mathrm{ha}^{-1}$ de zinco extraídos pelos frutos da cultura. $\mathrm{O}$ valor encontrado por Haag et al. (1978), foi de $16000 \mu \mathrm{g}$ de zinco nos frutos de uma planta e Fernandes et al. (1975), obtiveram 730 $\mu \mathrm{g}$ de zinco nos frutos de uma planta. Assim, a extração observada foi superior aos resultados obtidos por esses autores.

A superfície de resposta das quantidades de zinco extraídas pelos frutos (valores transformados), em função das doses de nitrogênio e potássio aplicadas via fertirrigação a cada 7 dias (Equação 26), é representada na Figura 29. A superfície de resposta possui ponto de mínimo em $-4,43$.

$\operatorname{Ln}($ Quant. de $Z n)=6,914995+0,004455 D N+0,001128 D K+0,00001467 D N^{2}$ $-0,000025339 D N D K+0,000011504 D K^{2}$

$\mathrm{R}^{2}=34,71(\%)$ e Prob $>\mathrm{F} 0,0199$

onde:

Quant. de $\mathrm{Zn}-$ Quantidade de zinco extraído $(\mu \mathrm{g})$ pelos frutos de duas plantas.

$\mathrm{DN}$ - Doses de nitrogênio em $\mathrm{kg} \mathrm{ha}^{-1}$, tal que $155 \leq \mathrm{DN} \geq 465$. 
DK - Doses de potássio em $\mathrm{kg} \mathrm{ha}^{-1}$, tal que $190 \leq \mathrm{DK} \geq 570$.

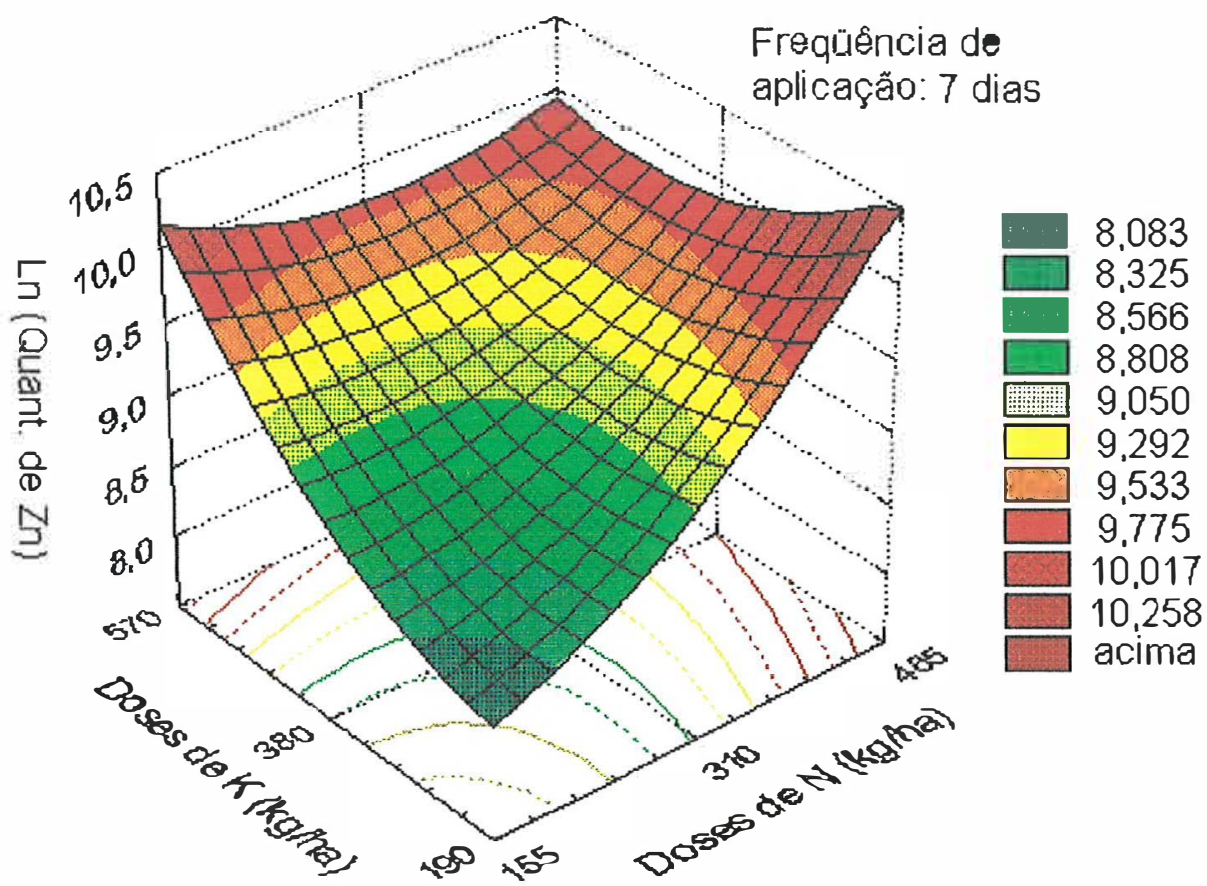

Figura 29: Superfície de resposta das quantidades de zinco extraídas pelos frutos de duas plantas em função das doses de nitrogênio e potássio $\left(\mathrm{kg} \mathrm{ha}^{-1}\right)$ aplicadas a cada 7 dias. 


\section{CONCLUSÕES}

Não foi possivel atingir uma produção satisfatória com os tratamentos aplicados.

A freqüência de aplicação de nutrientes via fertirrigação a cada sete dias proporciona maior eficiência que a freqüência a cada 3 dias, em relaçào aos nutrientes.

A extração de nutrientes pelos frutos seguiu a ordem: $N>K>P>M g=S$ $>\mathrm{Ca}, \mathrm{e} \mathrm{Zn}>\mathrm{Fe}>\mathrm{Cu}>\mathrm{Mn}>\mathrm{B}$. 


\section{REFERÊNCIAS BIBLIOGRÁFICAS}

ADAMS, P. Mineral nutrition. In: ATHERTON, J.C.; RUDICH, J. The tomato crop. London: Chapman \& Hall, 1996. p. 281-334.

ALVES, E. M.; BERNARDO, S.; SILVA, J. F.; CONDÉ, A. R. Efeito de diferentes lâminas d'água sobre a produção de três cultivares de tomateiro (Lycopersicum esculentum Mill), com a utilização da irrigação por gotejamento. Revista Ceres, v. 29, n.162, p. 145-154, 1982.

ATHERTON, J. G.; HARRIS. G. P. Flowering. In: ATHERTON, J.G.; RUDICH, J. (Ed.) The tomato crop. New York: Chapman and Hall, 1986. cap. 4, p.167-200.

BARBOSA, V. Nutrição e adubação de tomate rasteiro. In: SIMPÓSIO SOBRE NUTRIÇÃO E ADUBAÇÃO DE HORTALIÇAS, Jaboticabal - SP. 1990. Anais. Piracicaba: Associação Brasileira para a Pesquisa da Potassa e Fosfato, 1993. p. 323-339.

BATAGLIA, O. C.; FURLANI; A. M. C.; TEIXEIRA, J.P.F.; FURLANI; P. R.; GALLO, J. R. Métodos de análises químicas de plantas. Campinas: Instituto Agronômico, 1983. 48 p. (Boletim Técnico, 78) 
BERNARDO, S. Irrigação por Aspersão. In: Seminário Regional de Métodos de Irrigação para o Nordeste. Fortaleza, 1978. 24p.

CAMARGO FILHO, W. P.; MAZZEI, A. R. Necessidade de reconversão da produção de tomate em São Paulo: ações na cadeia produtiva. Informações econômicas, v. 26, n. 6, 1996, p. 105-116.

CARRIJO, O. A.; SILVA, W. L. C.; MAROUELLI, W. A.; SILVA, H. R. Tendências e desafios da fertirrigação no Brasil. In: FOLEGATTI, M. V. (coord.) Fertirrigação: citros, flores e hortaliças. Piracicaba: Agropecuária, 1999. p. 155 - 169.

CASARINI, E.; FOLEGATTI, M. Aspectos relevantes na fertirrigação de flores e hortaliças. In: FOLEGATTI, M. V. (coord.) Fertirrigação: citros, flores e hortaliças. Piracicaba: Agropecuária, 1999. p. 441 - 458.

EMPRESA BRASILEIRA DE AGROPECUÁRIA. Cultivo do tomate (Lycopersicon esculentum Mill.). Brasília: Anápolis, 1995. 22p.

FAO. Boletín trimestral FAO de estatísticas. Roma, 1999. 154p.

FAYAD, J. A. Absorção de nutrientes, crescimento e produção do tomateiro cultivado em condições de campo e de estufa. Viçosa, 1998. 81p. Dissertação (M.S.) - Universidade Federal de Viçosa.

FERNANDES, P. D., CHURATA-MASCA, M. G. C.; OLIVEIRA, G. D.; HAAG, H. P. Nutrição mineral de hortaliças XXVII. Absorção de nutrientes pelo tomateiro (Lycopersicon esculentum Mill.), em cultivo rasteiro. Anais da Escola Superior de agricultura “Luiz de Queiroz”, v.32, p.595-607, 1975. 
FILGUEIRA, F. A. R. Manual de olericultura: cultura e comercialização de hortaliças. 2. ed. São Paulo: Ed. Agronômica Ceres, 1982. v. 2. 352p.

FONTES, P. C. R.;SAMPAIO, R. A.; MANTOVANI, E. C. Tomato yield and potassium concentrations in soil and in plant petioles as affected by potassium fertirrigation. Pesquisa Agropecuária Brasileira, v.35, n.3, p.575-580, Mar. 2000.

FONTES, R. R.; HORINO, Y. Análise do solo e recomendações de adubação em tomateiro. In: ENCONTRO NACIONAL DE PRODUÇÃO DE TOMATE, 2. Jaboticabal-SP. 1991. Anais. Jaboticabal: UNESP,1991. p.197-211.

FREIRE, M. F.; MONNERAT, P. H.; MARTINS FILHO, C. A. S. Nutrição mineral e adubação do tomateiro. Informe Agropecuário, v.6, n.66, p.1320, Jun. 1980.

FRIZZONE, J. A. \& BOTREL, T. A. Aplicação de fertilizantes via água de irrigação. In: VITTI, G. C.; BOARETTO, A. E. (coord). Fertilizantes Fluidos. Piracicaba: POTAFOS, 1994. p.228-260.

FRIZZONE, J. A.; ZANINI, J. R.; DIAS PAES, L. A.; NASCIMENTO, V. M. Fertirrigação mineral. Boletim técnico 2. Itha Solteira: UNESP, 1985. 31p.

GARGANTINI, H.; BLANCO, H. G. Marcha de absorção de nutrientes pelo tomateiro. Bragantia, v.22, p.693-714, 1963.

GROVER, B.L.; LAMBORN, R.E. Preparation of porous ceramic cups to be used for extraction of soil water having low solute concentrations. Soil Science Society of America Proceedings, v.34, p.706-708, 1970. 
HAAG, H. P.; DECHEN, A. R.; CARMELlO, Q. A. C.; MONTEIRO, F. A. Princípios de nutrição mineral: aspectos gerais. In: SIMPÓSIO SOBRE NUTRIÇÃO DE PLANTAS, Jaboticabal - SP. 1990. Anais. Piracicaba: Associação Brasileira para Pesquisa da Potassa e do Fosfato, 1993. p.5173.

HAAG, H.P.; OLIVEIRA, G. D. de; BARBOSA, V.; SILVA NETO, J. M. Nutrição mineral de hortaliças XXXII. Marcha de absorção dos nutrientes pelo tomateiro (Lycopersicon esculentum Mill.) destinado ao processamento industrial. Anais da Escola Superior de Agricultura "Luiz de Queiroz". v.35, p.243-269, 1978.

HAINES, W.B. Studies in the physical properties of soil: V. The hysteresis effects in capillary properties and the models of moisture associated therewith. Journal Agronomy Science, v.20, p.97-116, 1930.

HERNANDEZ, F. B. T. Potencialidades da Fertirrigação. In: SIMPÓSIO BRASILEIRO SOBRE FERTILIZANTES FLUIDOS, 1., Piracicaba, 1993. Anais. Piracicaba: POTAFOS, 1993. p. 199-210.

HERNANDEZ, F. B. T. Potencialidades da Fertirrigação. In: VITTI, G. C.; BOARETTO, A. E. (coord). Fertilizantes Fluídos. Piracicaba: POTAFOS, 1994. p. 215-225.

HO, L. C.; HEWITT, J. D. Fruit development. In: ATHERTON, J.G.; RUDICH, J. (Ed.) The tomato crop. New York: Chapman and Hall, 1986. cap. 5, p.201-240. 
NAGAI, H. Avanços obtidos com o melhoramento genético do tomate no Brasil. In: ENCONTRO NACIONAL DE PRODUÇÃO E ABASTECIMENTO DO TOMATE,1., Viçosa, 1989. Anais. Viçosa, 1989. p.88-107.

RODRIGUES, S. D. Aplicação de fertilizantes via solo, foliar e fertirrigação afetando extração e concentração de nutrientes em tomateiro (Lycoprsicon esculentum Mill.) em estufa. Piracicaba, 1996. 78p. Dissertação (M.S.) Escola Superior de Agricultura "Luiz De Queiroz", Universidade de São Paulo.

SAMPAIO, R. A.; FONTES, P. C. R.; SEDIYAMA, C. S. Resposta do tomateiro à fertirrigação potássica e cobertura plástica do solo. Pesquisa Agropecuária Brasileira, v.34, n.1, p.21-30, Jan. 1999.

SARRUGE, J. R.; HAAG, H. P. Análises químicas em plantas. Piracicaba: ESA "Luiz de Queiroz", 1974. 57p.

SMITH, H. W. Interpretation of plant analysis. In: REUTER, D. J.; ROBINSON, J. B. Plant analysis. Melbourne: Inkata Press, 1986. p.1-12.

TAKAHASHI, H. W. Nutrição e adubação de tomate estaqueado. In: FERREIRA, M. E.; CATElLANE, P. D.; CRUZ, M. C. P. Nutrição e adubação de hortaliças. Piracicaba: Potafos, 1993. p. 301-322.

TRANI, P. E.; GROPPO, G. A.,SILVA. M. C. P.; MINAMI, K.; BURKE, T. J. Diagnóstico sobre a produção de hortaliças no estado de São Paulo. Horticultura brasileira, Brasília, v. 15, n. 1, p. 19-24, Mai. 1997.

TRANI, P. E.; NAGAI, H.; PASSOS, F. A. Tomate (estaqueado). In: RAIJ, B. van; CANTARELLA, H.; QUAGGIO, J. A.; FURLANI, A. M. C. 
Recomendações de adubação e calagem para o Estado de São Paulo, Campinas, Instituto Agronômico, 1996. p. 184.

TRANI, P. E.; NUCCI, T. A.; MINAMI, K.; HAAG, P. H. Nutrição mineral e adubação do tomateiro. Campinas: Instituto Agronômico, 1994. 67p. (Boletim Técnico, 151)

TRANI, P. E.; RAIJ, B. van. Hortaliças. In: RAIJ, B. van; CANTARELLA, H.; QUAGGIO, J. A.; FURLANI, A. M. C. Recomendações de adubação e calagem para o Estado de São Paulo, Campinas: Instituto Agronômico, 1996. p. $157-164$.

VITTI, G. C.; BOARETTO, A. E.; PENTEADO, S. R. Fertilizantes e Fertirrigação. In: Vitti, G. C.; Boaretto, A. E. (coord.). Fertilizantes Fluídos. Piracicaba: POTAFOS, 1994. p. 261-281.

WHITNEY, D. A.; COPE, J. P.; WELTCH, L. F. Prescribing soil and crop nutrient needs. In: ENGELSTED, O. P. (Ed.). Fertilizer technology and use. 3. ed. Madison: Soil Science Society of America, 1995. p. 25-62.

WOODWARD. G. D. Sprinkler Irrigation. Sprinkler Irrigation Association. New York, 1959. 377p. 